\title{
A COMPARATIVE STUDY OF RAPID PROTOTYPING SYSTEMS
}

A Thesis presented to the Faculty of the Graduate School

University of Missouri

In Partial Fulfillment

Of the Requirements for the Degree

Master of Science

by

CHEN-YU LIU

Dr. Luis G. Occeña, Thesis Supervisor

May 2013 
The undersigned, appointed by the Dean of the Graduate School, have examined the thesis entitled

\section{A COMPARATIVE STUDY OF RAPID PROTOTYPING SYSTEMS}

Presented by Chen-Yu Liu

A candidate for the degree of Master of Science

And hereby certify that in their opinion it is worthy of acceptance.

Professor Luis G. Occeña

Professor Cheng Alec Chang

Professor Sherif El-Gizawy

Professor Michael Klote 


\section{ACKNOWLEDGEMENTS}

I would first like to thanks my advisor Professor Dr. Luis G. Occeña for giving me the opportunity to improve my knowledge, for all his guidance and tireless instruction throughout my graduate studies at the University of Missouri, Columbia.

I would also like to express my appreciation to Mr. Michael Klote for his support, encouragement, dedication, all his helps, and providing insight into the Rapid Prototyping process.

Finally, grateful acknowledgement is made to my parents for their support and everything they gave to me. 


\section{Table of Contents}

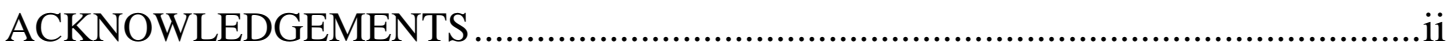

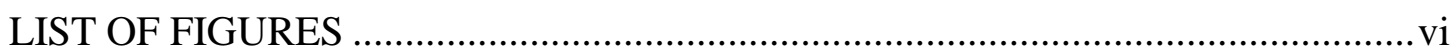

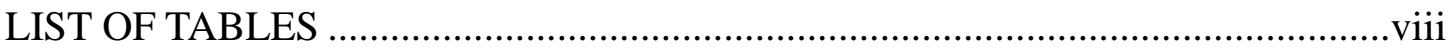

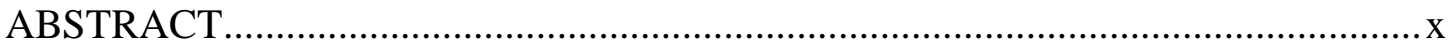

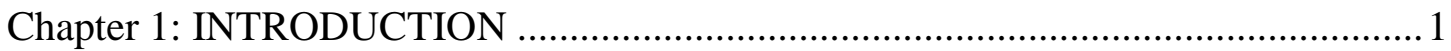

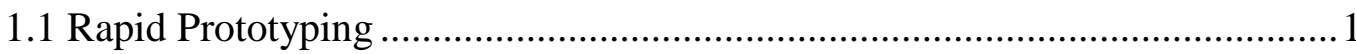

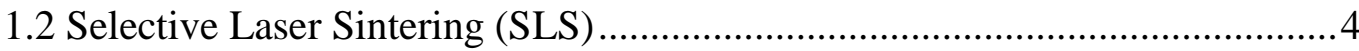

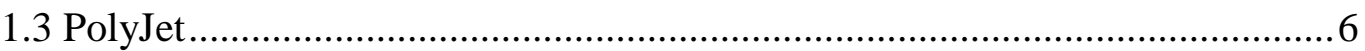

1.4 Fused Deposition Modeling (FDM) ..................................................... 8

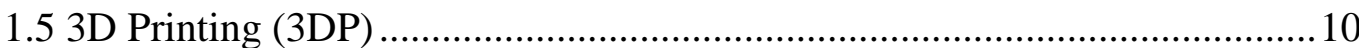

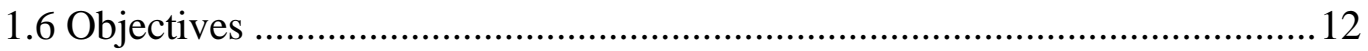

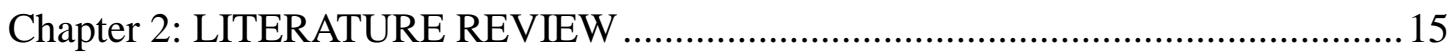

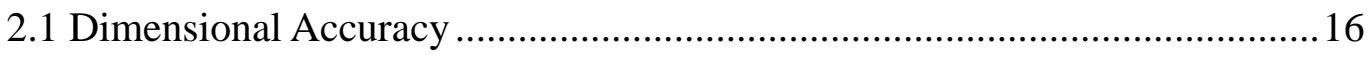

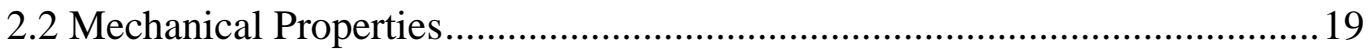

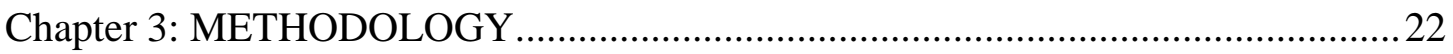

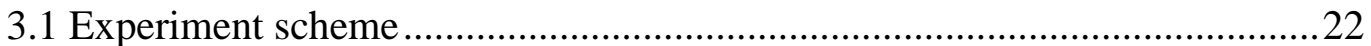

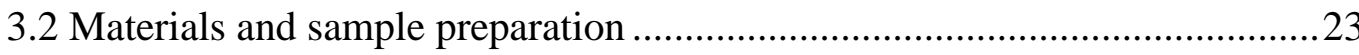


3.3 Shape of test specimen

3.4 Dimension measurement

3.5 Tensile testing

3.6 Water absorption 30

3.7 Shore Hardness

3.8 Microscopy .35

Chapter 4 RESULTS AND ANALYSIS .36

4.1 Dimensional accuracy .36

4.1.1 SLS Dimensional accuracy .37

4.1.2 PolyJet Dimensional accuracy .41

4.1.3 FDM Dimensional accuracy .45

4.1.4 3DP Dimensional accuracy .50

4.1.5 Summary - Dimensional accuracy .56

4.2 Tensile Properties .59

4.2.1 SLS Tensile Properties .59

4.2.2 PolyJet Tensile Properties 63

4.2.3 FDM Tensile Properties .67

4.2.4 3DP Tensile Properties .70

4.2.5 Summary - Tensile Properties .74 
4.5 Microscopy and Analysis ..... .88

Chapter 5: CONCLUSION AND FUTURE WORK.

5.1 Conclusion 91

5.2 Future work .95

REFERENCES 97 


\section{LIST OF FIGURES}

Figure

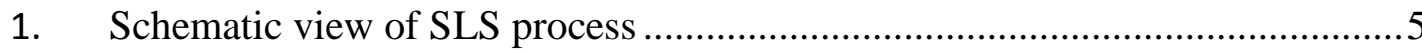

2. Schematic view of PolyJet process ..........................................................

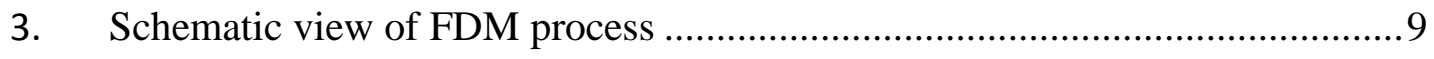

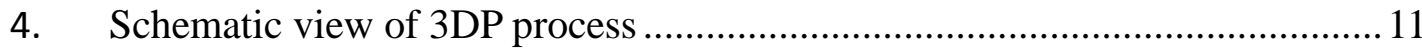

5. Specimens in three build orientations in each RP system .............................26

6. Shape of test specimen for tensile testing $(\mathrm{mm})$........................................2

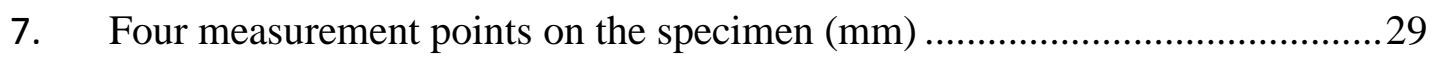

8. The test specimen is clamped by the jaws of the test machine ........................30

9. Specimens for water absorption sealed in a plastic bag ................................ 32

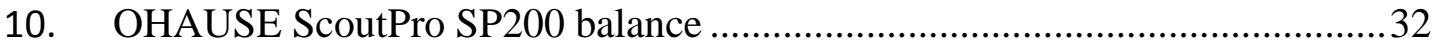

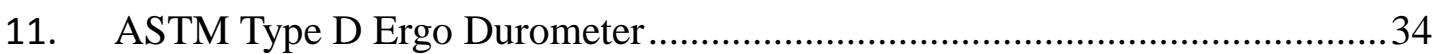

12. Measurement points for Shore hardness ….....................................................3

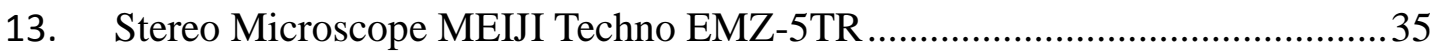

14. Dimensional Accuracy of four measurement points in SLS ..........................39

15. AVG Dimensional Accuracy of three build orientations in SLS.....................39

16. Dimensional Accuracy of four measurement points in PolyJet ......................43 
17. AVG Dimensional Accuracy of three build orientations in PolyJet

18. Dimensional Accuracy of four measurement points in FDM

19. AVG Dimensional Accuracy of three build orientations in FDM

20. Dimensional Accuracy of four measurement points

21. Dimensional Accuracy of four measurement points

22. AVG Dimensional Accuracy of three build orientations.

23. AVG Dimensional Accuracy of three build orientations.

24. Dimensional Accuracy

25. SLS Tensile Strength.

26. PolyJet Tensile Strength .65

27. FDM Tensile Strength

28. 3DP Tensile Strength

29. Tensile Strength.

30. Elongation .76

31. Elongation at Break

32. FDM specimen at 10 times magnification 


\section{LIST OF TABLES}

Table

1. Current RP systems in the market

2. Rapid Prototyping systems at the University of Missouri, Columbia .23

3. Materials used in RP systems at the University of Missouri, Columbia .24

4. Three build orientations .25

5. Dimensions of tensile test specimen (ASTM D638-10 Type IV)

6. Measured results in SLS .38

7. Measured results in PolyJet .42

8. Measured results in FDM .46

9. Measured results in 3DP .51

10. Dimensional Accuracy Summary .57

11. SLS Tensile Properties 60

12. PolyJet Tensile Properties .64

13. FDM Tensile Properties .68

14. 3DP Tensile Properties .71

15. Tensile Properties .78

16. The relative rate of Water Absorption in the four RP systems .81

17. Shore Hardness .85 
18. Stereo microscope pictures of the fracture surfaces of tensile testing specimens .90

19. Experiment results summary (Boldface indicate the best performance) 94 


\begin{abstract}
A general comparative study of the literature sources across different Rapid Prototyping systems and performance in different build orientations has shown that the publications are few in number. This research aims to provide general information including dimensional accuracy and tensile properties for different build orientations, and relative water absorption and Shore hardness properties between different Rapid Prototyping systems. Test specimens were fabricated in four popular commercial Rapid Prototyping systems: Selective Laser Sintering (SLS), PolyJet, Fused Deposition Modeling (FDM), and 3D Printing (3DP) at the University of Missouri, Columbia. The results can be used as a preliminary guide to help users determine optimal strategies for rapid prototyping system selection.
\end{abstract}




\section{Chapter 1: INTRODUCTION}

\subsection{Rapid Prototyping}

Rapid Prototyping (RP) is a process which fabricates a part layer-by-layer. This technology has also been referred to as layered manufacturing, additive manufacturing, and rapid manufacturing. Rapid prototyping automatically generates physical objects directly from 3D CAD data by depositing material layer by layer, unlike conventional methods, where material is removed to obtain the final object.

Fundamentally, the development of Rapid Prototyping technology can be split into four primary aspects: Input, Method, Material, and Applications [1]. Input refers to the electronic information required to describe the physical object with numerical data. In the last decade, a number of techniques for Rapid Prototyping have been developed. There are several methods employed in different Rapid Prototyping systems provided by each vendor. The materials used in different rapid prototyping systems are also varied. The initial state of these materials can be either a solid, liquid, or powder state. Applications can be grouped into design, education, engineering and analysis, and manufacturing and tooling [1]. A wide range of industries can benefit from rapid prototyping technology. 
Rapid Prototyping is the term that has been coined for processes that can produce an accurate model from a computer-aid design (CAD) database without any additional tooling or machining [2]. Because Rapid Prototyping can build solid model so quickly, it has revolutionized the way industries approach their product development cycles. With Rapid Prototyping, an engineer can design and build prototype models within a small amount of time. The ability to quickly verify a design prevents the investment of time and money in a poorly conceived project or component. The benefits provided by Rapid Prototyping include reduced lead time and cost to produce components, improved ability to visualize design geometry directly, earlier detection and reduction of design errors, and optimized part design to meet customer requirements. Also, Rapid Prototyping is advantageous in the elimination of waste and costly late design changes [3].

In order to create a part using Rapid Prototyping techniques, several steps have to be performed. All RP systems generally have similar process steps:

1. Create a CAD model to describe the physical object.

2. Convert the CAD model to a STereoLithography (STL) file format.

3. File preprocessing: correct file errors, slice the model into cross-sectional layers, and distribute model orientation.

4. Build the prototype. 
5. Postprocessing: clean and remove excess material from the model.

These steps are a generalization of Rapid Prototyping process, and each system can include its own individual steps. There are currently many Rapid Prototyping systems in the market. According to Kruth [4], the material accretion technologies may be divided by the state of the prototype material before part formation. All Rapid Prototyping systems can be categorized into (1) liquid-based (2) solid-based and (3) powder-based [1]. Table 1 shows a summarized category of RP systems. In the following sections, Rapid Prototyping systems at the University of Missouri, Columbia: Selective Laser Sintering (SLS), PolyJet, Fused Deposition Modeling (FDM), and 3D Printing (3DP) will be discussed in detail.

Table 1. Current RP systems in the market [1]

\begin{tabular}{|l|l|}
\hline \multirow{4}{*}{ Liquid-Based } & Stereolithography (SLA) \\
\cline { 2 - 2 } & Objet's PolyJet \\
\cline { 2 - 2 } & Cubital's Solid Ground Curing (SGC) \\
\cline { 2 - 2 } Solid-Based & Ballistic Particle Manufacture (BPM) \\
\hline Powder-Based & Laminated Object Manufacturing (LOM) \\
\cline { 2 - 2 } & Fused Deposition Modeling (FDM) \\
\hline & Selective Laser Sintering (SLS) \\
\cline { 2 - 2 } & 3D Printing (3DP) \\
\cline { 2 - 2 } & Laser Engineered Net Shaping (LENS) \\
\hline
\end{tabular}




\subsection{Selective Laser Sintering (SLS)}

The Selective Laser Sintering (SLS) process produces solid components using a carbon dioxide $\left(\mathrm{CO}_{2}\right)$ laser to heat powdered materials layer by layer so that the surface tensions of the grains are overcome and they fuse together. Before the powder is sintered, the entire chamber is heated to just below the melting point of the material in order to minimize thermal distortion and facilitate fusion to the previous layer [5].

The laser selectively fuses powdered materials by tracing the cross-sectional slices from a 3D digital description of the part. The interaction of the $\mathrm{CO}_{2}$ laser beam with the powder raises the temperature to the melting point, resulting in particle bonding, fusing the particles to themselves and the previous layer to form a solid [1]. The laser beam with adjustable intensity fuses the powder only in areas defined by the part's geometry. The powder not melted or fused during processing serves as support structure. Therefore, there is no need to have support material in the SLS process. After each cross-section is completely drawn, the powder bed is lowered by one layer thickness, and an additional layer of powder is deposited via a roller mechanism on top of the previous layer. The process: (1) new layer deposited, (2) laser beam trace, and (3) entire powder bed lowered is repeated until the part is complete. Figure 1 shows SLS process in brief with a diagram. 


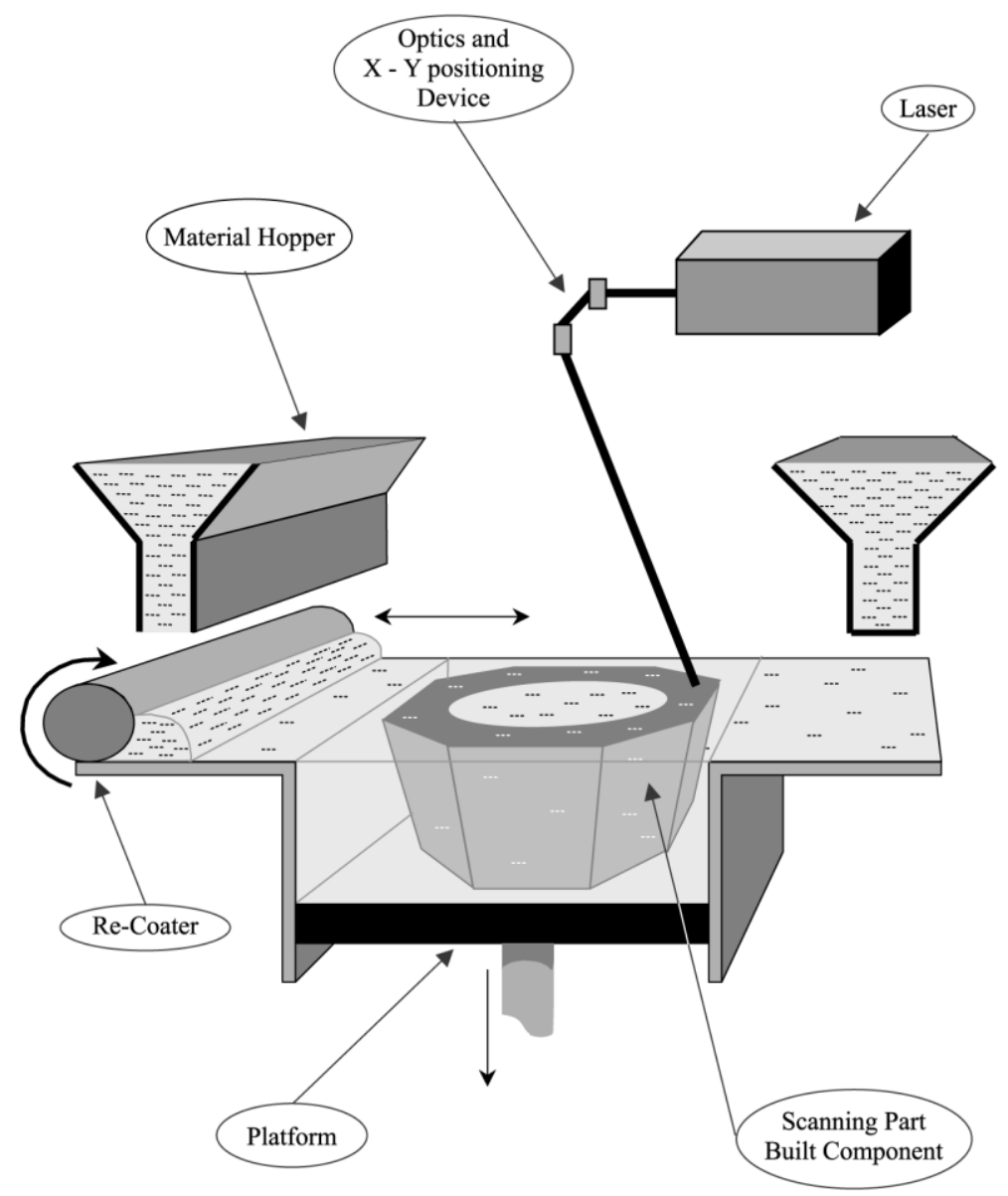

Figure 1. Schematic view of SLS process [6]

After the SLS build process, the build chamber is moved to a post-processing station. The loose powder simply falls away, and the SLS parts require some post-processing such as sanding with high pressure air and glass bead mixture, and cleaning with pressurized air.

There is a wide range of initial material available for the SLS system. At present, nylon, nylon composites, polycarbonates, metals, sand, wax, and ceramics are in use $[1,7]$. However, the materials employed by the system are sensitive to the different heating and laser parameters and each material requires specified settings. 
The products form the SLS system tend to have poorer surface finish due to the relatively large particle sizes of the powders used.

\subsection{PolyJet}

The manufacturer, Objet Geometries, was the first company to successfully jet photopolymer material using its patented PolyJet technology to produce a complex model from a 3D geometry file in early 2000 [8]. A composed printing head injects a $20 \mu \mathrm{m}$ thick layer of photopolymer material on the build tray only in the areas that correspond to the cross-sectional profile from a 3D digital description of the part. Simultaneously, the photopolymer layer is cured by UV light after it is jetted, and each layer is adjusted to $16 \mu \mathrm{m}$ by a roller that is moved across the build tray immediately after deposition [9]. The repeated addition and solidification of photopolymer material layers produces a solid three-dimensional model until it is complete. To avoid the collapse of structures during production, a gel-like support material, which is specially designed to support complicated geometries, is injected together with the model material. When the model is completed, the support material is easily removed by hand and water jetting to leave only the hardened photopolymer material. Figure 2 shows Objet's PloyJet technology in brief with a diagram. 


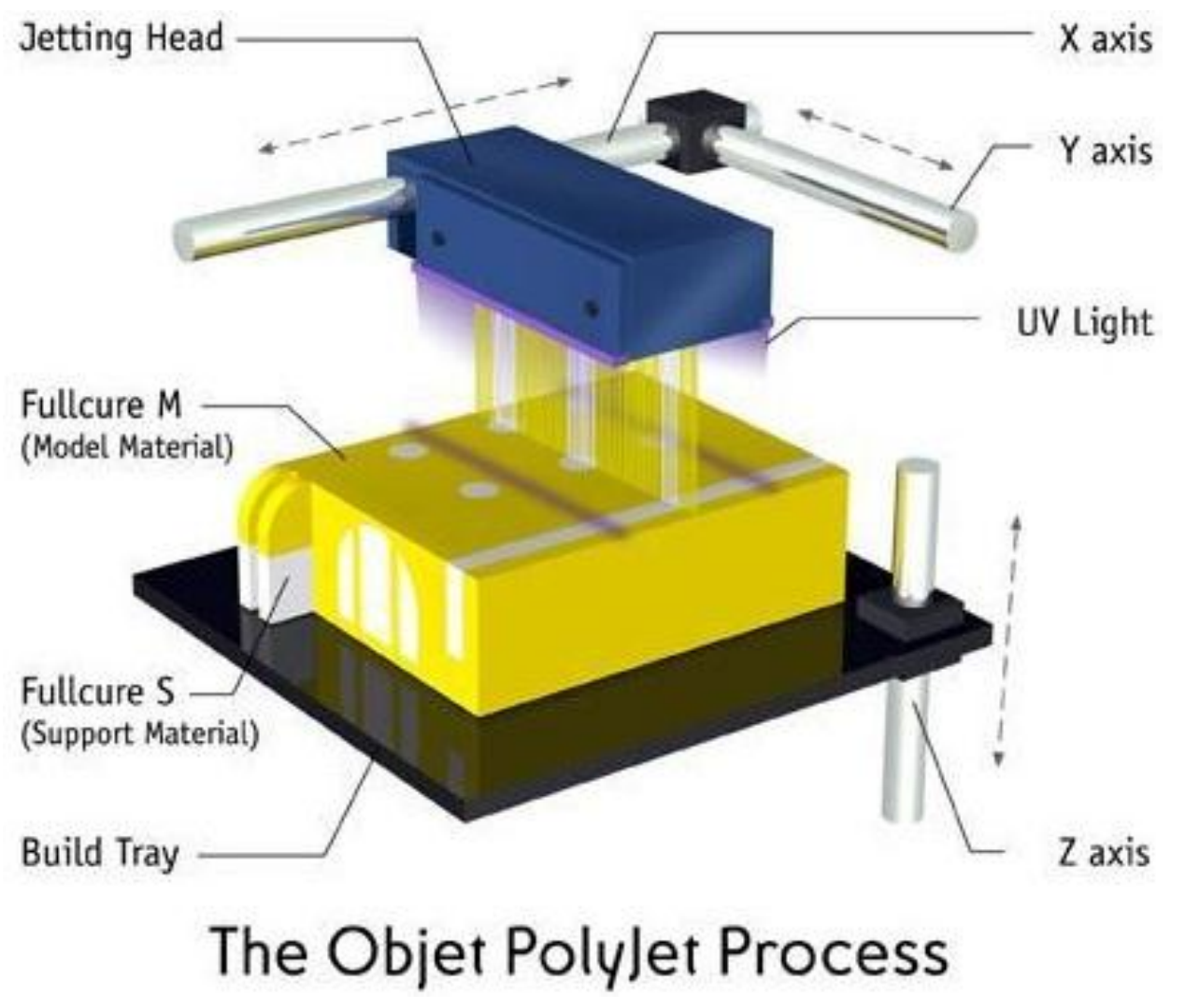

Figure 2. Schematic view of PolyJet process [8]

Objet's PolyJet provides a wide variety of materials for different geometries, mechanical properties, and colors; use of the same support material for all model types makes switching material easy and fast. Furthermore, PolyJet Matrix Technology enables simultaneous jetting of different types of model materials. It can jet two distinct photopolymer model materials in preset combinations. 


\subsection{Fused Deposition Modeling (FDM)}

Scott Crump, the president and CEO of Stratasys Inc, developed the Fused Deposition Modeling (FDM) process in 1988 and the patent was awarded in the U.S. in 1992 [1, 3]. The FDM process fabricates parts by extruding semi-molten material thought a extrusion head that traverses in $\mathrm{X}$ axis and $\mathrm{Y}$ axis to create each two dimensional layer of the part [10]. The movable extrusion head composed of two extrusion nozzles: one for build material and the other for support material $[1,7,11]$. This process can be seen in Figure 3. The extrusion head deposits a filament of molten material either build material or support material onto a foam base. The build material is heated to $0.5^{\circ} \mathrm{C}$ above its melting point so that it solidifies about $0.1 \mathrm{~s}$ after extrusion and cold welds to the previous layers [7]. In general, an outline of the perimeter of the part is extruded from the head first and then the interior is raster filled by the extruder head [10]. Once a layer is built, the platform lowers, and the extrusion head deposits another layer. The machine continues to build the part layer by layer until it is complete. When the part is finished, it is removed from the machine and the support material need to move away to reveal the finished product. There are two types of support material: Soluble support system and Break-Away Support System (BASS) [12]. It can be removed with specialized equipment utilizing water-based sodium 
hydroxide solution, or break it away by hand.

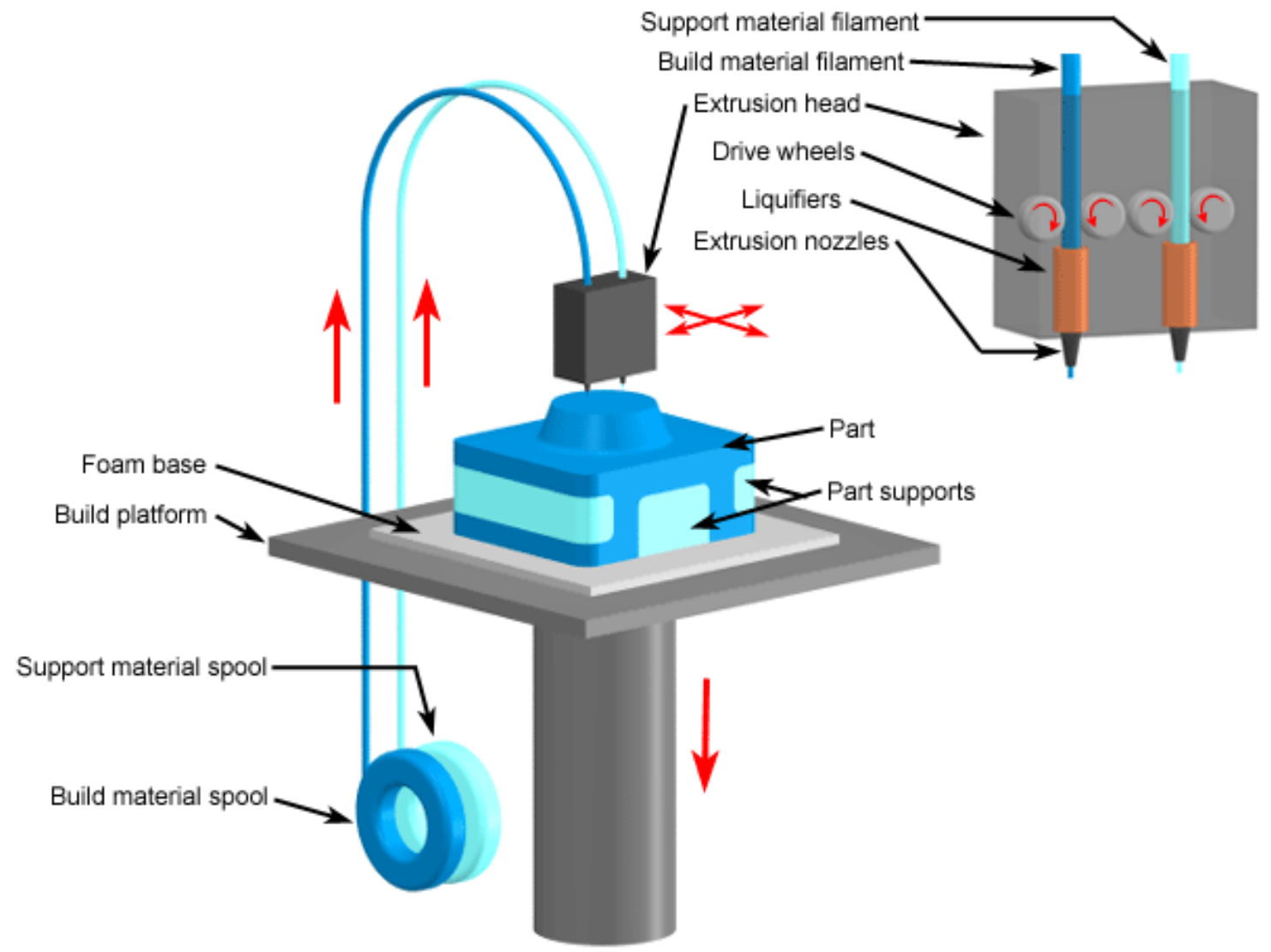

Figure 3. Schematic view of FDM process [13]

In the FDM process, there is also a large range of colors and materials available, such as investment casting wax and thermoplastic [7]. The material generally used is a thermoplastic including ABS plastic, medical grade ABS (MABS), elastomers, polycarbonate, polyphenyl-sulfone (PPSF), and Ultem 9085 [1, 14]. The main advantages of using FDM technology are fabrication of functional parts, minimal material wastage, ease of support material removal, and ease of material change [1].

A disadvantage of using FDM technology is that the surface finish of the parts 
is worse than other rapid prototyping systems due to the resolution of the process

which is dictated by the filament thickness $[7,15]$. The other disadvantage is that the building process is slow, as the whole cross-sectional area needs to be filled with building material. Unpredictable shrinkage is also a disadvantage of using FDM technology. As the FDM process extrudes the build material from its extrusion head and cools them rapidly on deposition, stresses induced by such rapid cooling invariably are introduced into the model. As such, shrinkages and distortions caused to the model built are a common occurrence and are usually difficult to predict [1].

\subsection{D Printing (3DP)}

Z Corporation commercialized its first 3D Printer, the Z 402 System, based on three-dimensional technology (3DP) in 1997 [1]. The core technology was invented and patented at the Massachusetts Institute of Technology. It was subsequently licensed and further developed by Z Corporation. Z Corporation was acquired by 3D Systems on January 3, 2012 [16]. The 3D Printing (3DP) process is similar to the Selective Laser Sintering (SLS) process, but instead of using a $\mathrm{CO}_{2}$ laser to sinter the powdered material, an ink-jet printing head deposits a liquid adhesive that binds the material. The 3D Printing machine has two pistons: one for feeding the powder and 
the other for lowering/raising the building chamber shown in Figure 4.

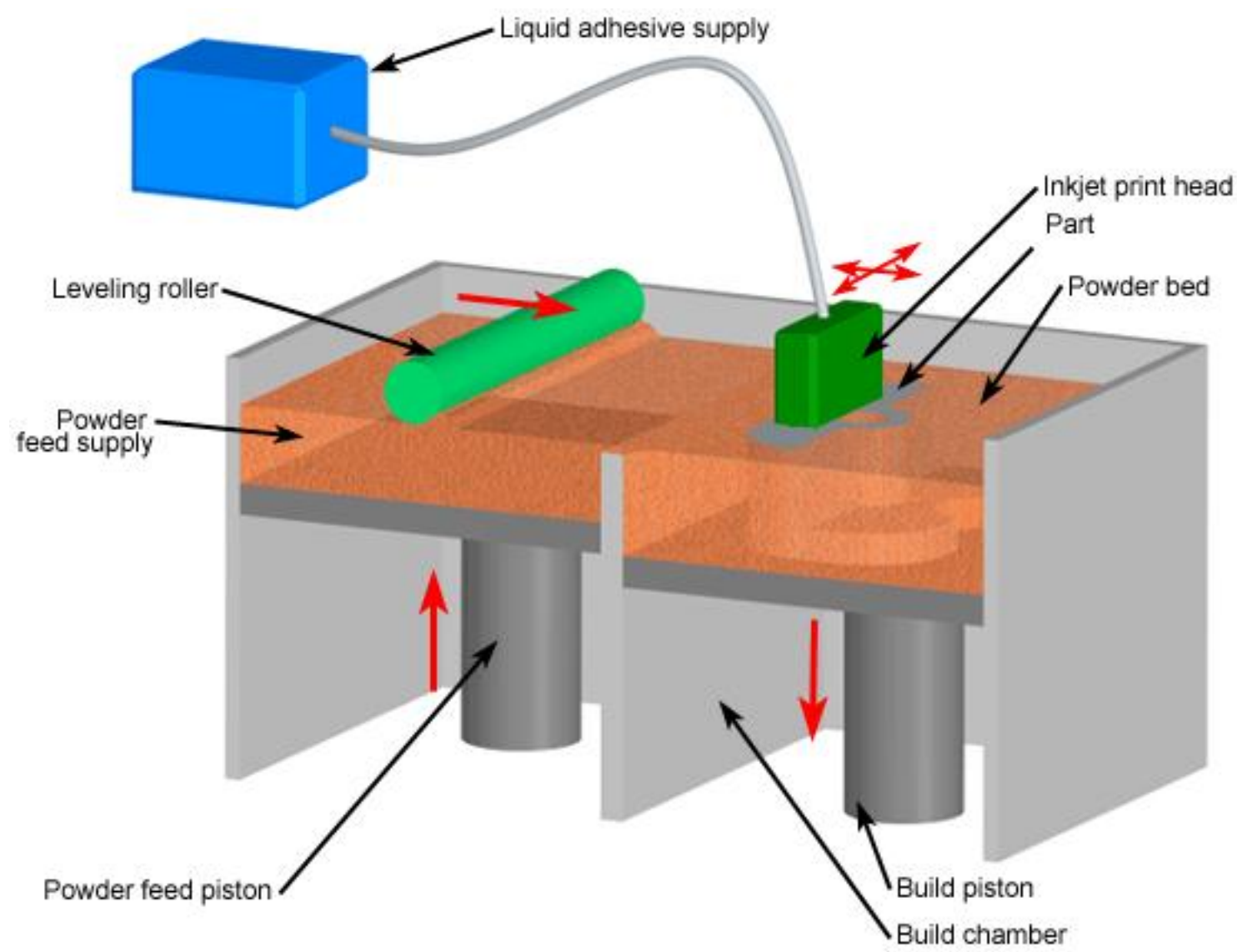

Figure 4. Schematic view of 3DP process [17]

The 3D Printing process begins with the powder supply being raised by a piston and a leveling roller distributing a thin layer of powder to the top of the build chamber [17]. The multi-channel ink-jet printing head then deposits binder solution onto the loose powder, forming the first cross-section [1]. These regions of powder are glued together wherever the binder is printed. The remaining powder remains loose and supports the part during the process. When the cross-section is completed, the build piston is lowered, the powder feed piston is raised, and a new layer of powder is 
added on the previous layer by the leveling roller. The process is repeated and the part grows layer by layer on the build piston until the part is finished. Finally the build piston is raised and the loose powder is brushed and the part removed [1]. 3D Printed parts are typically infiltrated with a hardener to improve strength and surface finish.

The main advantages of using 3D Printing technology are color capability, shorter build times, and inexpensive raw materials when compared to other rapid prototyping systems $[1,6]$. No support structures needed is also an advantage of 3D Printing. The powder bed provides self-support to allow complex geometry to be created. The disadvantages of using 3D Printing technology are the printed part is relatively fragile compared to other rapid prototyping systems, the infiltration post-processing is needed, and the surface finish is relatively poor [6].

\subsection{Objectives}

Rapid Prototyping is a fast growing technology that can substantially help engineers shorten the time and decrease the cost of developing a new product from the initial idea to production. There are also many restrictions with many rapid prototyping procedures, primarily in the number of available materials and their properties, which may differ significantly from the properties of end product material. 
The research objective of this thesis is to develop combined experiments and analyses approach to compare the specimens fabricated in different build orientations and different rapid prototyping systems. In this research, test specimens were made in four popular commercial rapid prototyping systems: SLS (EOS Formiga P100), PolyJet (Objet Eden 350V), FDM (Dimension Elite 3D Printer), and 3DP (Z Corporation Spectrum Z510). This research includes (1) Dimensional Accuracy: to provide comparative information of dimensional accuracy when specimens are fabricated in three build orientations (Horizontal, Side, and Vertical) in each of four rapid prototyping systems. A comparative study of dimensional accuracy across different rapid prototyping systems is also provided in this research (2) Tensile Property: provide a comparative study of tensile property based on specimens produced in three build orientations (Horizontal, Side, and Vertical) and four different rapid prototyping systems (3) Water Absorption: provide information about the relative water absorption across different rapid prototyping systems will be included in this research (4) Shore hardness: the Shore hardness of test specimens fabricated in different rapid prototyping systems will be presented in this research. The lack of knowledge in the performance of different build orientations across different rapid prototyping systems is motivation for this investigation. The main objective of this research is to provide users with a preliminary guide to help determine optimal strategies for rapid 
prototyping system selection.

A literature review is presented in Chapter two to review and discuss previous work performed by researchers on four rapid prototyping systems. In Chapter three, the experiment methodology is presented. In Chapter four, the experiment results of dimensional accuracy, tensile property, water absorption, and Shore hardness are presented and discussed. In Chapter five, the conclusions and future work are discussed. 


\section{Chapter 2: LITERATURE REVIEW}

Rapid prototyping is a term that the manufacturing industry has struggled with

for many years. In the early day, layer-based rapid prototyping (RP) technologies were mainly concerned with producing physical parts as quickly as possible from a design concept, for the purpose of design verification [18]. The initial term, established by 3D Systems (Valencia, CA), was "StereoLithography," or three-dimensional printing. The growing field has been widely referred to in technical and industrial publications as "Rapid Prototyping".

Nowadays, with the fast development of rapid prototyping technologies: more available materials, with various mechanical properties to meet a variety of applications, and higher accuracy of parts produced, rapid prototyping technologies have been used for fabrication of functional parts and tooling [19, 20]. As rapid prototyping parts are made by additive processes, they may have properties that are quite different from parts that are made by conventional manufacturing processes. It is difficult to directly compare the many properties of rapid prototyping parts, as these depend not only on the material being used, but also on the direction in which the property is being measured. In this study, the properties: (1) dimensional accuracy, (2) 
tensile property, (3) water absorption, and (4) Shore hardness were investigated. The following sections will present previous work and literature resource related to these topics.

\subsection{Dimensional Accuracy}

Dimensional accuracy of a rapid prototyping product is influenced by a specific rapid prototyping technique used, the material chosen, and the operating parameter values. Due to different processes and materials used in rapid prototyping technologies, parts differ in their tendency to shrink or deform. In the paper by Durham et al. [21], the shrinkage of the Stereolithography (SLA) epoxy was significantly less than the Selective laser sintering (SLS) plastic material, and the small shrinkage of Stereolithography (SLA) resins was simple to predict and easy to control.

In 1997, D.T. Pham and R.S. Gault [7] presented and summarized different rapid prototyping technologies. The paper presented an overview of rapid prototyping technologies and commented on their strengths and weaknesses. In this study, data such as layer thickness, system accuracy and speed of operations were given. The following rapid prototyping technologies were included in this paper. 


\begin{tabular}{|c|c|c|}
\hline \multirow{12}{*}{$\begin{array}{l}\text { Material } \\
\text { addition } \\
\text { technologies }\end{array}$} & \multirow{9}{*}{$\begin{array}{l}\text { Processes involving } \\
\text { liquid }\end{array}$} & Stereolithography (SLA) \\
\hline & & Liquid thermal polymerization (LTP) \\
\hline & & Beam interference solidification (BIS) \\
\hline & & Solid ground curing (SGC) \\
\hline & & Holograhpic interference solidification (HIS) \\
\hline & & Electrosetting (ES) \\
\hline & & Ballistic particle manufacture (BPM) \\
\hline & & Fused deposition modelling (FDM) \\
\hline & & $\begin{array}{l}\text { Three dimensional welding (3DW) } \\
\text { Shape deposition manufacturing (SDM) }\end{array}$ \\
\hline & \multirow[t]{2}{*}{$\begin{array}{l}\text { Processes involving } \\
\text { discrete particles }\end{array}$} & $\begin{array}{l}\text { Fusing of particles by laser } \\
\text { Selective laser sintering (SLS) }\end{array}$ \\
\hline & & $\begin{array}{l}\text { Gas phase deposition (GPD) } \\
\text { Joining of particles with a binder } \\
\text { Three dimensional printing (3DP) } \\
\text { Spatial forming (SF) }\end{array}$ \\
\hline & $\begin{array}{l}\text { Technologies } \\
\text { which use solid }\end{array}$ & $\begin{array}{l}\text { Laminated object manufacture (LOM) } \\
\text { Solid foil polymerisation (SFP) }\end{array}$ \\
\hline $\begin{array}{l}\text { Material } \\
\text { removal } \\
\text { technology }\end{array}$ & & Desktop milling (DM) \\
\hline
\end{tabular}

The accuracy data in this paper was obtained from technical publications and from company literature. There was no comparative information available for different build orientations.

In 2003, Steve Upcraft and Richard Fletcher [6] represented an overview study for various rapid prototyping technologies including Stereolithography (SLA), Selective laser sintering (SLS), Laminated object manufacturing (LOM), Fused 
deposition modeling (FDM), Multi-jet modeling (MJM) and Three dimensional printing (3DP). Build method, advantages, disadvantages and main suppliers of these rapid prototyping systems were listed. The test specimens were made by SLA, SLS, LOM and FDM to investigate surface roughness and dimensional accuracy. Mechanical properties including tensile strength, elastic modulus and Shore hardness were available in the paper. The data presented were supplied by the material suppliers or equipment manufacturers. There was also no comparative information of different build orientations.

The surface finish is one major issue with using rapid prototyping technologies. In 2006, Armillotta [22] presented an investigation into the surface finish of FDM parts. The main research topic is the stair-stepping effect caused by layered fabrication. By using the method in the research, it could build FDM parts with the shape of millimeter scale features, a layer thickness of $0.127 \mathrm{~mm}$. In 2010 , Weiss E et al. [23] developed the multi-directional layers disposition method to decrease the model errors. Two model errors were discussed and analyzed: (1) external errors and (2) internal errors. External errors of models include: conversion error, staircase and error of slicing into layers. Internal errors of models are related to the method of filling the interior of disposed layer. This paper proposed the solution, the multi-directional layer disposition method, to decrease these two errors. By using this 
method, it enables users to prepare individual strategy of material layer disposition for each desired case.

\subsection{Mechanical Properties}

In this section, the literature source related to mechanical properties is presented. The choice of deposition strategy plays an important role in the Fused Deposition Modeling (FDM). Different deposition strategies may cause different performance in mechanical properties. In 1999, Kulkarni and Dutta [24] investigated the effects of different deposition paths on the FDM process. They compared the experimental results (material properties) of parts manufactured by the different strategies. An analytical model developed using laminate analysis was taken. The result of using their laminate model can be used to help a designer tailor the deposition strategy.

In 2002, Ahn S. et al. [25] developed six build rules that can improved the tensile strengths, compressive strengths and quality of FDM parts. The rapid prototyping machine they used was Stratasys Fused Deposition Modeling 1650. Tensile strengths and compressive strengths of FDM fabricated specimens were also compared with specimens created by injection molding ABS P400 material. The same material was used for specimens produced by both FDM and injection molding. For the FDM parts, the typical tensile strength ranged between 65 and 72 percent of the 
strength of injection molding ABS P400, while the compressive strength ranged from 80 to 90 percent of the injection molding. The following build rules were obtained from the paper by Ahn S. et al. [25]: (1) Build parts such that tensile loads will be carried axially along the fibers. (2) Be aware that stress concentrations occur at radiused corners. This is because the FDM beads (or roads; this is the thickness of the bead that the FDM nozzle deposits.) exhibit discontinuities at such transitions. (3) Use a negative air gap to increase both strength and stiffness. (4) Consider the issues of bead width. (5) Consider the effect of build orientation on part accuracy. (6) Be aware that tensile loaded area tends to fail easier than compression loaded area. By applying these build rules, the strength and quality of FDM parts can be improved.

In 2009, Ana P. et al. [26] presented an experimental analysis of material properties for rapid prototyping technologies. The test specimens were manufactured in the 3D Printing (ZPrinter 310 Plus) and the PolyJet (Objet Eden 330) systems. The materials used for the test specimens made on the Objet Eden 330 are VeroBlack, VeroBlue and FullCure 720, while the ZPrinter 310 Plus used zp 102 powder, zb 56 binding agent and Loctite 406 and Loctite Hysol 9483 A\&B reinforcers glue. The experiment results included the analysis of the dimensions, roughness of surfaces and mechanical properties (flexural properties and tensile properties). The results of measuring dimensions showed the PolyJet (Objet Eden 330) is more accurate than the 
3D Printing (ZPrinter 310 Plus). The surface of test specimens made by the ZPrinter 310 Plus were rougher than VeroBlack and VeroBlue material which were used on the PolyJet system, while the FullCure material showed the lowest value of surface roughness. The best mechanical properties (flexural properties and tensile properties) showed in the test specimens made of FullCure on the PolyJet technology. The worst mechanical properties are from the test specimens made of powder which used on the 3D Printing system. 


\section{Chapter 3: METHODOLOGY}

Different build orientations in specified rapid prototyping systems may have significant effects on physical and mechanical properties. This paper presents a comparative study in three build orientations across four rapid prototyping systems: Selective Laser Sintering (SLS), PolyJet, Fused Deposition Modeling (FDM), and 3D Printing (3DP) at the University of Missouri, Columbia. The investigations of dimensional accuracy and tensile properties testing for three build orientations are provided in this paper. Furthermore, the experiments of water absorption and Shore hardness across these four rapid prototyping systems are also available in this study.

\subsection{Experiment scheme}

The test specimens were made by Selective Laser Sintering (SLS), PolyJet, Fused Deposition Modeling (FDM), and 3D Printing (3DP) at the University of Missouri, Columbia. Table 2 shows the manufacturers and models of these four rapid prototyping systems. Their technical characteristics can be found in the literature [27-31]. In determining the dimensions of the test specimens, a digital caliper was used, with the measurement range 0-150/0.01 mm. The ADMET eXpert 2611 
universal testing system was used to test the tensile properties. Tests were performed at a temperature of $72{ }^{\circ} \mathrm{F}$ with air-conditioning. The horizontal build orientation was been chosen to make specimens for investigating their water absorption rate and Shore hardness.

Table 2. Rapid Prototyping systems at the University of Missouri, Columbia

\begin{tabular}{|l|l|l|}
\hline \multicolumn{1}{|c|}{ System } & \multicolumn{1}{c|}{ Manufacturer } & \multicolumn{1}{c|}{ Model } \\
\hline SLS & EOS & Formiga P100 \\
\hline PolyJet & Objet & Eden 350V \\
\hline FDM & Dimension & Elite 3D Printer \\
\hline 3DP & Z Corporation & Spectrum Z510 \\
\hline
\end{tabular}

\subsection{Materials and sample preparation}

Materials used in this study were commercially available polyamide, photopolymer resin, ABS plastic, and gypsum. Table 3 shows the materials and the machine settings that were used in the specified rapid prototyping systems. The materials that were used in this research were the most popular in the current commercial marketplace. The machine settings were also listed in Table 3.The test specimens were fabricated by these four RP systems in three build orientations as shown in Table 4 , and the dimensions conformed to ASTM D638 Type IV.

Figure 5 illustrates the three build orientations in each RP system. For 3D 
Printing technology, the Z-Corporation Model Spectrum Z510 3D printer constructed the test specimens. Materials for the specimens consisted of ZP 131 (gypsum) powder and Z-Bond 90 binder. Once the part was completed and the support powder was removed, the part was dipped in binder and dried for 24 hours.

Table 3. Materials used in RP systems at the University of Missouri, Columbia

\begin{tabular}{|l|l|l|}
\hline System & \multicolumn{1}{|c|}{ Material } & \multicolumn{1}{c|}{ Machine Setting } \\
\hline \multirow{3}{*}{ SLS } & $\begin{array}{l}\text { PA 2200 Balance 1.0 } \\
\text { (polyamide 12) }\end{array}$ & $\begin{array}{l}\text { Default } \\
\text { Standard calibration for PA2200 } \\
\text { Z-Axis }=0.100 \mathrm{~mm}\end{array}$ \\
\hline \multirow{3}{*}{ PolyJet } & $\begin{array}{l}\text { FullCure 835 VeroWhitePlus } \\
\text { (UV curable acrylic plastic) }\end{array}$ & $\begin{array}{l}\text { Default } \\
\text { Print mode }=\text { High Quality } \\
\text { Z-Axis }=0.016 \mathrm{~mm}\end{array}$ \\
\hline \multirow{3}{*}{ FDM } & $\begin{array}{l}\text { ABSplus-P430 } \\
\text { (ABS plastic) }\end{array}$ & $\begin{array}{l}\text { Default } \\
\text { Model interior fill = Sparse }- \text { High density } \\
\text { Support Fill = Sparse } \\
\text { Z-Axis = 0.007 inch }(0.1778 \mathrm{~mm})\end{array}$ \\
\hline & ZP 131 (gypsum) & $\begin{array}{l}\text { Default } \\
\text { Powder }=\text { ZP 131 } \\
\text { Z-Axis = 0.004 inch }(0.1016 \mathrm{~mm})\end{array}$ \\
\hline
\end{tabular}


Table 4. Three build orientations

\begin{tabular}{|c|c|}
\hline \multicolumn{2}{|c|}{ Build Orientation } \\
\hline Horizontal & \\
\hline Side & \\
\hline & \\
\hline
\end{tabular}




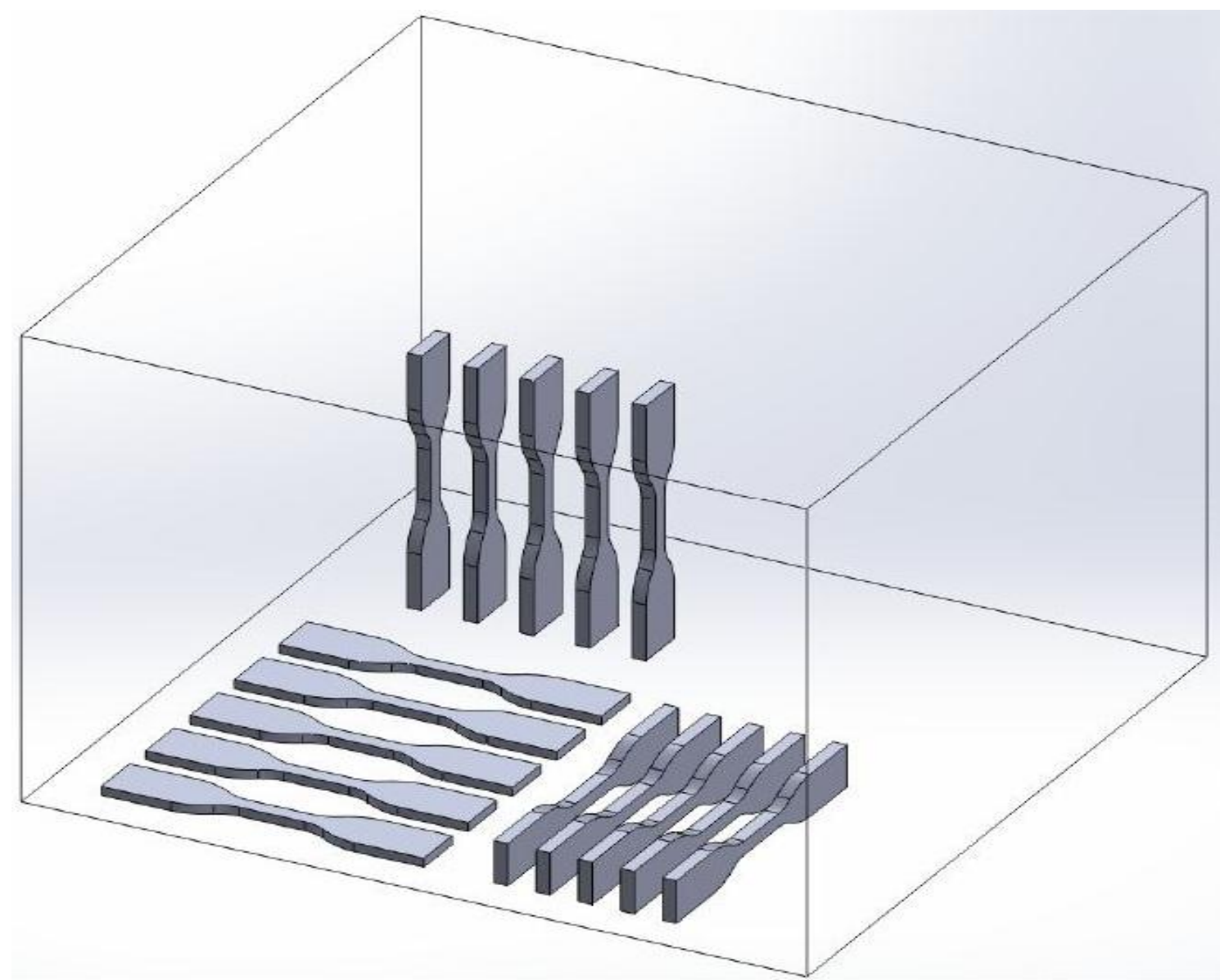

Figure 5. Specimens in three build orientations in each RP system

\subsection{Shape of test specimen}

The tensile properties of rigid and semi-rigid plastics were determined according to the ASTM D638-10 standard, and the Type IV specimen was used when directly comparing between different rigid materials. Table 5 presents the dimensions of the tensile test specimen. Figure 6 shows the location of these dimensions and the shape of the test specimen for tensile testing. A minimum of five test specimens are recommended by the standard. The testing speed for the specimen ASTM D638 Type 
IV is $5 \pm 25 \% \mathrm{~mm} / \mathrm{min}$, and the higher speeds $50 \pm 10 \% \mathrm{~mm} / \mathrm{min}$ and $500 \pm 10 \%$ $\mathrm{mm} / \mathrm{min}$ were used, which attains rupture within $1 / 2$ to 5 -min testing time.

Table 5. Dimensions of tensile test specimen (ASTM D638-10 Type IV)

\begin{tabular}{|l|c|}
\hline \multicolumn{1}{|c|}{ ASTM D638-10 Type IV } & Dimensions (mm) \\
\hline W - Width of narrow section & 6 \\
\hline L - Length of narrow section & 33 \\
\hline WO - Width overall, min & 19 \\
\hline LO - Length overall, min & 115 \\
\hline G - Gage length & 25 \\
\hline D - Distance between grips & 65 \\
\hline R - Radius of fillet & 14 \\
\hline RO - Outer radius & 25 \\
\hline T - Thickness & 4 \\
\hline
\end{tabular}

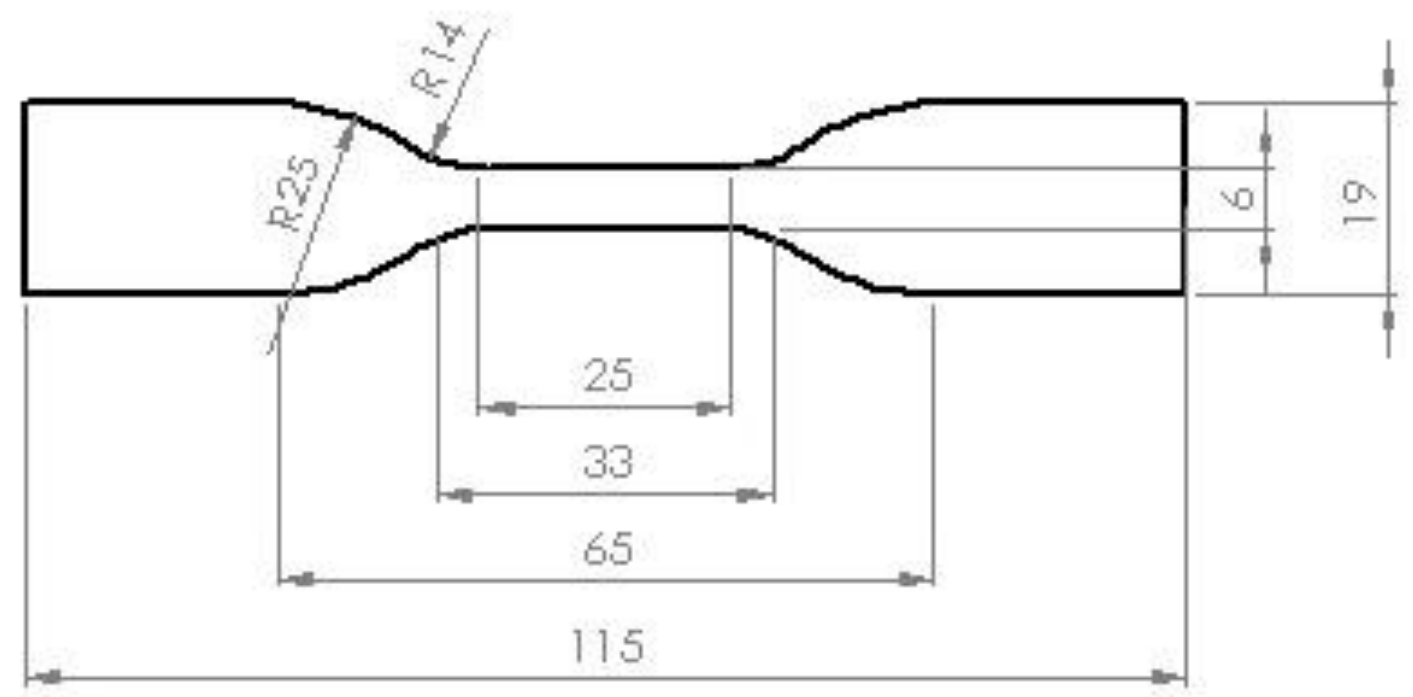

Figure 6. Shape of test specimen for tensile testing (mm) 


\subsection{Dimension measurement}

Five ASTM D638 Type IV specimens were made in each of three build orientations (Horizontal, Side, and Vertical) in the SLS, PolyJet, and FDM systems. Considering the relatively fragile material used in the 3DP system, eight ASTM D638 Type IV specimens were made in each of three build orientations (Horizontal, Side, and Vertical).

There are four measurement points: width of narrow section $(W)$, width overall (WO), length overall $(L O)$, and thickness $(T)$ on each specimen as shown in Figure 7. Dimension of the specimen was measured by a Pittsburgh digital caliper with the measurement range $0-150 / 0.01 \mathrm{~mm}$. The measurements were done on each measurement point, and the values were then recorded. For the measurement point of width overall, both side on each specimen were measured, and the values were then recorded. For the measurement point of thickness, two ends and middle on each specimen were measured, and then the values were recorded. The average values and standard deviation of each measurement point for specified build orientations and rapid prototyping systems were then calculated. 


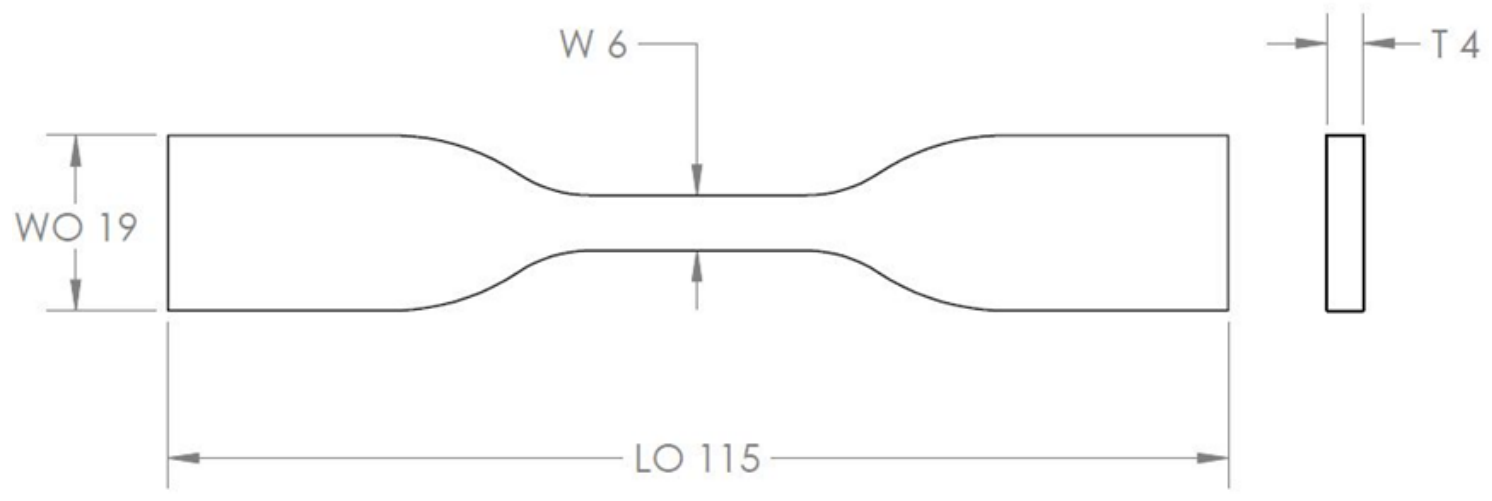

Figure 7. Four measurement points on the specimen (mm)

\subsection{Tensile testing}

Five to eight ASTM Type IV specimens were made in each of three build orientations (Horizontal, Side, and Vertical) in each rapid prototyping systems (five specimens in each of three build orientations for SLS, PolyJet and FDM systems; eight specimens in each of three build orientations for 3DP). Tensile tests were performed on a universal testing machine (ADMET eXpert 2611) equipped with a 10 $\mathrm{kN}$ load cell. All the tests were conducted at the same temperature of $72^{\circ} \mathrm{F}$.

For determining the tensile properties the test specimen is clamped by the jaws of the test machine as shown in Figure 8 and extended with force, at testing speed 5 $\mathrm{mm} / \mathrm{min}$ as defined by ASTM D638-10 standard. The reported data are the average values from five/eight replications. 


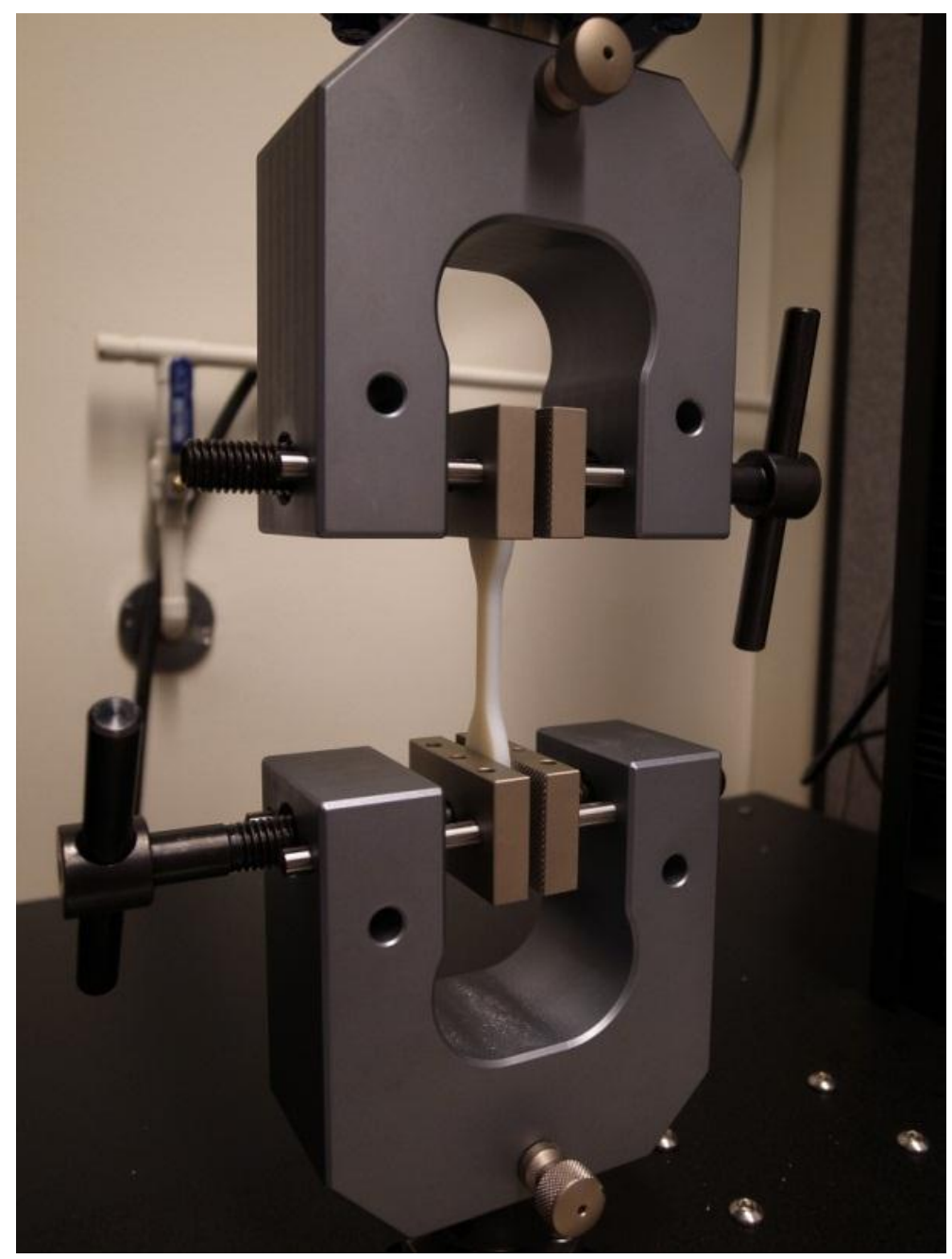

Figure 8 . The test specimen is clamped by the jaws of the test machine

\subsection{Water absorption}

The Horizontal build orientation was chosen to make specimens for investigating the relative rate of water absorption by plastics when immersed. The reason to choose Horizontal build orientation was the shortest machine duration compared with Side and Vertical. For the water absorption investigation, the independent variable was the specified rapid prototyping system and its relative 
material used, and the dependent variable was the weight change when water absorbed. The independent variable, build orientations, was not included in this investigation. Two specimens were made in each of four rapid prototyping systems. Prior to infiltration, all specimens were sealed in a zip lock plastic bag for one week (168 hours) at the same environment condition as shown in Figure 9. This step kept all specimens under the same environment condition and decreased experimental errors. When the desired time was reached, all specimens were immediately measured for the initial weight. The specimens were placed in a container of distilled water maintained at a temperature of $72 \pm 1^{\circ} \mathrm{F}$ and entirely immersed for 24 hours. When the desired time was reached, the specimens were then taken out, wiped gently with a dry tissue paper and weighed immediately. The specimens were weighed using a precision balance, OHAUS ScoutPro Series SP200 with 200g x $0.1 \mathrm{~g}$ tolerance as shown in Figure 10. Percentage of moisture absorption was calculated based on the weight change as shown in Equation 1.

Equation 1:

Water absorption (percent) $=\left[\frac{\text { Weight after conditioning for } 24 \text { hours }(g)-\text { initial weight }(g)}{\text { initial weight }(g)}\right] \times 100$ 


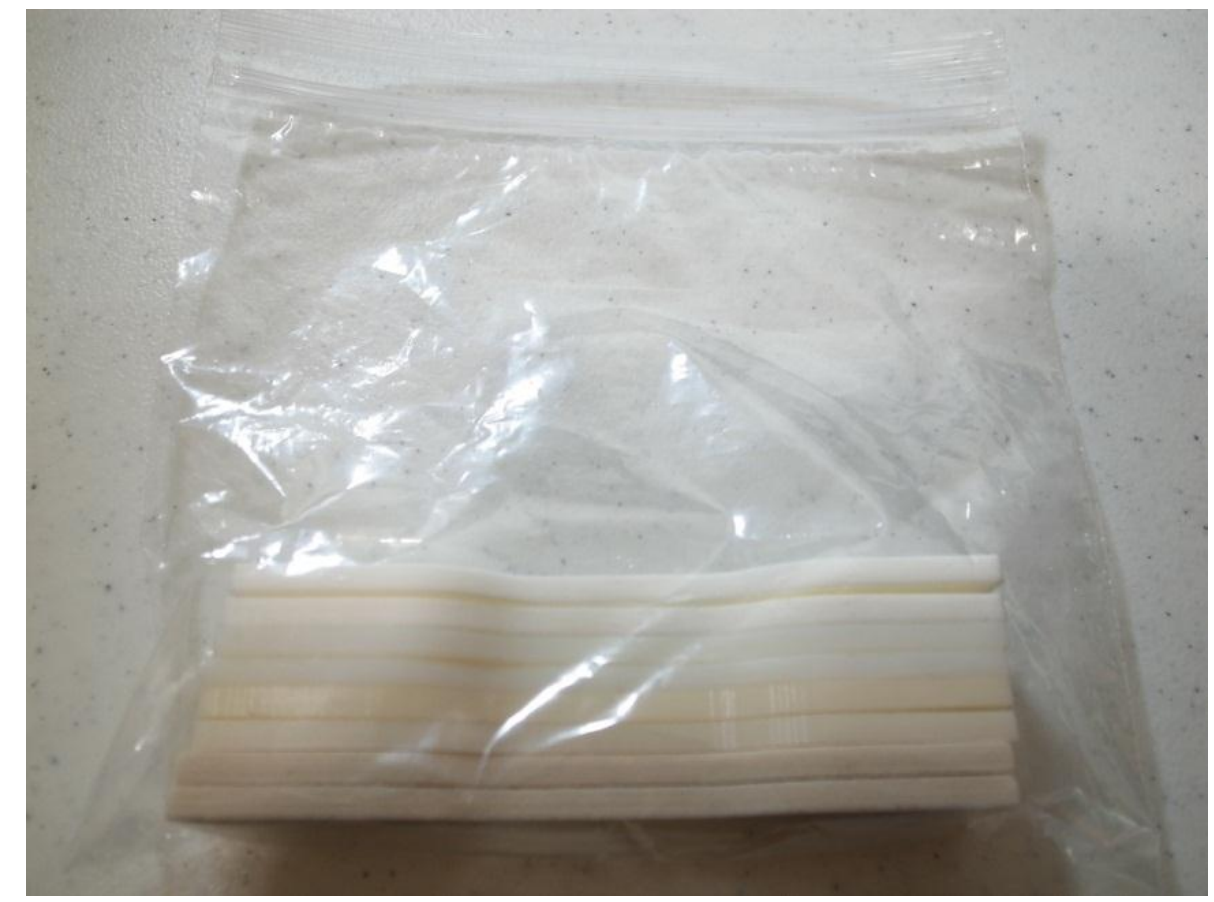

Figure 9. Specimens for water absorption sealed in a plastic bag

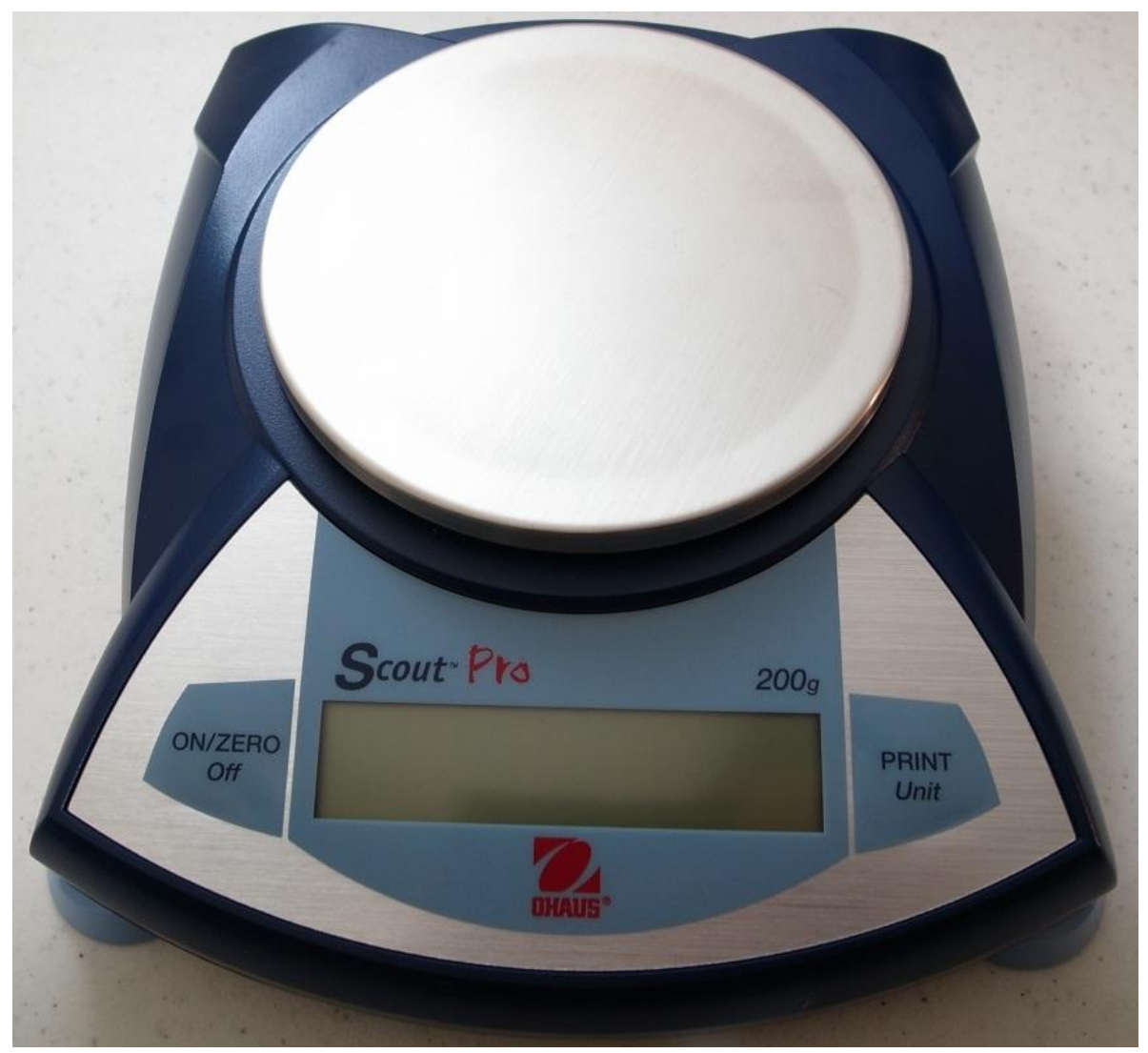

Figure 10. OHAUSE ScoutPro SP200 balance 


\subsection{Shore Hardness}

The Horizontal build orientation was chosen to create specimens in the four rapid prototyping systems for investigating the Shore hardness. Two specimens were made in each of the four rapid prototyping systems. Hardness of elastomers and most other polymer materials (Thermoplastics, Thermosets) is measured by the Shore D scale. The durometer, Pacific Transducer Corp. Model 409 ASTM Type D, as shown in Figure 11, was used to measure the Shore hardness. The durometer is a hand-hold device consisting of a needle-like spring-loaded indenter, which is pressed into the test specimen surface, and the penetration of the needle is measured directly from a scale on the device in terms of degrees of hardness. There were six measurement points (three on each side) on each specimen as shown in Figure 12. The measurement was done three times in each measurement point and the average value was then recorded. 


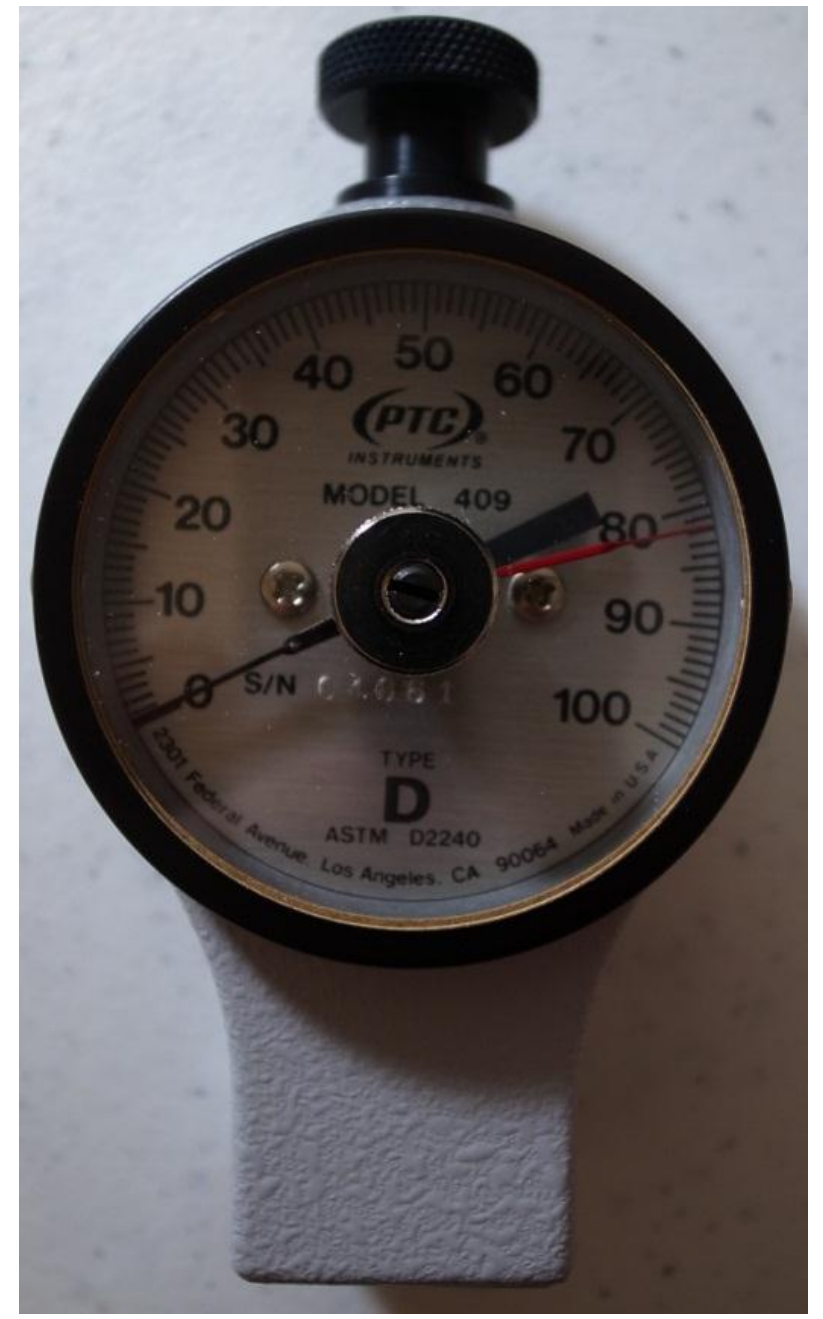

Figure 11. ASTM Type D Ergo Durometer

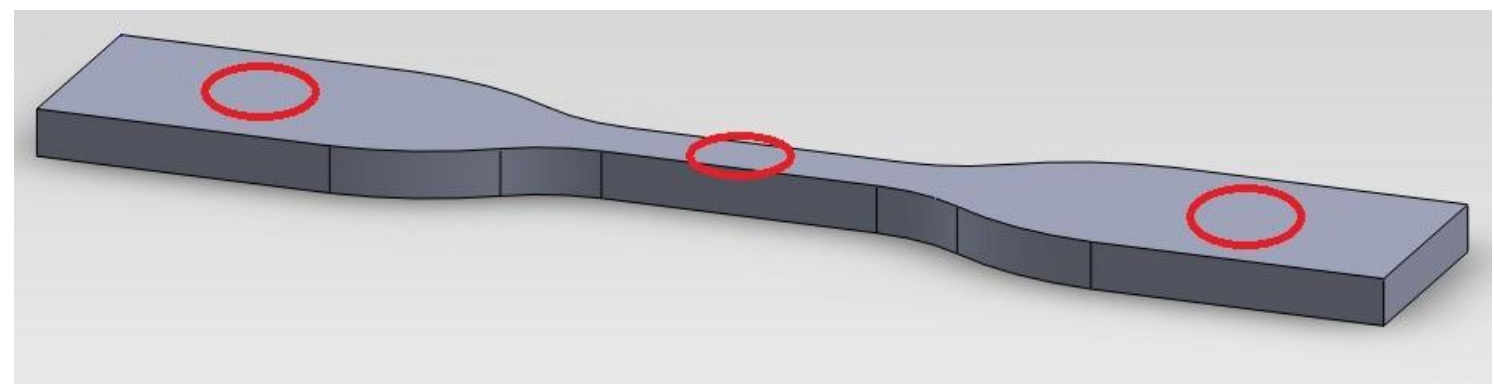

Figure 12. Measurement points for Shore hardness 


\subsection{Microscopy}

A stereo microscope, MEIJI Techno EMZ-5TR equipped with MA502 eyepieces as shown in Figure 13, was used to capture magnified photographs from the specimens after tensile properties testing to investigate their internal structure. The magnification capability is 7 times to 45 times. A digital camera, Moticam 10, was used to connect the stereo microscope and capture large scale images for documentation purposes. The software, Motic Images Plus 2.0, was used to capture JPEG images as a multi-media demonstration platform. All specimens made for tensile testing in three build orientations in SLS, PolyJet, FDM, and 3DP systems were examined using the stereo microscope to observe their fractured surface. The results are presented in Section 4.5 Microscopy.

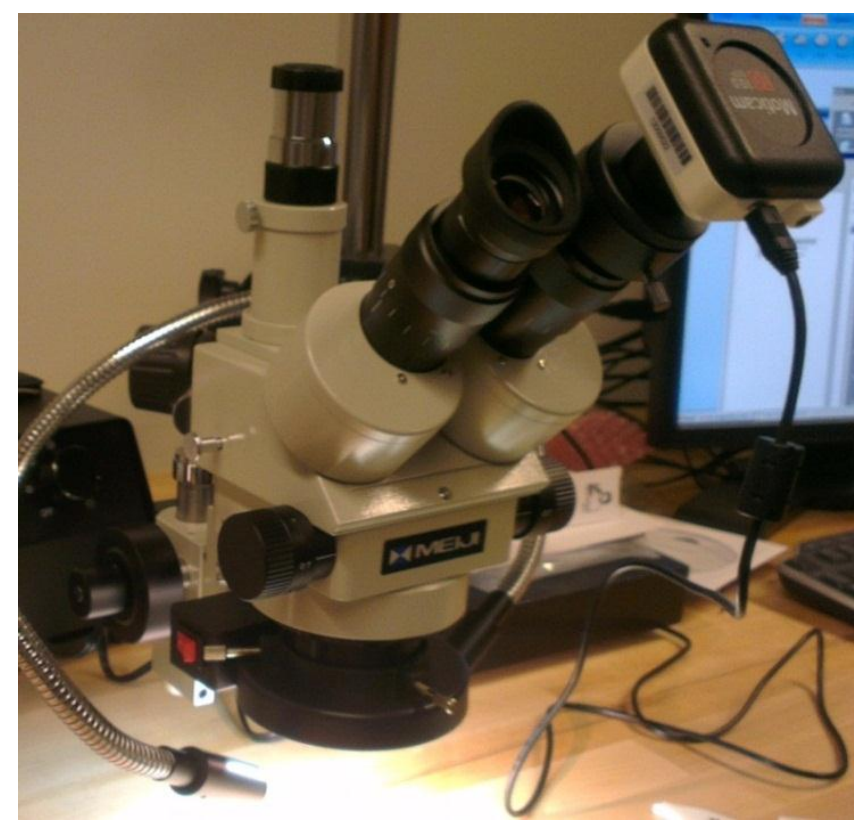

Figure 13. Stereo Microscope MEIJI Techno EMZ-5TR 


\section{Chapter 4 RESULTS AND ANALYSIS}

\subsection{Dimensional accuracy}

Before doing tensile property test, all specimens were measured to investigate their dimensional accuracy. Dimensional accuracy for each measurement point and each fabricated orientation from specified rapid prototyping systems was also presented in the following sections. Equation 2 shows how to calculate Dimension Change Rate. Equation 3 shows Dimensional Accuracy which is the absolute value of dimension change rate from Equation 2. Measured results and the standard deviations were presented in the following sections.

Equation 2:

Dimension Change Rate $($ percent $)=\left[\frac{\text { Measured value }(\mathrm{mm})}{\text { Desired value }(\mathrm{mm})}-1\right] \times 100$

Equation 3:

Dimensional Accuracy $($ percent $)=\left|\left[\frac{\text { Measured value }(\mathrm{mm})}{\text { Desired value }(\mathrm{mm})}-1\right] \times 100\right|$ 


\subsubsection{SLS Dimensional accuracy}

In this section, the measured results of the specimens for three build orientations in the Selective Laser Sintering (SLS) system would be presented. Table 6 lists the measured average values, standard deviations, dimension change rate, and dimensional accuracy. The average dimensional accuracy of four measured points was also included in the last row of Table 6 . Figure 14 shows the average dimensional accuracy for each measured points on three fabricated orientations. Dimensional analysis indicated that build orientation had a significant effect on accuracy. The measured value of the length overall in Vertical build orientation provided the most accuracy $(0.0470 \%)$. Through analysis of Table 6 and Figure 14, it appears that measured points of Vertical build orientation are less variable than Horizontal and Side build orientations. 
Table 6. Measured results in SLS

\begin{tabular}{|c|c|c|c|c|}
\hline \multirow{2}{*}{\multicolumn{2}{|c|}{$\begin{array}{c}\text { ASTM } \\
\text { Type IV (mm) }\end{array}$}} & \multicolumn{3}{|c|}{ SLS } \\
\hline & & Horizontal & Side & Vertical \\
\hline \multirow{4}{*}{$\begin{array}{l}W \\
6\end{array}$} & $\mathrm{AVG}$ & 5.8620 & 6.1560 & 5.9880 \\
\hline & SD & 0.0303 & 0.0114 & 0.0303 \\
\hline & Dimension Change Rate (\%) & -2.3000 & 2.6000 & -0.2000 \\
\hline & Dimensional Accuracy (\%) & 2.3000 & 2.6000 & 0.4667 \\
\hline \multirow{4}{*}{$\begin{array}{c}\text { WO } \\
19\end{array}$} & AVG & 18.8180 & 19.1380 & 18.9480 \\
\hline & $\mathrm{SD}$ & 0.0295 & 0.0303 & 0.0356 \\
\hline & Dimension Change Rate (\%) & -0.9579 & 0.7263 & -0.2737 \\
\hline & Dimensional Accuracy (\%) & 0.9579 & 0.7263 & 0.2737 \\
\hline \multirow{4}{*}{$\begin{array}{l}\mathrm{LO} \\
115\end{array}$} & AVG & 114.7740 & 114.9340 & 114.9740 \\
\hline & $\mathrm{SD}$ & 0.0773 & 0.0195 & 0.0590 \\
\hline & Dimension Change Rate (\%) & -0.1965 & -0.0574 & -0.0226 \\
\hline & Dimensional Accuracy (\%) & 0.1965 & 0.0574 & 0.0470 \\
\hline \multirow{4}{*}{$\begin{array}{l}\mathrm{T} \\
4\end{array}$} & AVG & 4.2160 & 3.8980 & 4.0500 \\
\hline & SD & 0.0114 & 0.0164 & 0.0361 \\
\hline & Dimension Change Rate (\%) & 5.4000 & -2.5500 & 1.2500 \\
\hline & Dimensional Accuracy (\%) & 5.4000 & 2.5500 & 1.2500 \\
\hline \multicolumn{2}{|c|}{ SD - Dimensional Accuracy } & 2.0583 & 1.1670 & 0.6335 \\
\hline \multicolumn{2}{|c|}{ AVG Dimensional Accuracy (\%) } & 2.2136 & 1.4834 & 0.5093 \\
\hline
\end{tabular}




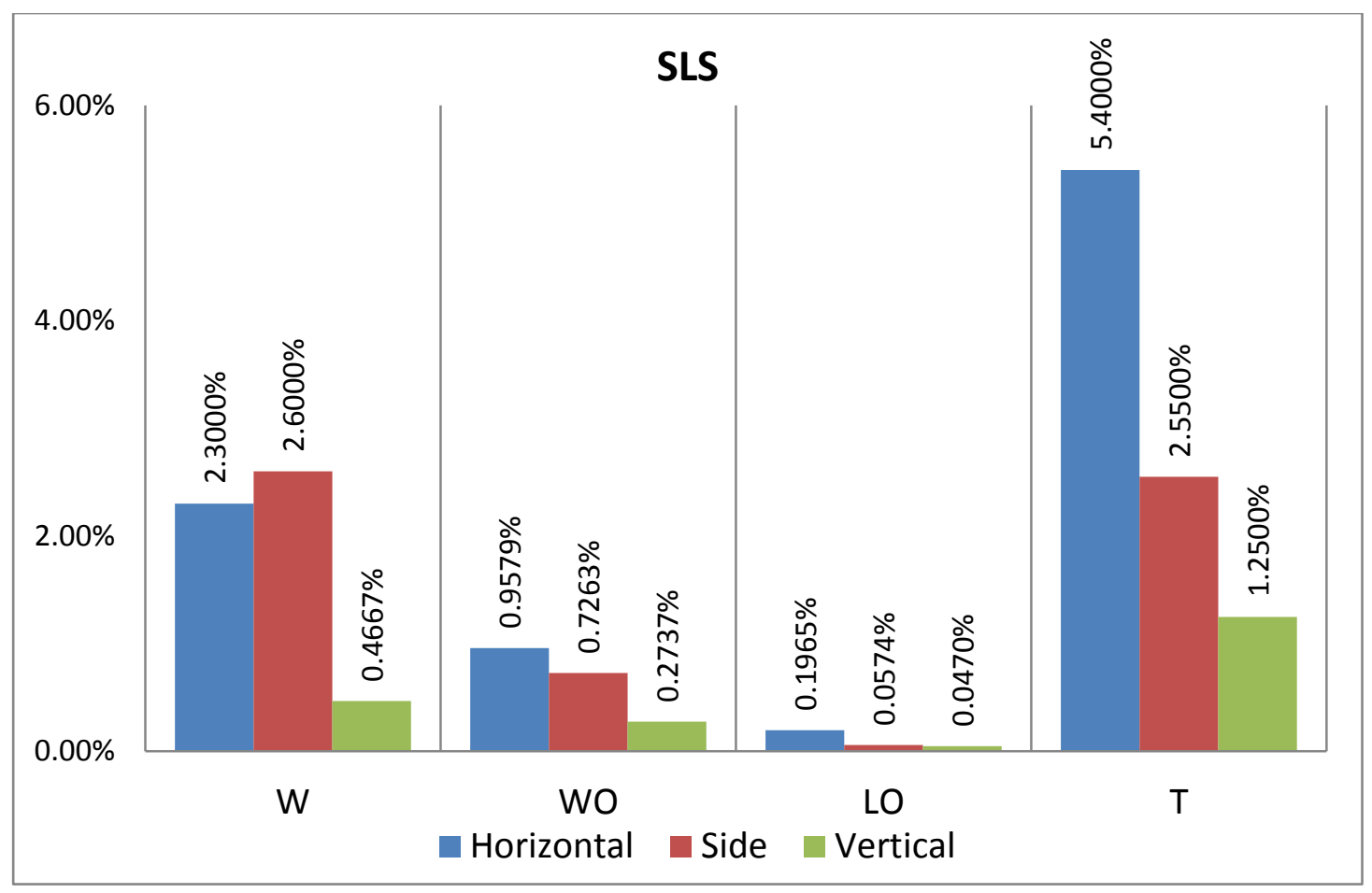

Figure 14. Dimensional Accuracy of four measurement points in SLS

The average dimensional accuracy of four measured points indicates that Vertical build orientation provided the best accuracy (0.5093\%) as shown in Figure 15.

Vertical build orientation is more accurate in the SLS system.

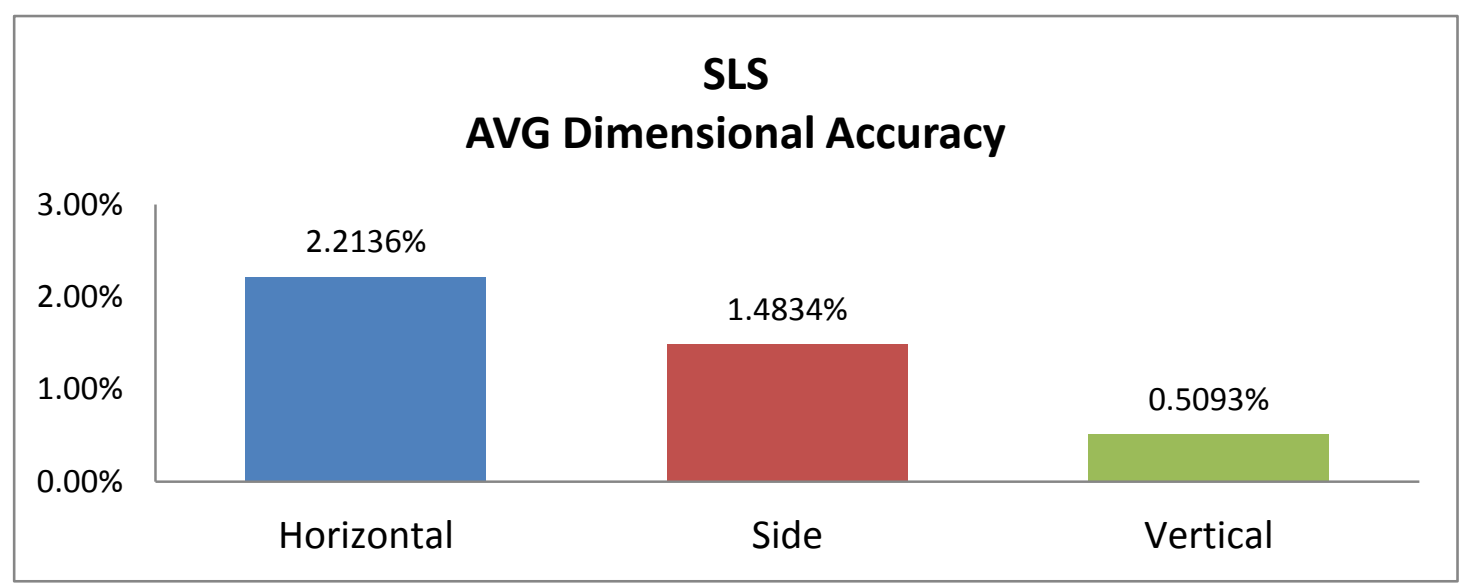

Figure 15. AVG Dimensional Accuracy of three build orientations in SLS 


\section{Statistical Analysis}

One-Way ANOVA was chosen to analyze the experiment results for the SLS

technology. It can be seen in the ANOVA table below from Minitab that the p-value

0.001 of factor (Orientation) is less than 0.05 . Therefore, we can say the build orientation significantly affects the dimensional accuracy in the SLS system. In the Normal Plot of Residual, we can find that most of the points displayed near the straight line and few points are a little far from the line. We can say that these experiment results can mostly satisfy the model adequacy and the points follow the normal distribution. The boxplot shows the Vertical build orientation is more accurate than the Horizontal and Side orientations.

\section{One-way ANOVA: SLS Accuracy versus Orientation}

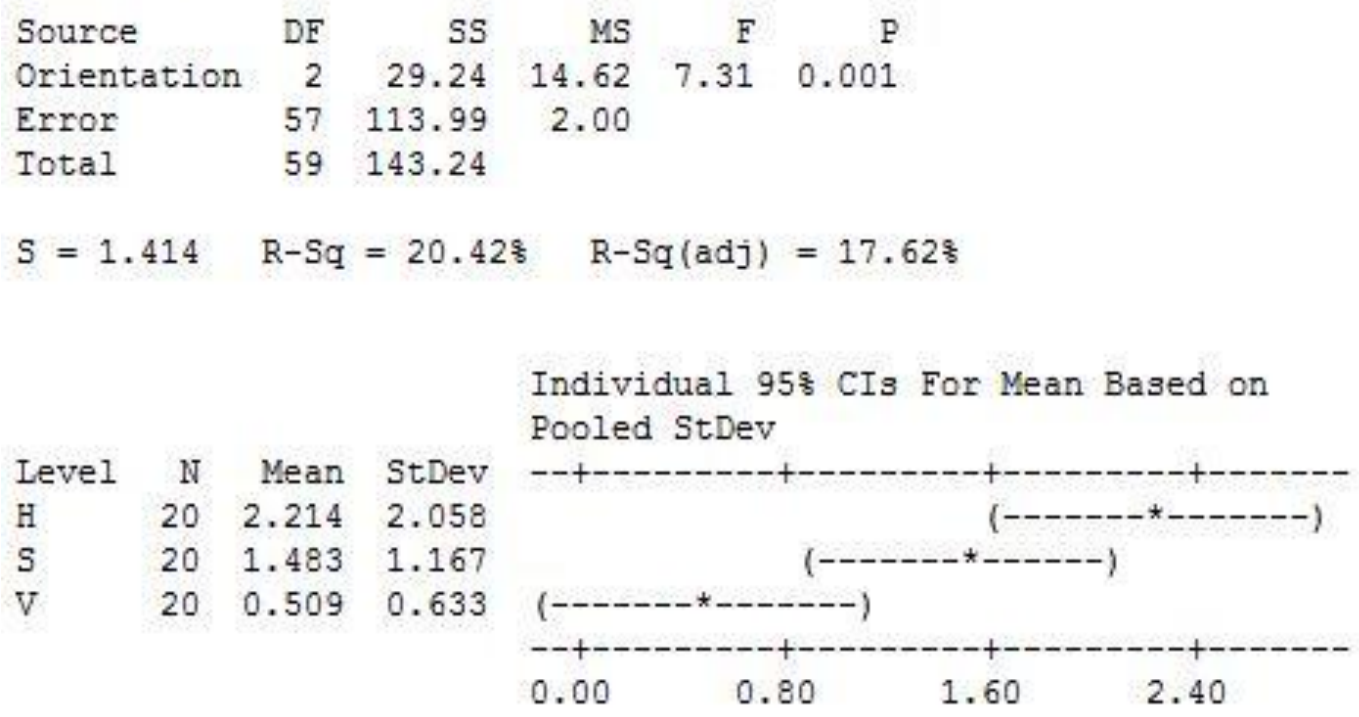

Pooled StDev $=1.414$ 

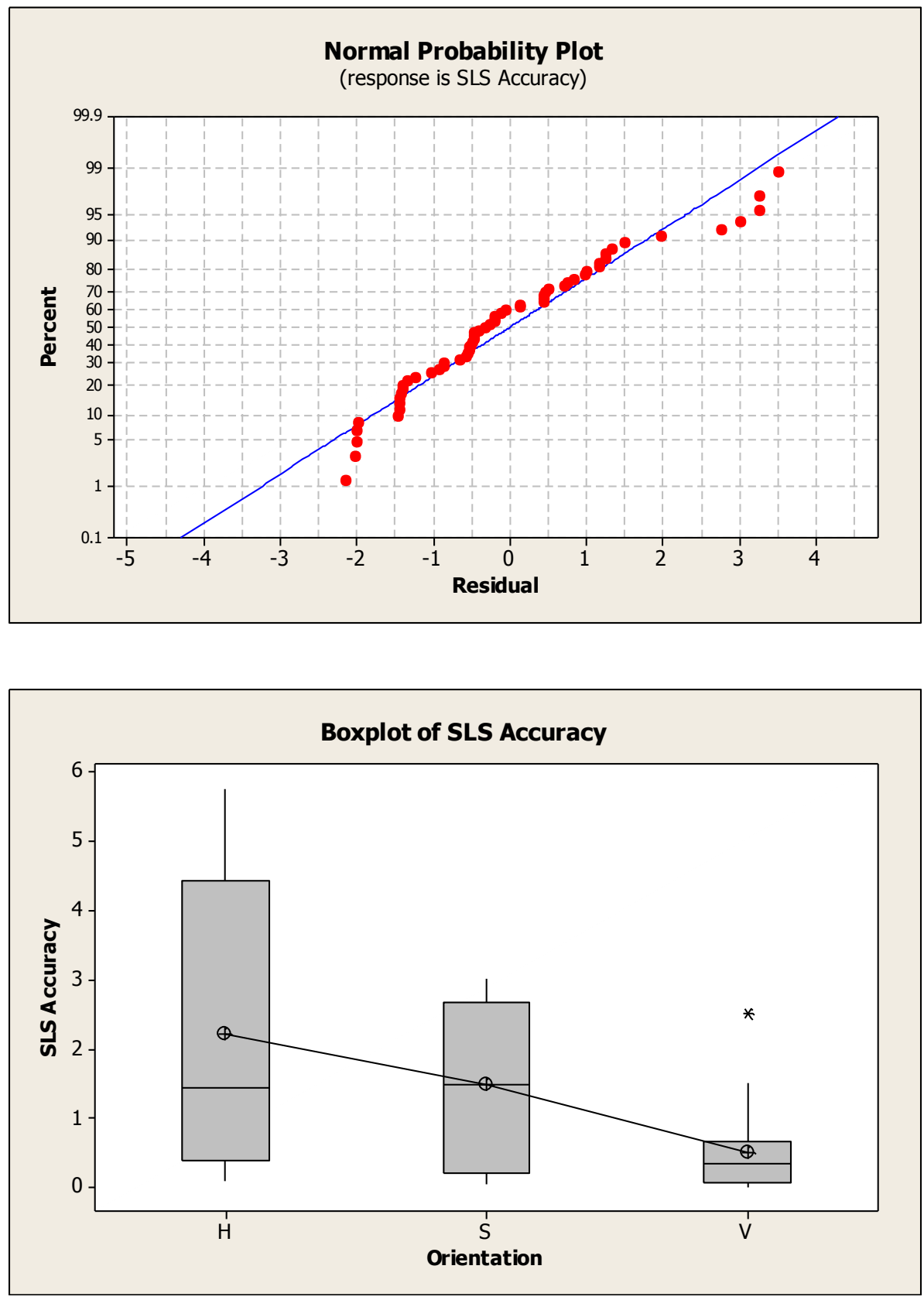

\subsubsection{PolyJet Dimensional accuracy}

Table 7 and Figure 16 show the results of four measured points in the PolyJet system. The measured points of $\mathrm{T}$ (thickness) in Horizontal orientation provided the most accurate results $(0.1000 \%)$. Comparing the measured results of Horizontal and 
Side build orientation in Figure 16, the values of Horizontal shows a more stable trend than Side.

Table 7. Measured results in PolyJet

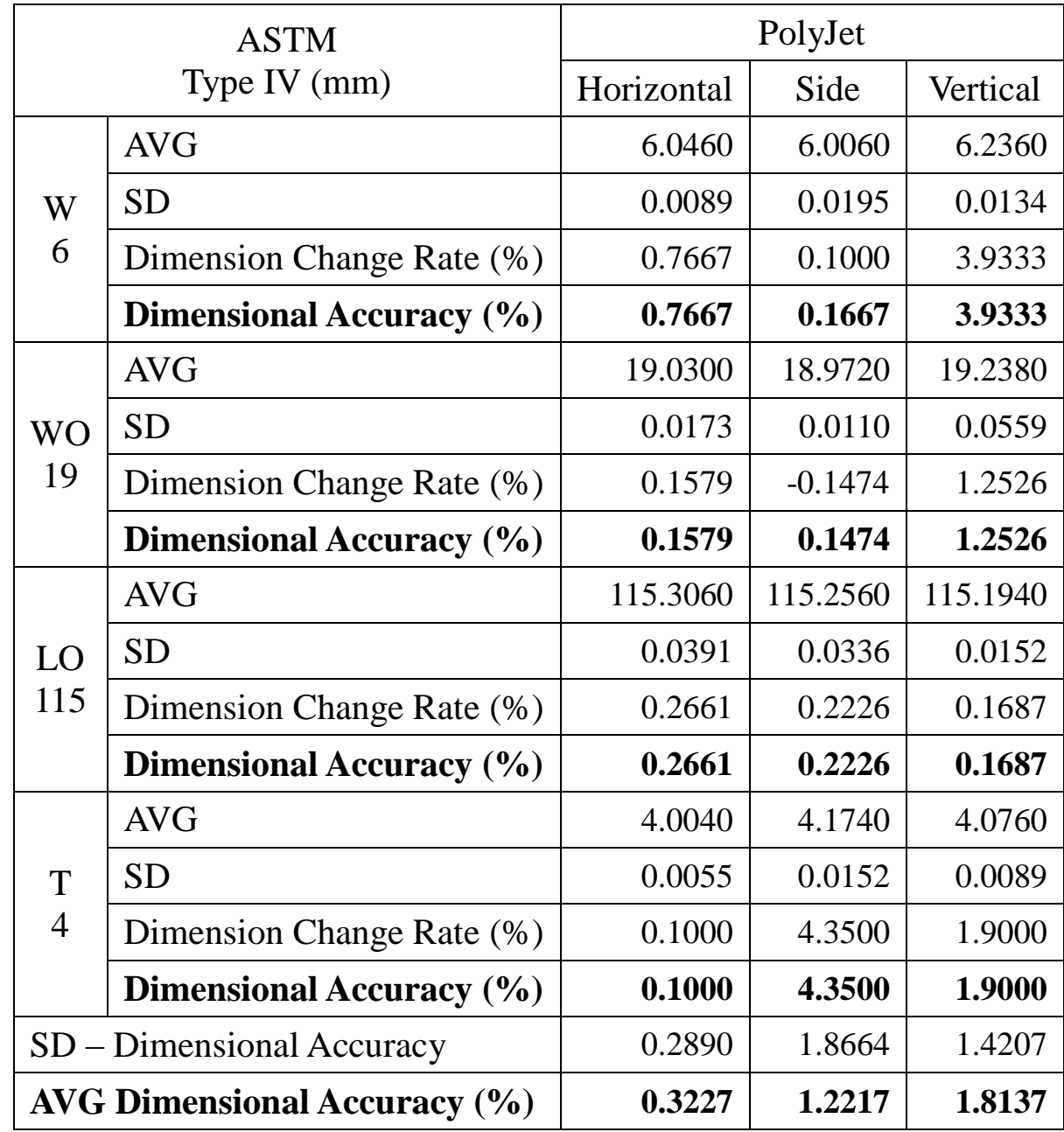




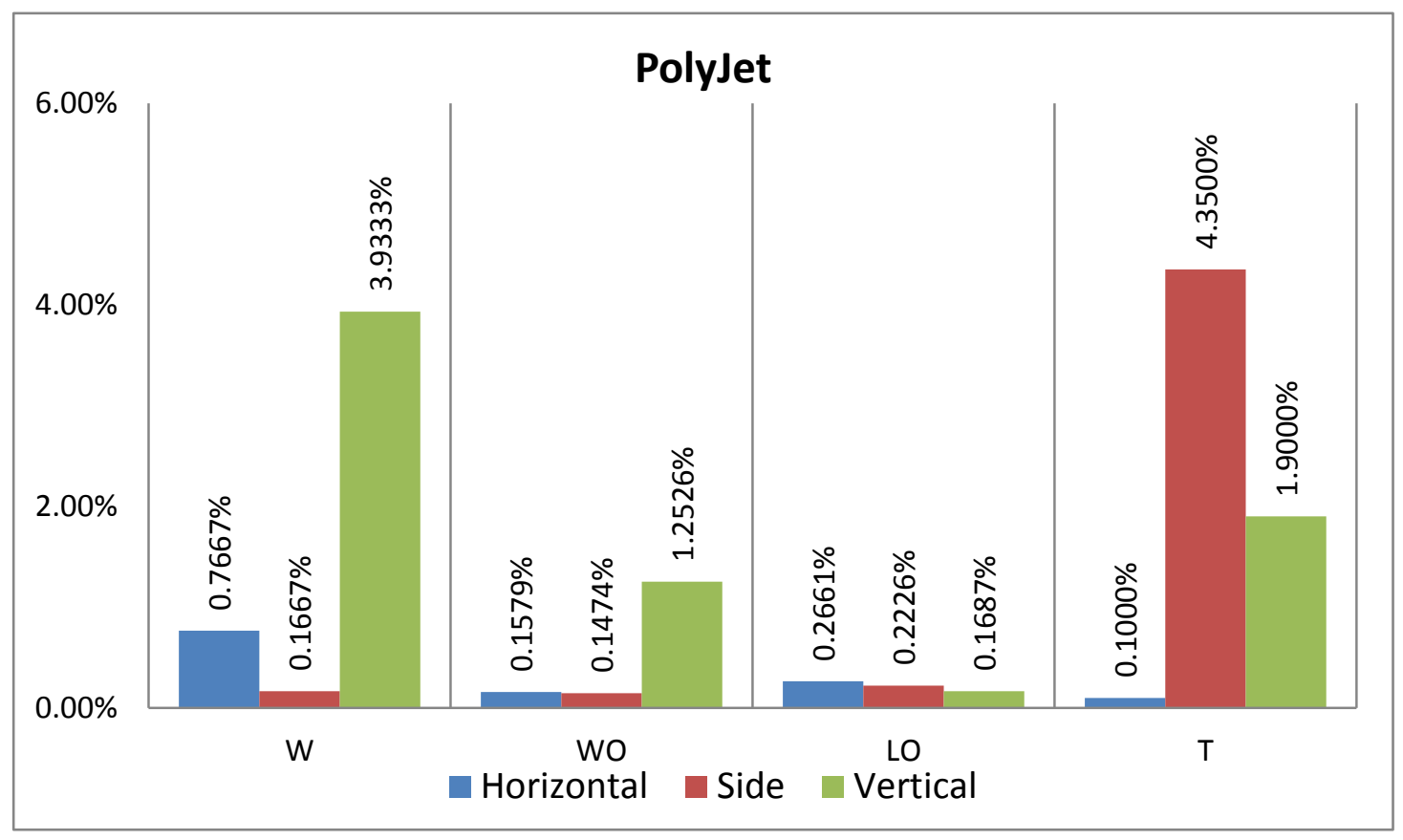

Figure 16. Dimensional Accuracy of four measurement points in PolyJet

Figure 17 shows the average dimensional accuracy of three orientations in the PolyJet system. It can be seen that the difference in build orientations results in the different accuracy of specimens. In Figure 17, the Horizontal build orientation provided more accuracy $(0.3227 \%)$ than the Side and Vertical orientations for the PolyJet system.

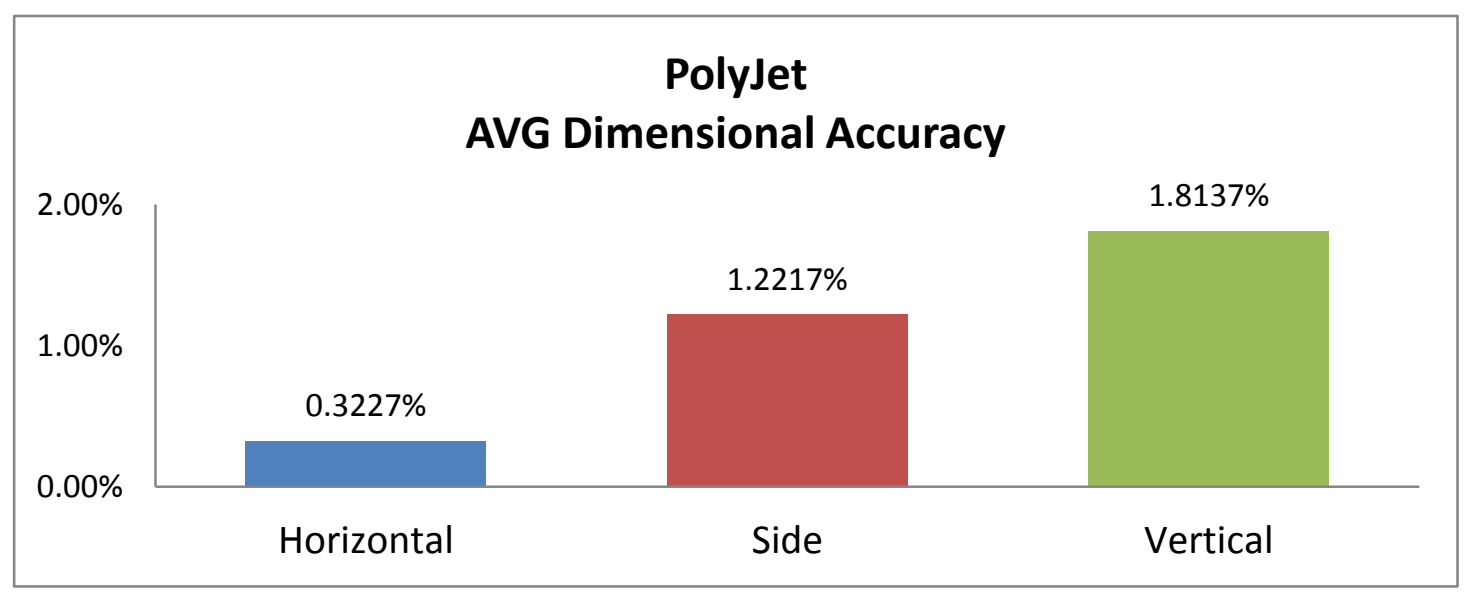

Figure 17. AVG Dimensional Accuracy of three build orientations in PolyJet 


\section{Statistical Analysis}

One-Way ANOVA was chosen to analyze the experiment results in PolyJet. In the ANOVA table below from Minitab, the p-value 0.004 of factor (Orientation) is less than 0.05 . We can say the build orientation significantly affects the dimensional accuracy in PolyJet. In the Normal Probability Plot, most points displayed near the straight line, we can say that these experiment results can mostly satisfy the model adequacy and the points follow the normal distribution. In the ANOVA table and the boxplot, it can be seen that the Horizontal build orientation is more accurate than the Side and Vertical orientations.

\section{One-way ANOVA: Polyjet Accuracy versus Orientation}

$\begin{array}{lrrrrr}\text { Source } & \text { DF } & \text { SS } & \text { MS } & \text { F } & \text { P } \\ \text { Orientation } & 2 & 22.55 & 11.27 & 6.05 & 0.004 \\ \text { Error } & 57 & 106.12 & 1.86 & & \\ \text { Total } & 59 & 128.67 & & & \\ \text { S }=1.364 & \text { R-Sq }=17.52 \% & \text { R-Sq }(\text { adj })=14.63 \%\end{array}$

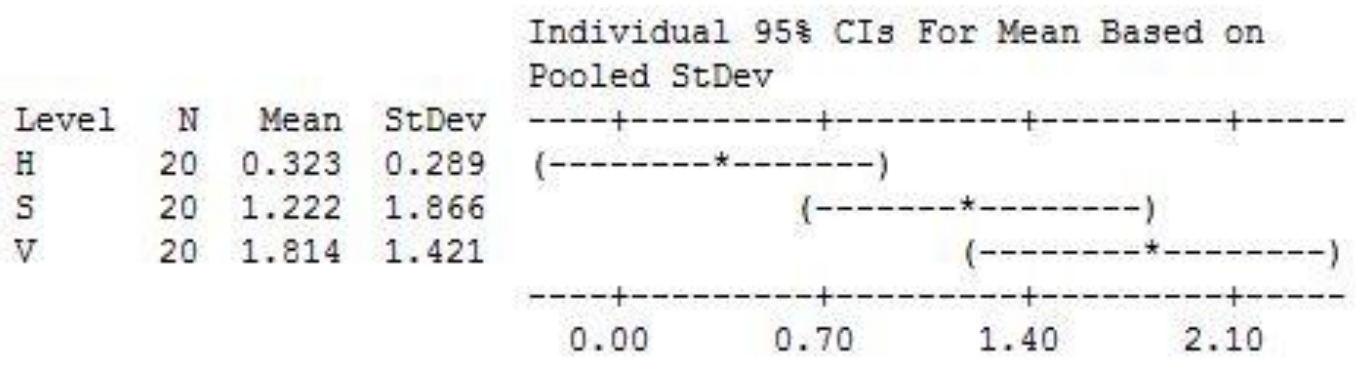

Pooled StDev $=1.364$ 

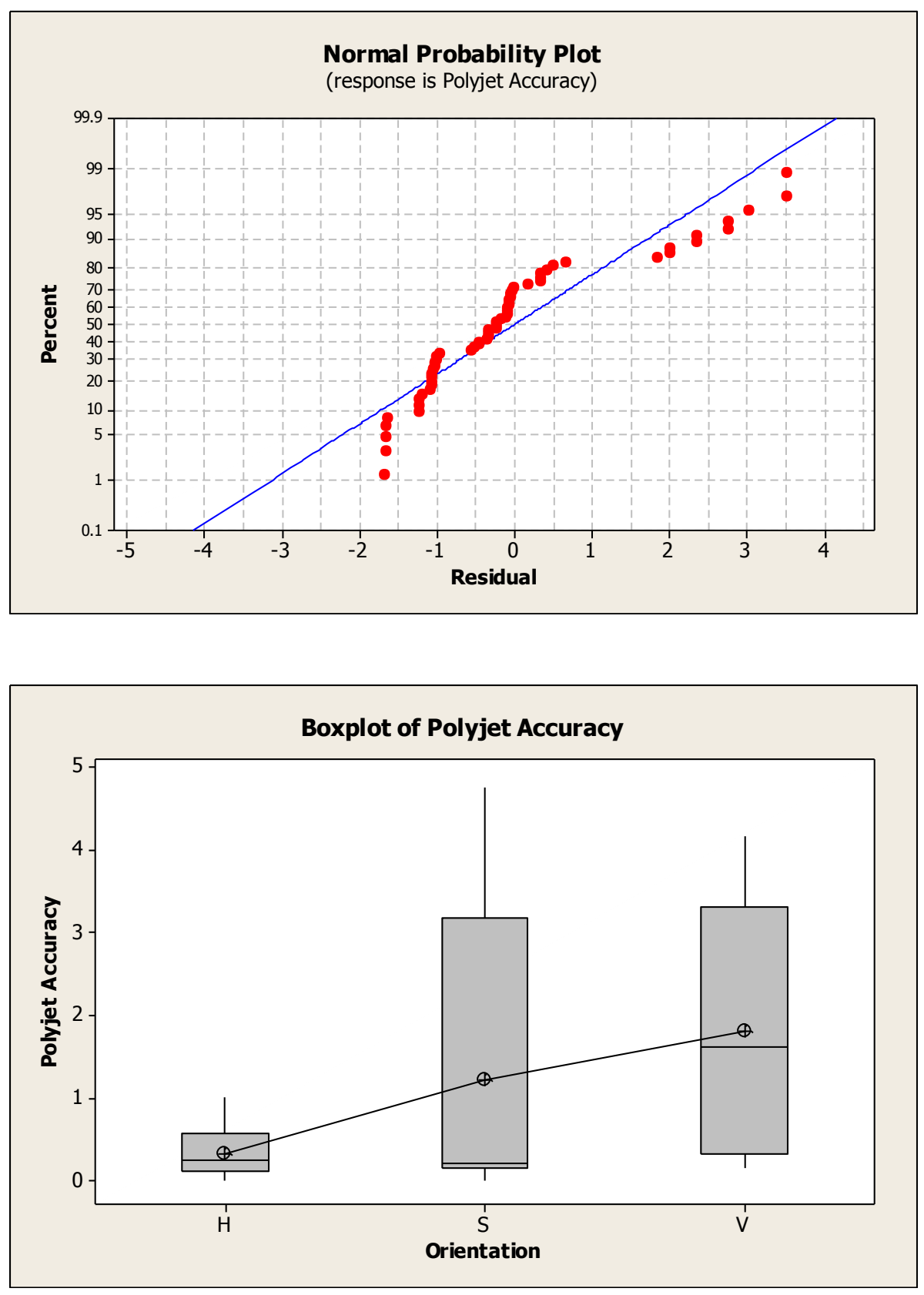

\subsubsection{FDM Dimensional accuracy}

In this section, the dimensional accuracy of three build orientations in the Fused

Deposition Modeling (FDM) system are discussed. Table 8 tabulates the measured results of four points for three build orientations. The most accurate value $(0.1617 \%)$ 
appears in the measured point of LO (length of overall) in the Horizontal orientation.

Figure 18 shows the dimensional accuracy of four measured points for each build orientation. From at through analysis of Table 8 and Figure 18, it can be seen that measured points of Horizontal build orientation are less variable than others.

Table 8. Measured results in FDM

\begin{tabular}{|c|c|c|c|c|}
\hline \multirow{2}{*}{\multicolumn{2}{|c|}{$\begin{array}{c}\text { ASTM } \\
\text { Type IV (mm) }\end{array}$}} & \multicolumn{3}{|c|}{ FDM } \\
\hline & & \multirow{2}{*}{$\begin{array}{r}\text { Horizontal } \\
6.1300 \\
\end{array}$} & \multirow{2}{*}{$\begin{array}{l}\text { Side } \\
6.2140\end{array}$} & \multirow{2}{*}{$\begin{array}{r}\text { Vertical } \\
6.1500 \\
\end{array}$} \\
\hline \multirow{4}{*}{$\begin{array}{l}W \\
6\end{array}$} & AVG & & & \\
\hline & SD & 0.0300 & 0.0089 & 0.0122 \\
\hline & Dimension Change Rate (\%) & 2.1667 & 3.5667 & 2.5000 \\
\hline & Dimensional Accuracy (\%) & 2.1667 & 3.5667 & 2.5000 \\
\hline \multirow{4}{*}{$\begin{array}{l}\text { WO } \\
19\end{array}$} & AVG & 19.0820 & 18.6940 & 19.1540 \\
\hline & SD & 0.0217 & 0.0397 & 0.0270 \\
\hline & Dimension Change Rate (\%) & 0.4316 & -1.6105 & 0.8105 \\
\hline & Dimensional Accuracy (\%) & 0.4316 & 1.6105 & 0.8105 \\
\hline \multirow{4}{*}{$\begin{array}{l}\text { LO } \\
115\end{array}$} & AVG & 115.1860 & 115.2580 & 115.2040 \\
\hline & $\mathrm{SD}$ & 0.0182 & 0.0471 & 0.0723 \\
\hline & Dimension Change Rate (\%) & 0.1617 & 0.2243 & 0.1774 \\
\hline & Dimensional Accuracy (\%) & 0.1617 & 0.2243 & 0.1774 \\
\hline \multirow{4}{*}{$\begin{array}{l}\mathrm{T} \\
4\end{array}$} & AVG & 4.0660 & 4.1380 & 4.2100 \\
\hline & $\mathrm{SD}$ & 0.0305 & 0.0148 & 0.0552 \\
\hline & Dimension Change Rate (\%) & 1.6500 & 3.4500 & 5.2500 \\
\hline & Dimensional Accuracy (\%) & 1.6500 & 3.4500 & 5.2500 \\
\hline \multicolumn{2}{|c|}{ SD - Dimensional Accuracy } & 0.9519 & 1.4368 & 2.1145 \\
\hline \multicolumn{2}{|c|}{ AVG Dimensional Accuracy (\%) } & 1.1025 & 2.2129 & 2.1845 \\
\hline
\end{tabular}




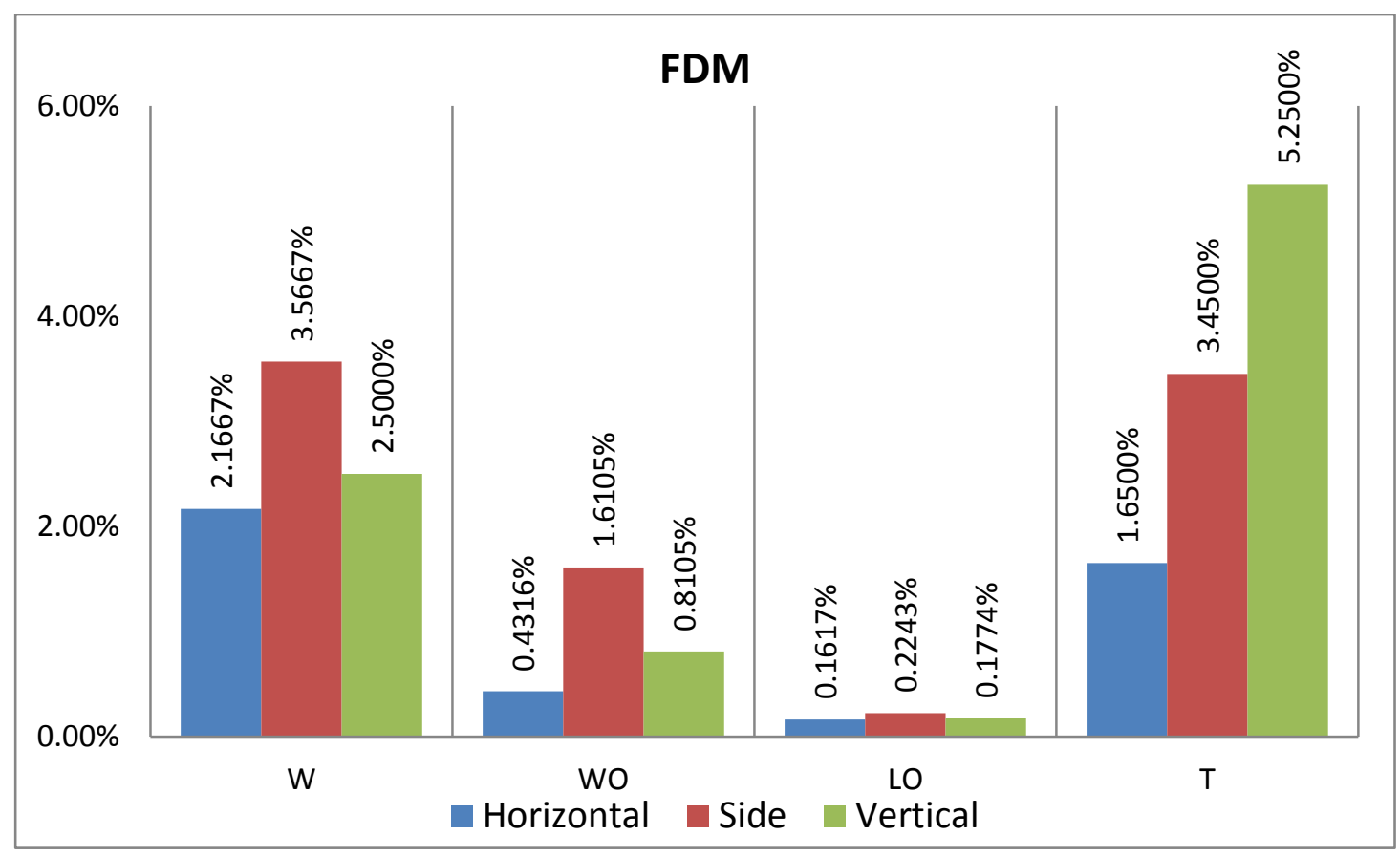

Figure 18. Dimensional Accuracy of four measurement points in FDM

Figure 19 shows the average value of dimensional accuracy in four measured points. It can be seen that the most accurate build orientation appears in the Horizontal orientation. Considering the variation of all measured points, Horizontal also provides less variability as shown in Figure 18. Therefore, we can say that Horizontal build orientation is more accurate than Side and Vertical in the FDM system.

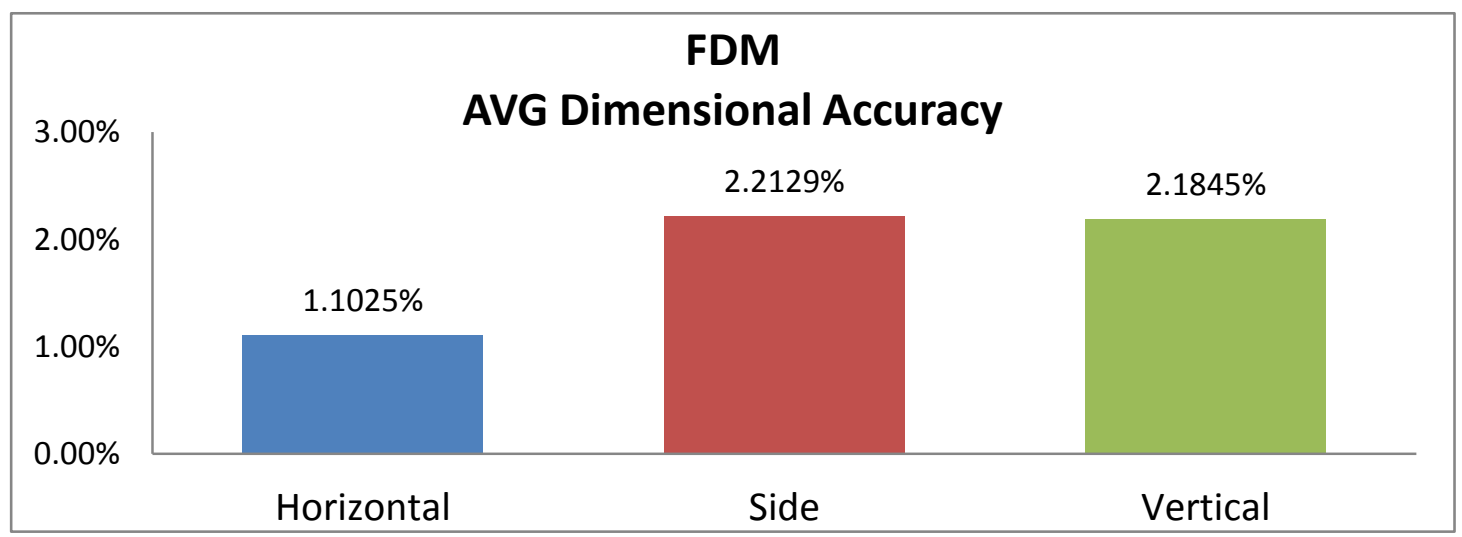

Figure 19. AVG Dimensional Accuracy of three build orientations in FDM 


\section{Statistical Analysis}

One-Way ANOVA was chosen to analyze the experiment results in FDM. In the ANOVA table below from Minitab, the p-value 0.047 of factor (Orientation) is less than 0.05 , therefore we can say the build orientation significantly affects the dimensional accuracy in FDM. Most points are displayed near the straight line in Normal Probability Plot. Therefore, we can say that these experiment results can mostly satisfy the model adequacy. In the ANOVA table and the boxplot, it can be seen that Horizontal build orientation is more accurate than Side and Vertical.

\section{One-way ANOVA: FDM Accuracy versus Orientation}

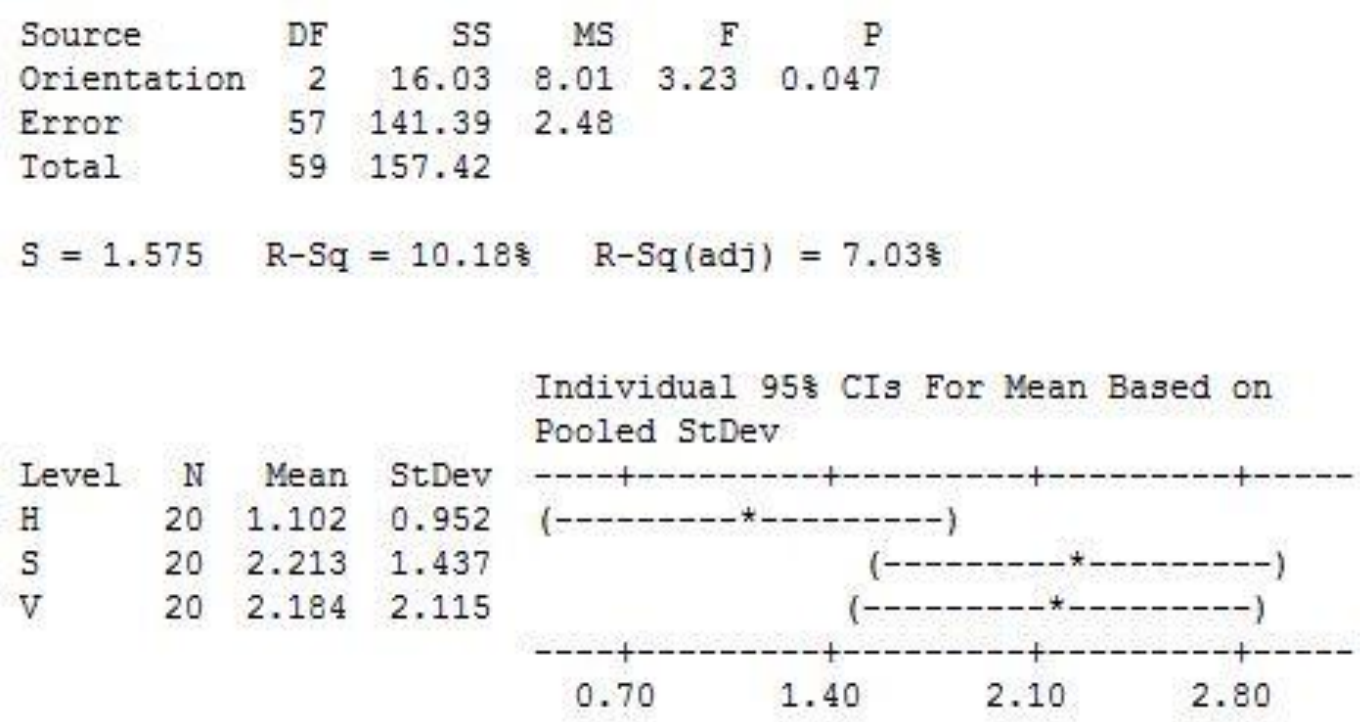

Pooled StDev $=1.575$ 

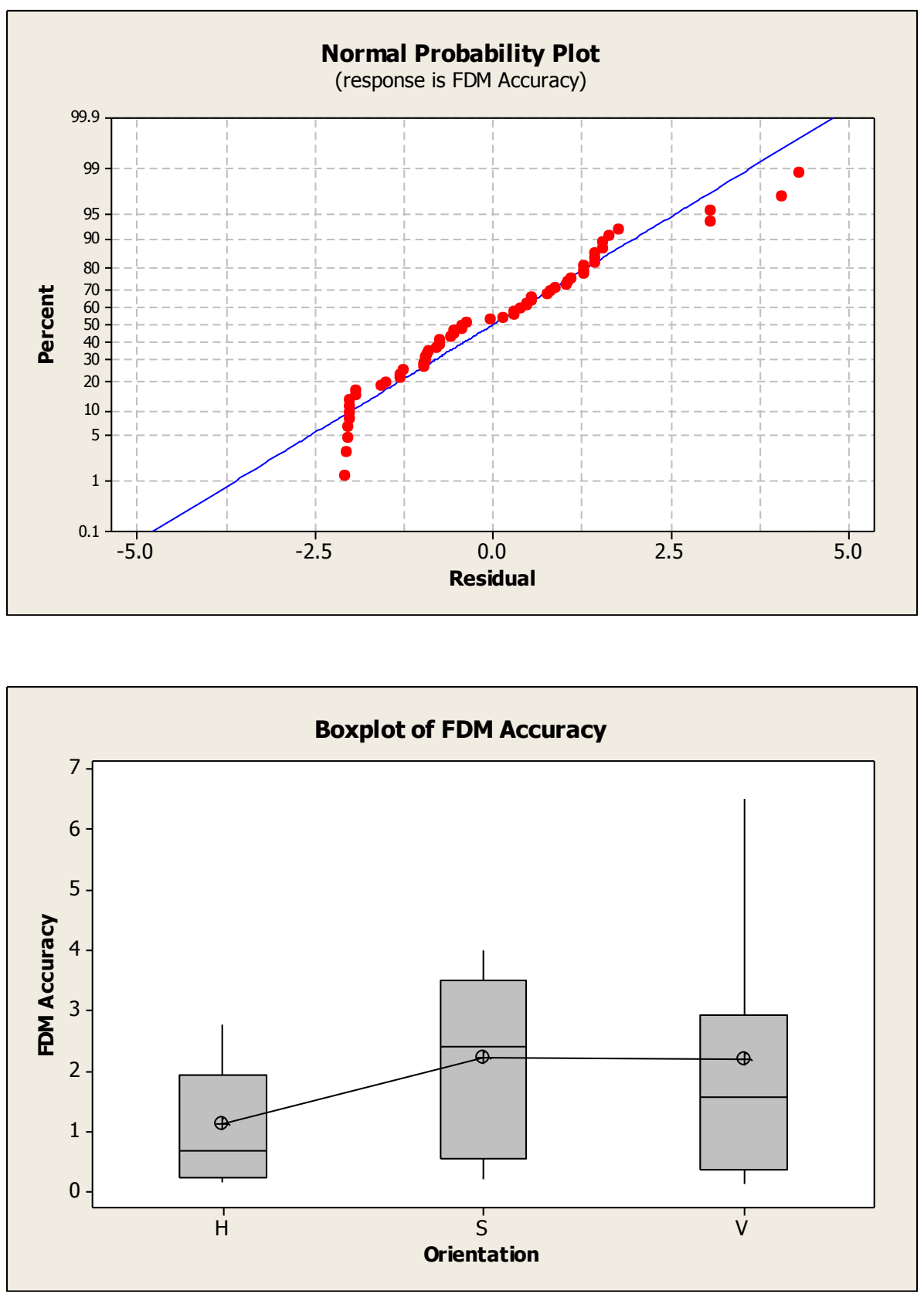


\subsubsection{DP Dimensional accuracy}

A Z-Corporation Model Spectrum Z510 3D printer constructed the test specimens. Materials for the specimens consist of ZP 131 (gypsum) powder and Z-Bond 90 binder. In 3DP system, the post-processing hardening is required. Once the part is completed and the support powder is removed, the part needs to be dipped in a binder (Z-Bond 90) and so that its strength can be improved. The measured values of "Before Harden" and "After Harden" for dimensional accuracy were tabulated in Table 9. Comparing the measured results between hardening post-processing, it can be found that the dimensional tolerance becomes more accurate after hardening. The most accurate value $(0.1696 \%)$ can be found in the Side build orientation of LO (length of overall) in 3DP After Harden. Figure 20 and Figure 21 show dimensional accuracy of four measured points in each build orientation in 3DP Before Harden and 3DP After Harden. 
Table 9. Measured results in 3DP

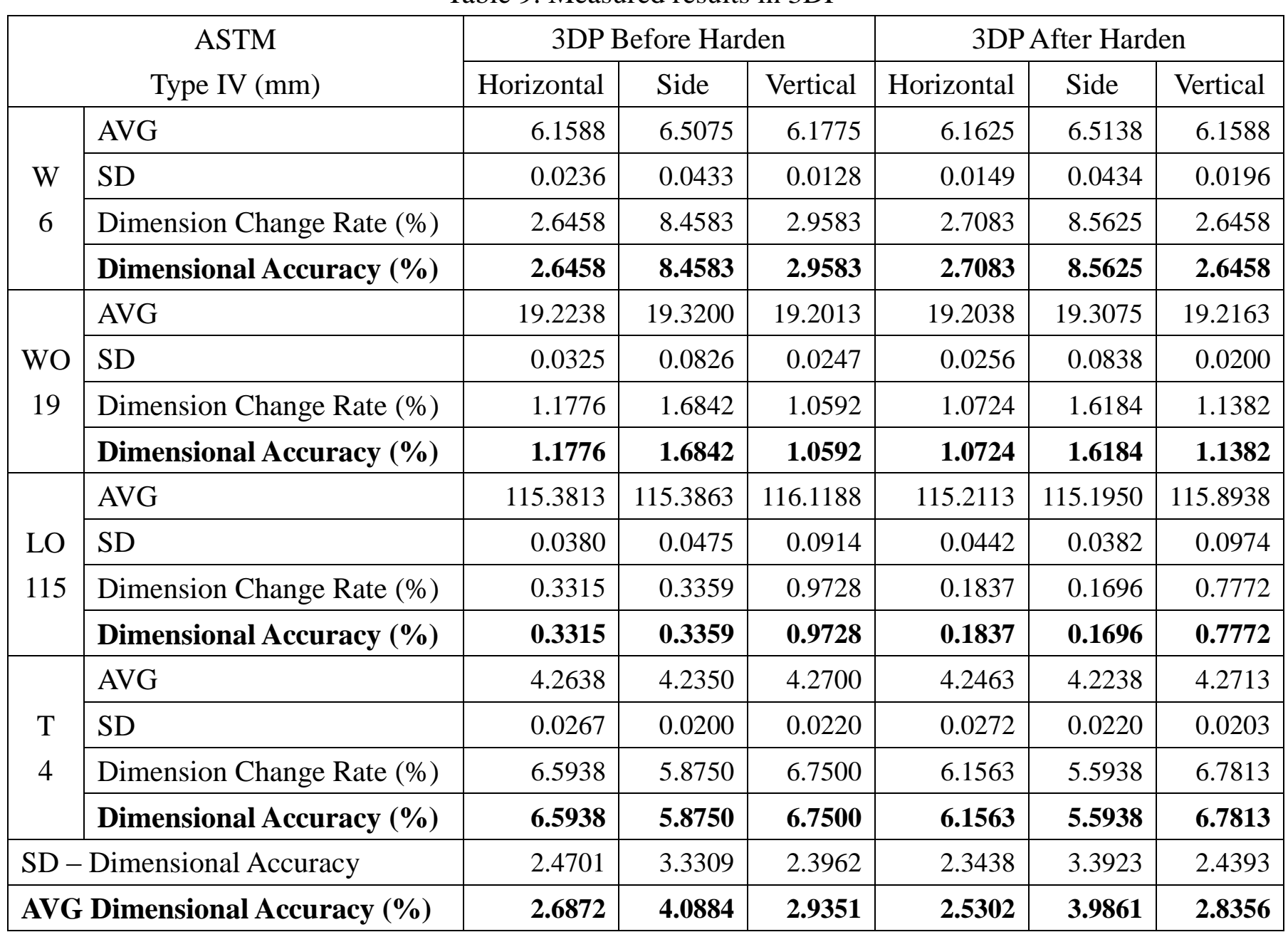




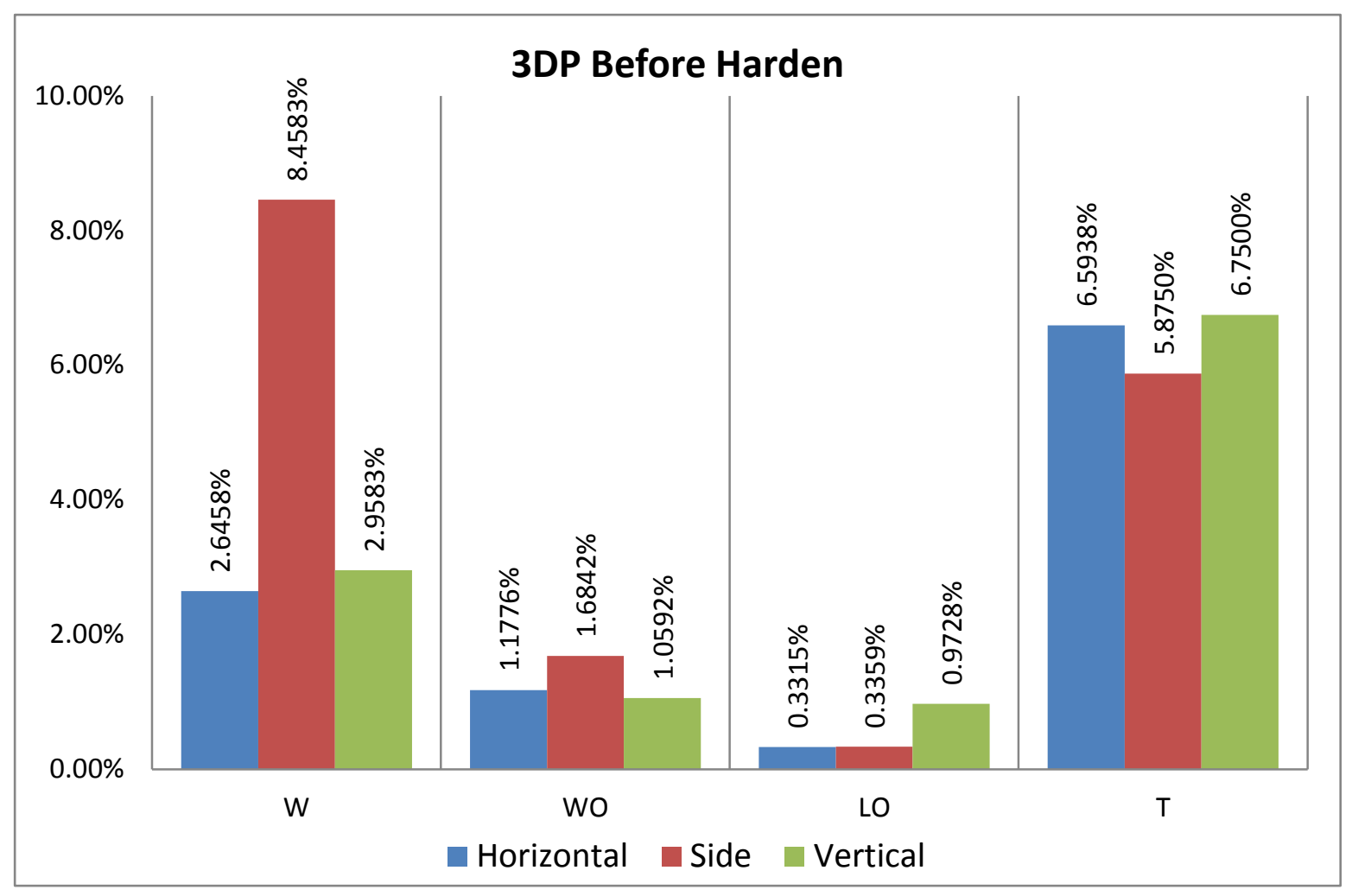

Figure 20. Dimensional Accuracy of four measurement points

in 3DP Before Harden

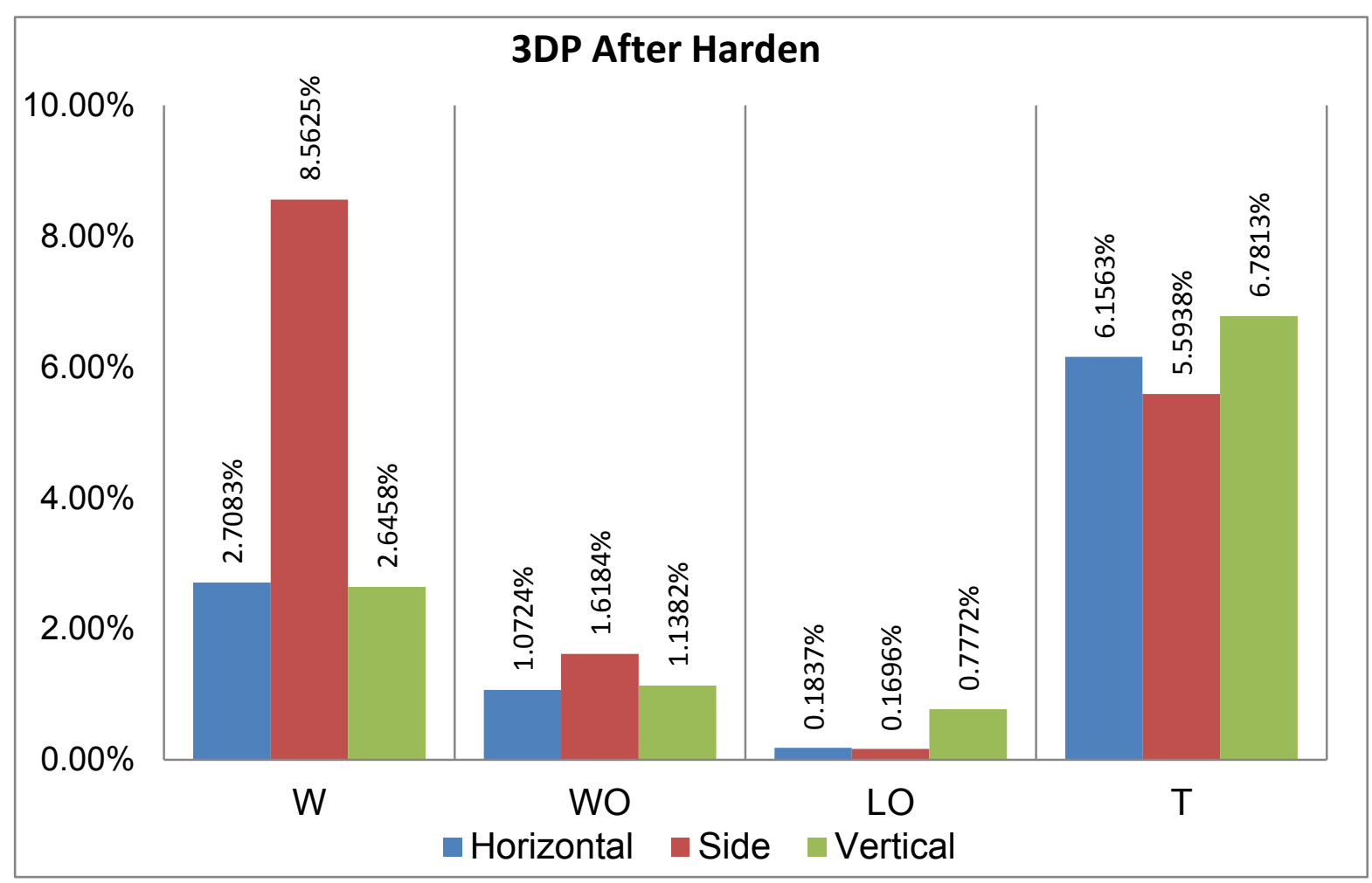

Figure 21. Dimensional Accuracy of four measurement points in 3DP After Harden 
Figure 20 and Figure 21 show the average dimensional accuracy of three orientations in 3DP Before Harden and 3DP After Harden. It can be seen that the effect of different build orientations on the dimensional accuracy of the specimens. Considering the variation of four measurement points in Figure 21 and the average value in Figure 23, the Horizontal build orientation provided more accuracy than the Side and Vertical orientations in the 3DP system.

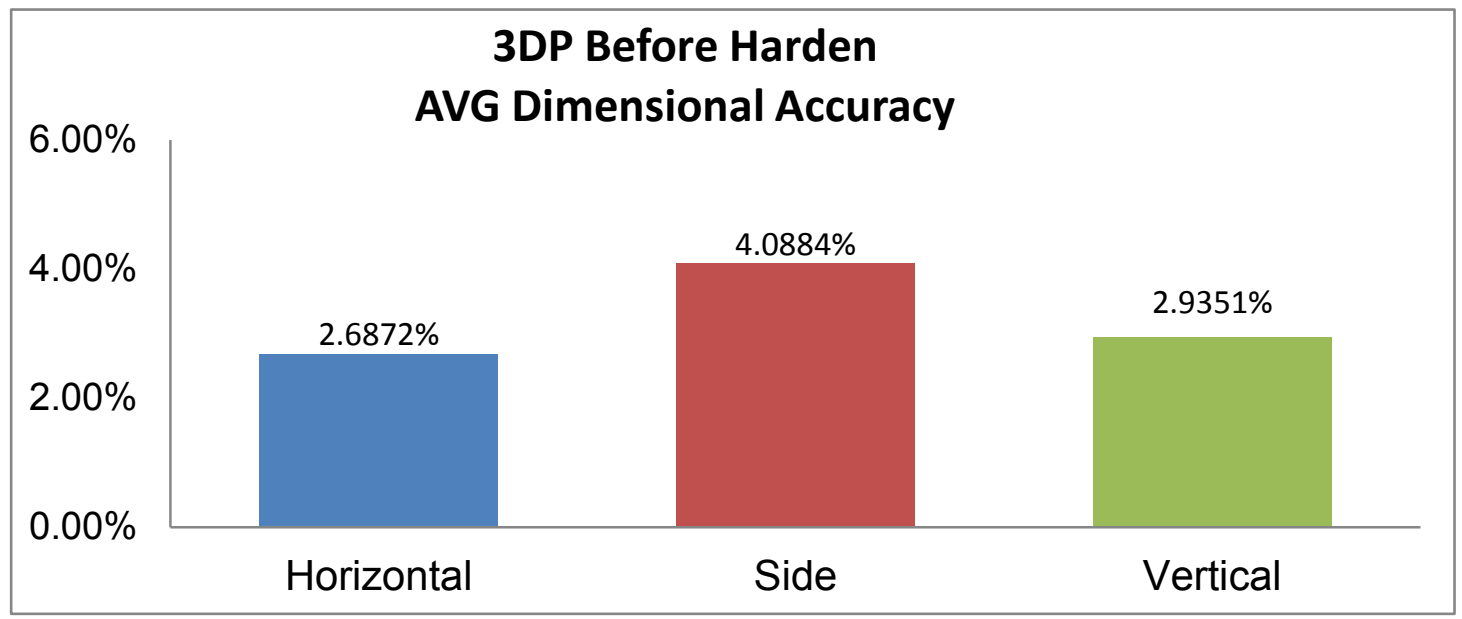

Figure 22. AVG Dimensional Accuracy of three build orientations in 3DP Before Harden

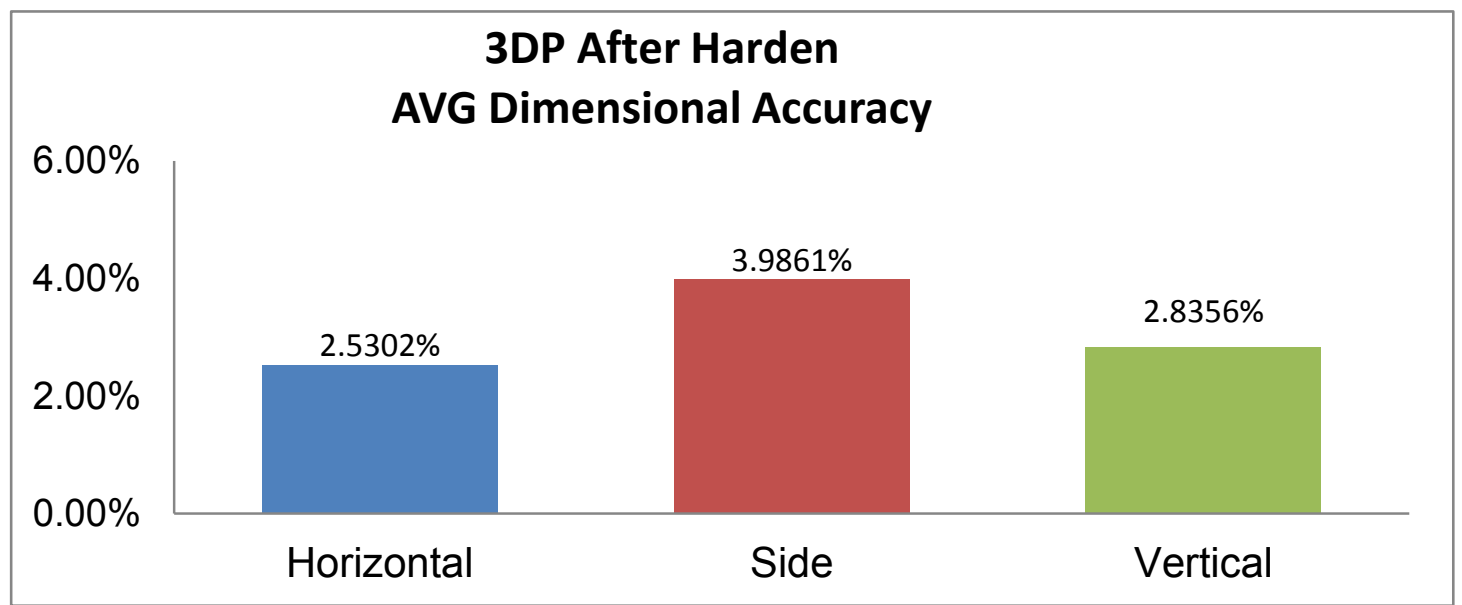

Figure 23. AVG Dimensional Accuracy of three build orientations in 3DP After Harden 


\section{Statistical Analysis}

One-Way ANOVA was chosen to analyze the experiment results in 3DP Before Harden and 3DP After Harden. It can be seen in the ANOVA tables below from Minitab that the p-value 0.102 and 0.091 of factor (Orientation) are both greater than 0.05 . We cannot say that the experiment results satisfy the model adequacy. The post-processing, manual dipping parts in the binder may cause the variation in this experiment. Therefore, additional statistical analysis is necessary.

\section{One-way ANOVA: 3DP - Before Harden versus Orientation}

$\begin{array}{lrrrrr}\text { Source } & \text { DF } & \text { SS } & \text { MS } & \text { F } & \text { P } \\ \text { Orientation } & 2 & 35.78 & 17.89 & 2.34 & 0.102 \\ \text { Error } & 93 & 711.07 & 7.65 & & \\ \text { Total } & 95 & 746.85 & & & \\ \text { S }=2.765 & \text { R-Sq }=4.798 & \text { R-Sq (adj) } & =2.74 \text { s }\end{array}$

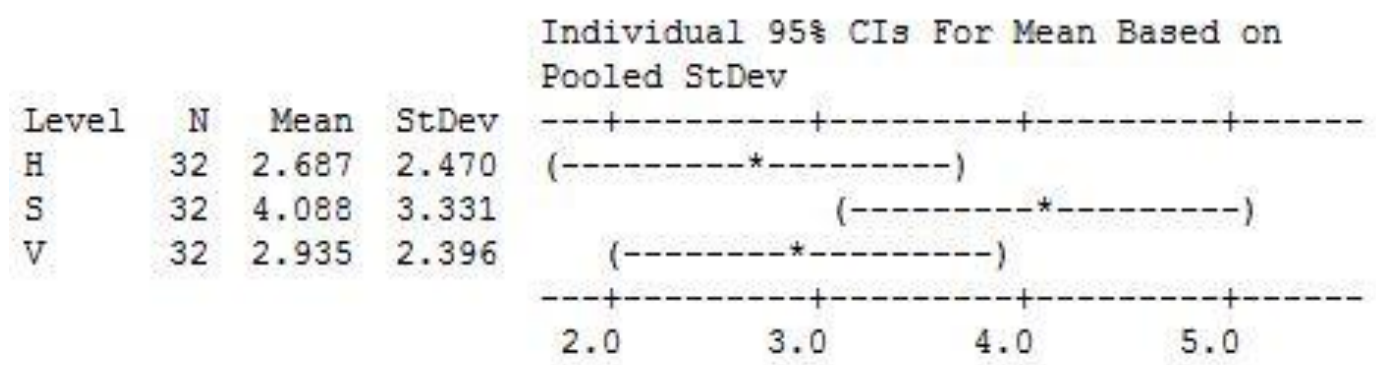

Pooled StDev $=2.765$ 
One-way ANOVA: 3DP - After Harden versus Orientation

$\begin{array}{lrrrrr}\text { Source } & \text { DF } & \text { SS } & \text { MS } & \text { F } & \text { P } \\ \text { Orientation } & 2 & 37.72 & 18.86 & 2.47 & 0.091 \\ \text { Error } & 93 & 711.51 & 7.65 & & \\ \text { Total } & 95 & 749.23 & & & \\ \text { S }=2.766 & \text { R-Sq }=5.03 \% & \text { R-Sq }(\text { adj })=2.99 \%\end{array}$

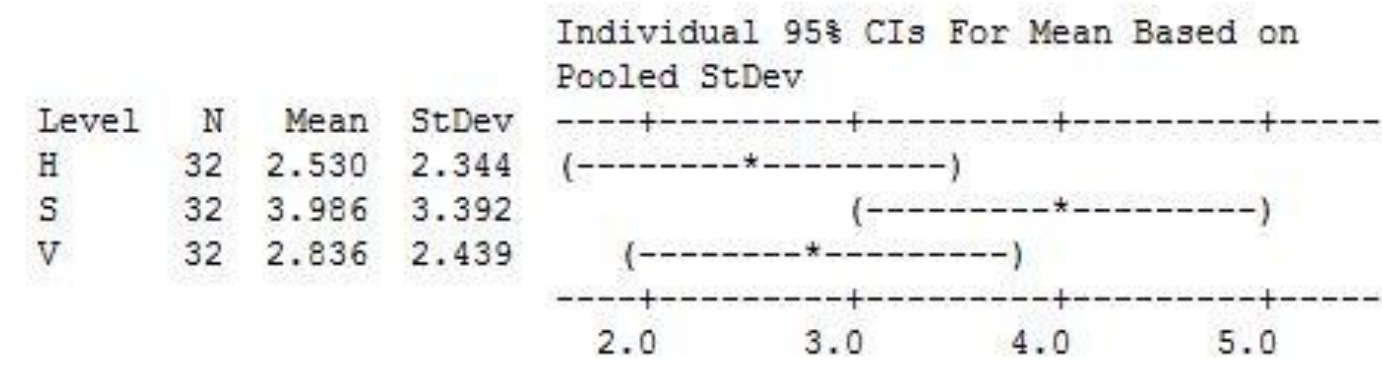

Pooled StDev $=2.766$
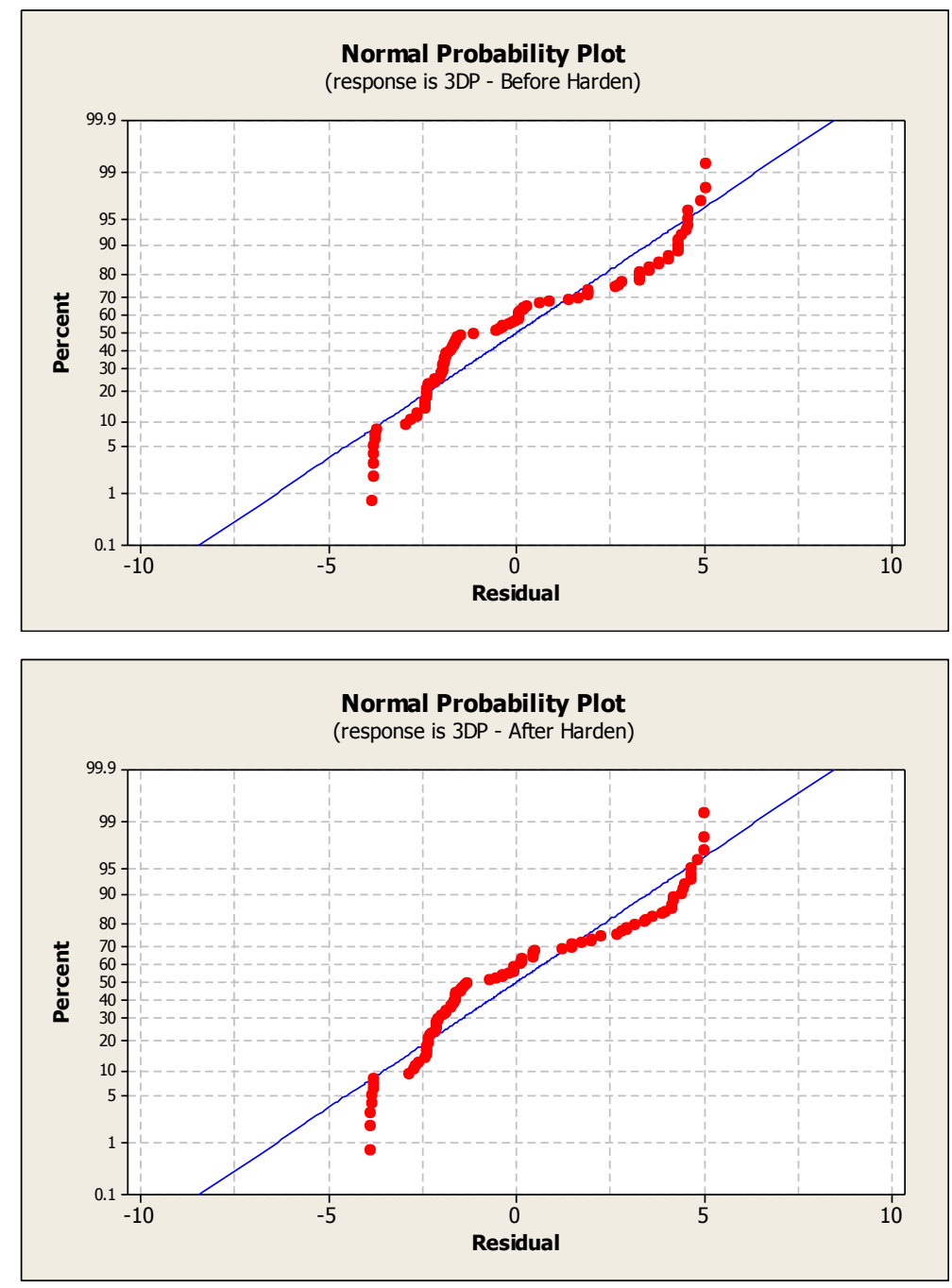

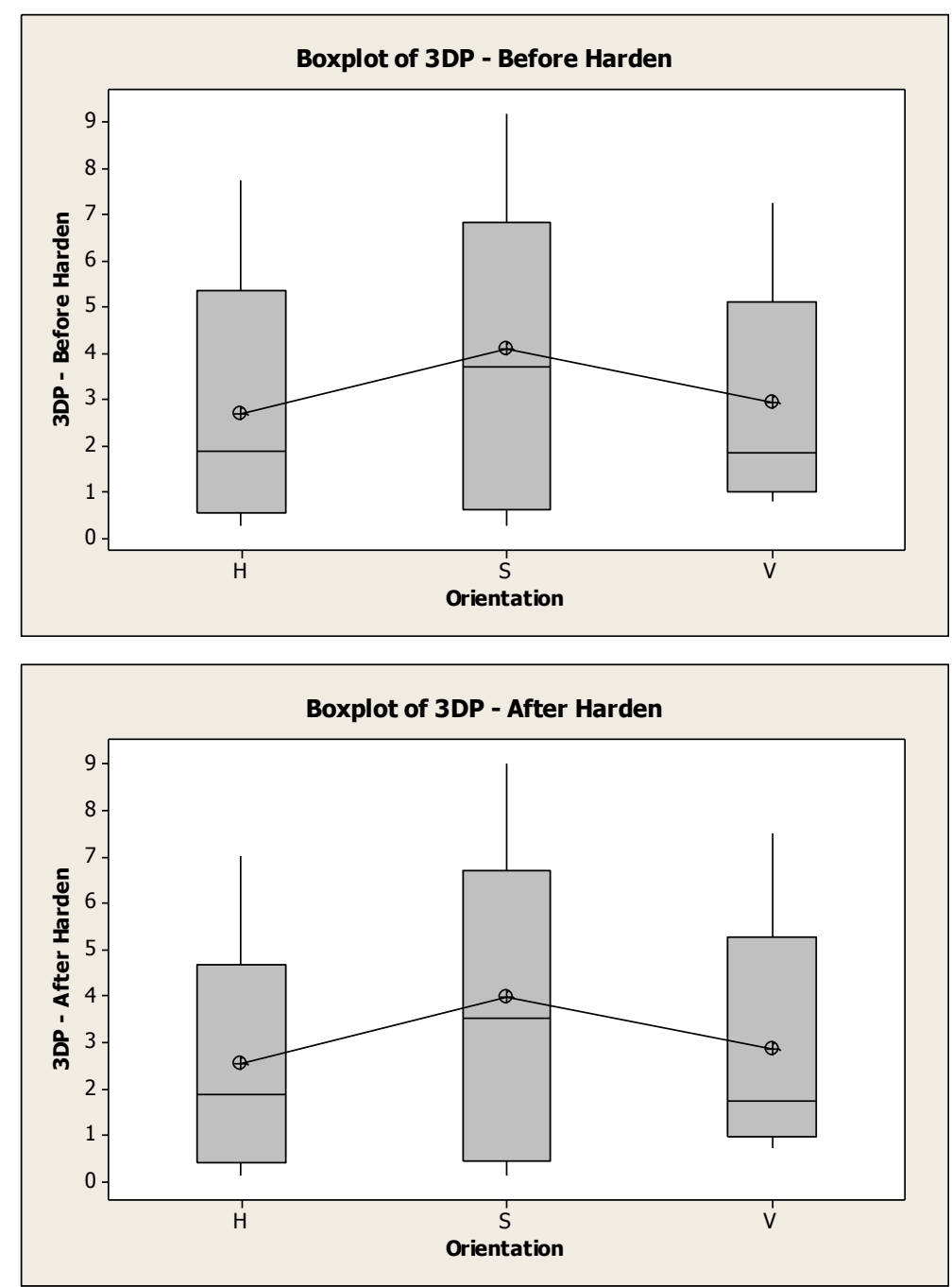

\subsubsection{Summary - Dimensional accuracy}

Figure 24 shows the summary dimensional accuracy of four measurement points in each rapid prototyping system. Considering different rapid prototyping systems, PolyJet performs with the best dimensional accuracy. Considering the build orientations, Horizontal is more accurate than Side and Vertical in PolyJet, FDM, and 3DP, with the exception of the SLS system. In SLS, the Vertical build 
orientation has more dimensional accuracy than others. Table 10 tabulates the summary dimensional accuracy in these four rapid prototyping systems.

Table 10. Dimensional Accuracy Summary

\begin{tabular}{|c|c|c|}
\hline RP System & Build Orientation & Dimensional Accuracy (\%) \\
\hline \multirow{4}{*}{ SLS } & Horizontal & 2.2136 \\
\cline { 2 - 3 } & Side & 1.4834 \\
\cline { 2 - 3 } & Vertical & 0.5093 \\
\hline \multirow{4}{*}{ PolyJet } & Horizontal & 0.3227 \\
\cline { 2 - 3 } & Side & 1.2217 \\
\cline { 2 - 3 } & Vertical & 1.8137 \\
\hline \multirow{4}{*}{ FDM } & Horizontal & 1.1025 \\
\cline { 2 - 3 } & Side & 2.2129 \\
\cline { 2 - 3 } & Vertical & 2.1845 \\
\hline \multirow{3}{*}{ 3DP Before Harden } & Horizontal & 2.6872 \\
\cline { 2 - 3 } & Side & 4.0884 \\
\cline { 2 - 3 } & Vertical & 2.9351 \\
\hline \multirow{3}{*}{ 3DP After Harden } & Horizontal & 2.5302 \\
\cline { 2 - 3 } & Side & 3.9861 \\
\cline { 2 - 3 } & Vertical & 2.8356 \\
\hline
\end{tabular}




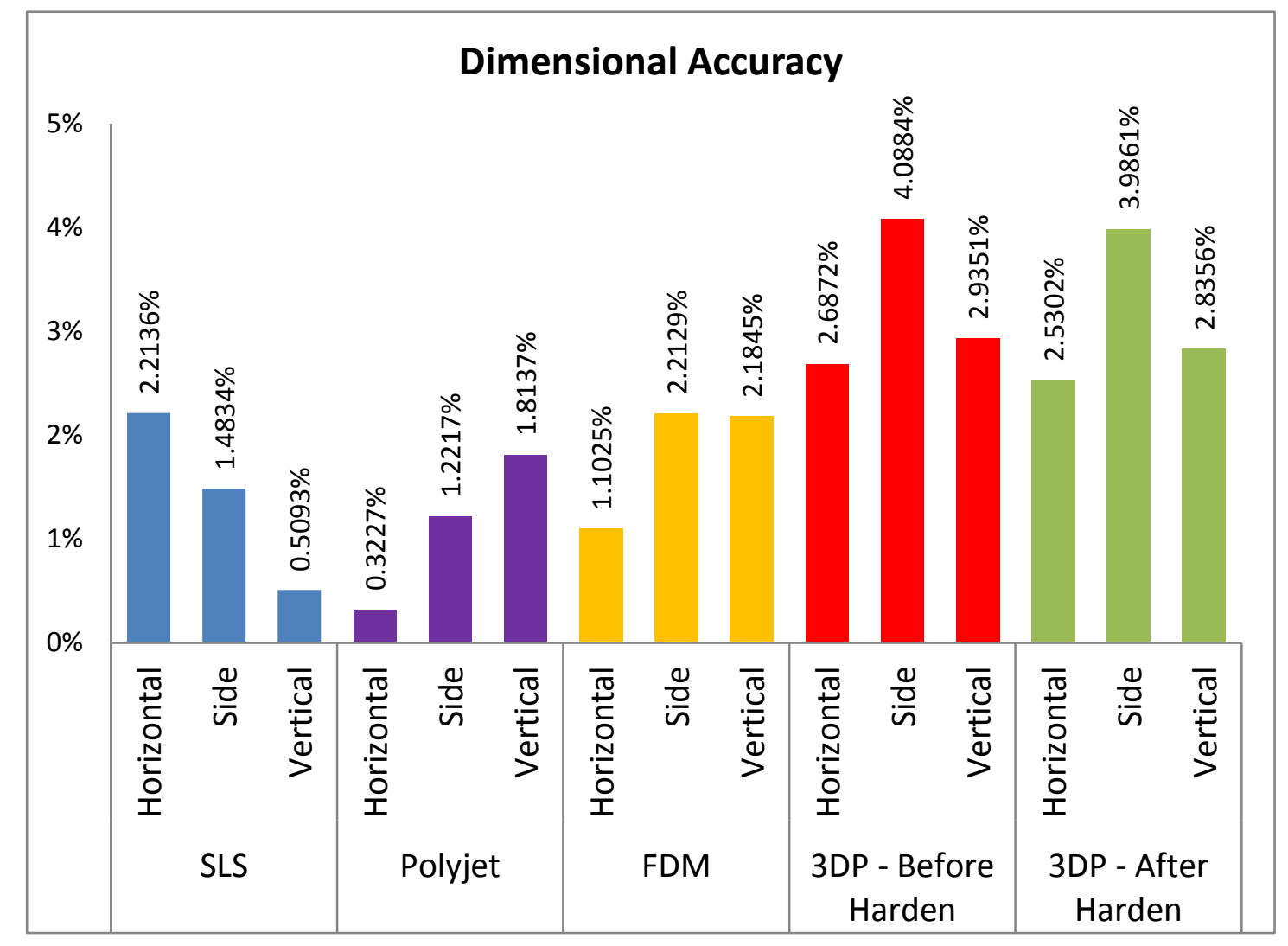

Figure 24. Dimensional Accuracy 


\subsection{Tensile Properties}

From the tasks performed in Chapter 3, the results obtained from tensile testing are displayed in this section. Test specimens were fabricated with three build orientations (Horizontal, Side and Vertical) in four rapid prototyping machines (SLS, PolyJet, FDM, and 3DP). For each type of the specimen, five to eight replications were fabricated and tested. Tensile testing was performed on the specimens using a universal testing machine: ADMET eXpert 2611. The ADMET software was used to calculate the Tensile Strength, Elongation, and Elongation at break of each test sample. The testing results are presented in the following sections.

\subsubsection{SLS Tensile Properties}

In this section, specimens with five repetitions fabricated in three build orientations in SLS (EOS Formiga P100) for tensile testing will be presented and discussed. Table 11 presents the test results and the data provided by the machine manufacturer. It can be found that the experiment results of tensile strength are close to the data provided by the manufacturer. However, the experiment results of Elongation at Break are not as high as the company's data. Figure 25 summarizes the testing result of tensile strength for the specimens with three build orientations. In 
the SLS technology, the specimens created in Horizontal orientation have the highest tensile strength (7367.4 psi) compared with Side and Vertical build orientations (7122.8 and 6801.8 psi). Considering Elongation, specimens created in the Vertical orientation have the greatest performance. Considering Elongation at Break, specimens fabricated in the Horizontal orientation had the best test result. The summarized values in tensile strength and elongation at break indicate that Horizontal built samples provided the highest tensile strength at 7367.4 psi. For SLS technology, fabricated productions in Horizontal build orientation have the greatest performance on tensile properties.

Table 11. SLS Tensile Properties

\begin{tabular}{|c|l|r|r|r|r|}
\hline \multicolumn{2}{|c|}{ RP System } & \multicolumn{4}{c|}{ SLS } \\
\hline \multicolumn{2}{|c|}{ Build Orientation } & Horizontal & \multicolumn{1}{c|}{ Side } & Vertical & Company \\
\hline \multirow{2}{*}{ Tensile Strength (psi) } & AVG & $\mathbf{7 3 6 7 . 4}$ & 7122.8 & 6801.8 & 6962 \\
\cline { 2 - 6 } & SD & 27.364 & 107.816 & 87.480 & \\
\hline \multirow{2}{*}{ Elongation (\%) } & AVG & 7.4545 & 7.3296 & $\mathbf{7 . 7 4 1 4}$ & \multirow{2}{*}{ NA } \\
\cline { 2 - 6 } & SD & 0.4283 & 0.1661 & 0.5687 & \\
\hline \multirow{2}{*}{ Elongation at Break (\%) } & AVG & $\mathbf{1 6 . 5 3 3 4}$ & 15.7361 & 12.4673 & \multirow{2}{*}{24} \\
\cline { 2 - 6 } & SD & 1.2306 & 0.4489 & 1.2016 & \\
\hline
\end{tabular}




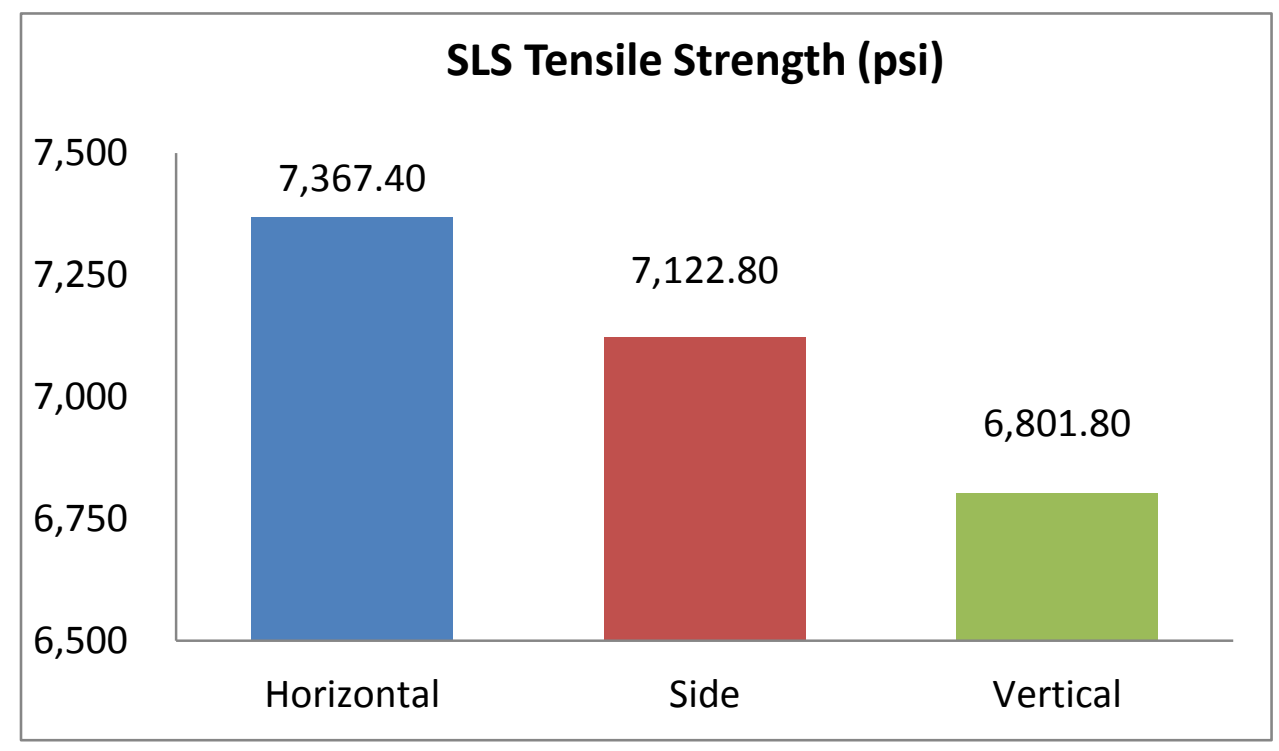

Figure 25. SLS Tensile Strength

\section{Statistical Analysis}

The ANOVA table below provides good indication that tensile testing for SLS specimens is significant at 0.000 . We can say that build orientations affect tensile properties of parts created with SLS (EOS Formiga P100) technology significantly. Most points displayed near the straight line in Normal Probability Plot. Therefore, we can say that these experiment results can mostly satisfy the model adequacy. In the ANOVA table and the boxplot, it can be seen that Horizontal build orientation has the highest tensile strength when compared with Side and Vertical. 
One-way ANOVA: SLS Tensile Strength versus Orientation

$\begin{array}{lrrrrr}\text { Source } & \text { DF } & \text { SS } & \text { MS } & \text { F } & \text { P } \\ \text { Orientation } & 2 & 804623 & 402311 & 60.27 & 0.000 \\ \text { Error } & 12 & 80103 & 6675 & & \\ \text { Total } & 14 & 884725 & & & \\ \text { S }=81.70 & \text { R-Sq }=90.95 \% & \text { R-Sq }(\text { adj })=89.44 \%\end{array}$

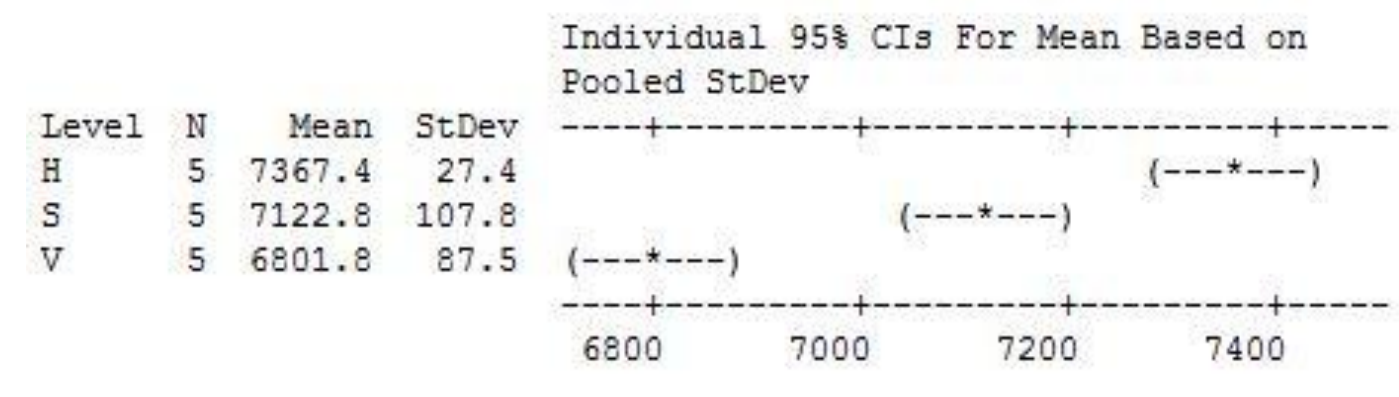

Pooled StDev $=81.7$

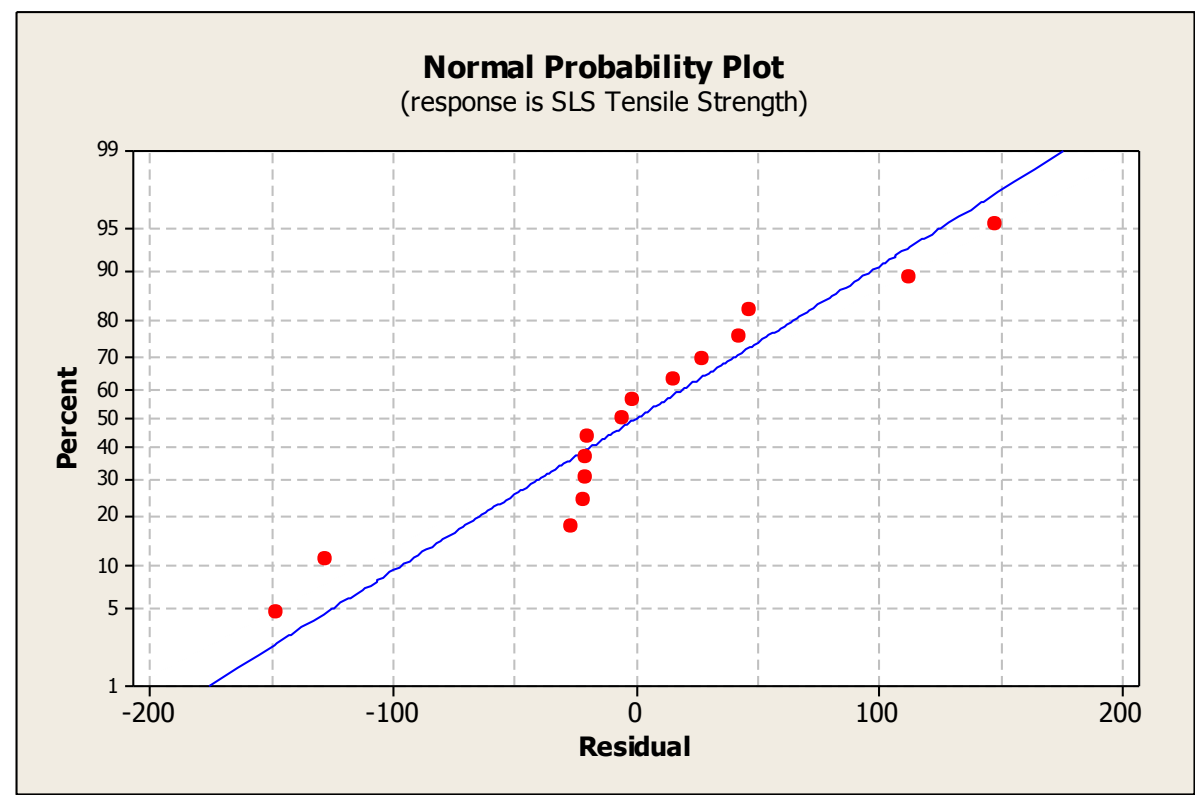




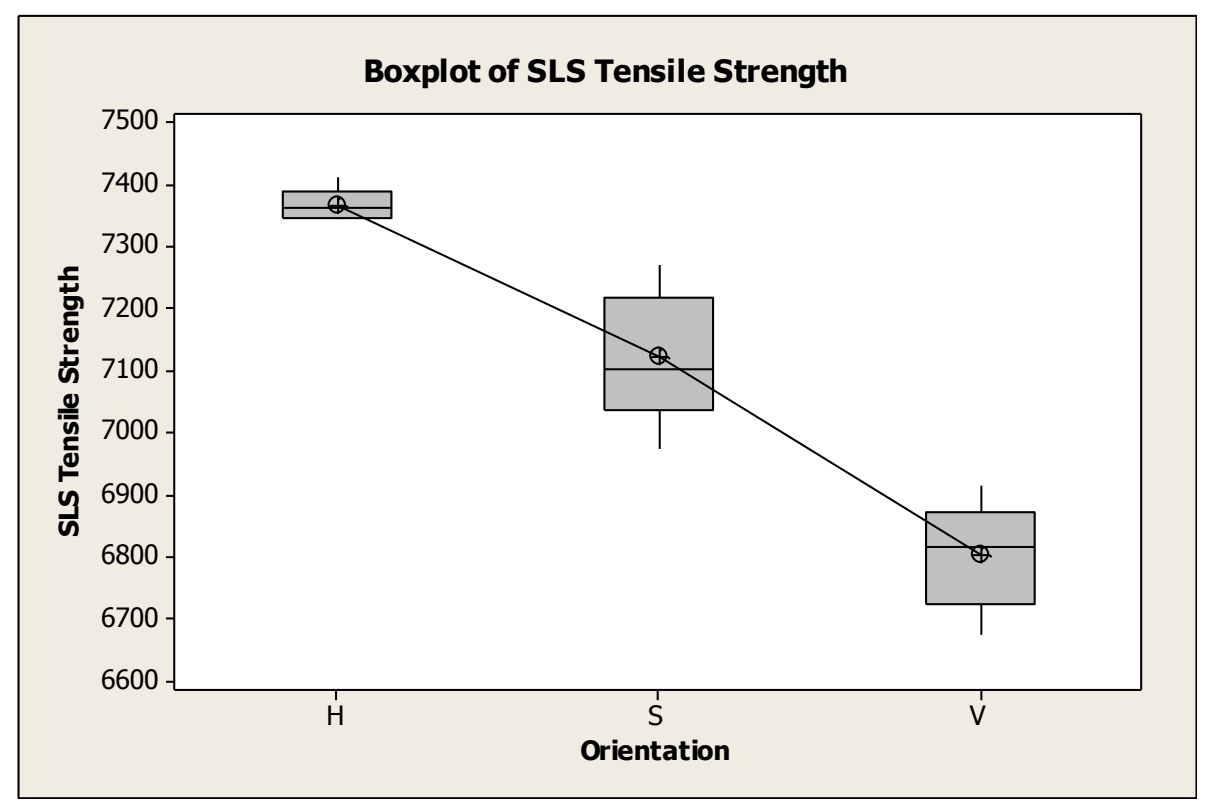

\subsubsection{PolyJet Tensile Properties}

In this section, the tensile testing results of specimens created with three build orientations in the PolyJet technology (Objet Eden 350V) are presented. Table 12 shows the tensile testing results and the data provided by the machine manufacturer. It can be found that the experiment results of tensile strength in the Horizontal and Side build orientations are close to the data provided by the manufacturer. However, the company did not release any information regarding build orientation. The experiment results of Elongation at Break are also not close to the data they provided. Further research is necessary to investigate the experiment results with the information provided by the company. The specimens created in the Side orientation have the greatest performance in tensile properties including tensile strength, 
elongation and elongation at break, compared to the Horizontal and Vertical orientations. Figure 26 shows summarized tensile strength with three build orientations. The specimens which created in Vertical build orientation resulted in the weakest tensile strength because the tensile loads were resisted only by the bonding between layers. The users of PolyJet technology should create parts using a Side build orientation, and avoid loading strength at the same direction as the bonding between layers.

Table 12. PolyJet Tensile Properties

\begin{tabular}{|c|l|r|r|r|r|}
\hline \multicolumn{2}{|c|}{ RP System } & \multicolumn{4}{c|}{ PolyJet } \\
\hline \multicolumn{2}{|c|}{ Build Orientation } & Horizontal & \multicolumn{1}{c|}{ Side } & Vertical & Company \\
\hline \multirow{2}{*}{ Tensile Strength (psi) } & AVG & 8868.2 & $\mathbf{9 7 2 8 . 2}$ & 5137.4 & $7250-9450$ \\
\cline { 2 - 5 } & SD & 259.802 & 235.482 & 325.681 & \\
\hline \multirow{2}{*}{ Elongation (\%) } & AVG & 3.9132 & $\mathbf{4 . 0 8 8 4}$ & 1.6080 & NA \\
\cline { 2 - 6 } & SD & 0.1312 & 0.1007 & 0.1315 & \\
\hline \multirow{2}{*}{ Elongation at Break (\%) } & AVG & 5.0635 & $\mathbf{5 . 7 5 4 2}$ & 1.6235 & $10-25$ \\
\cline { 2 - 5 } & SD & 0.9452 & 0.5506 & 0.1316 & \\
\hline
\end{tabular}




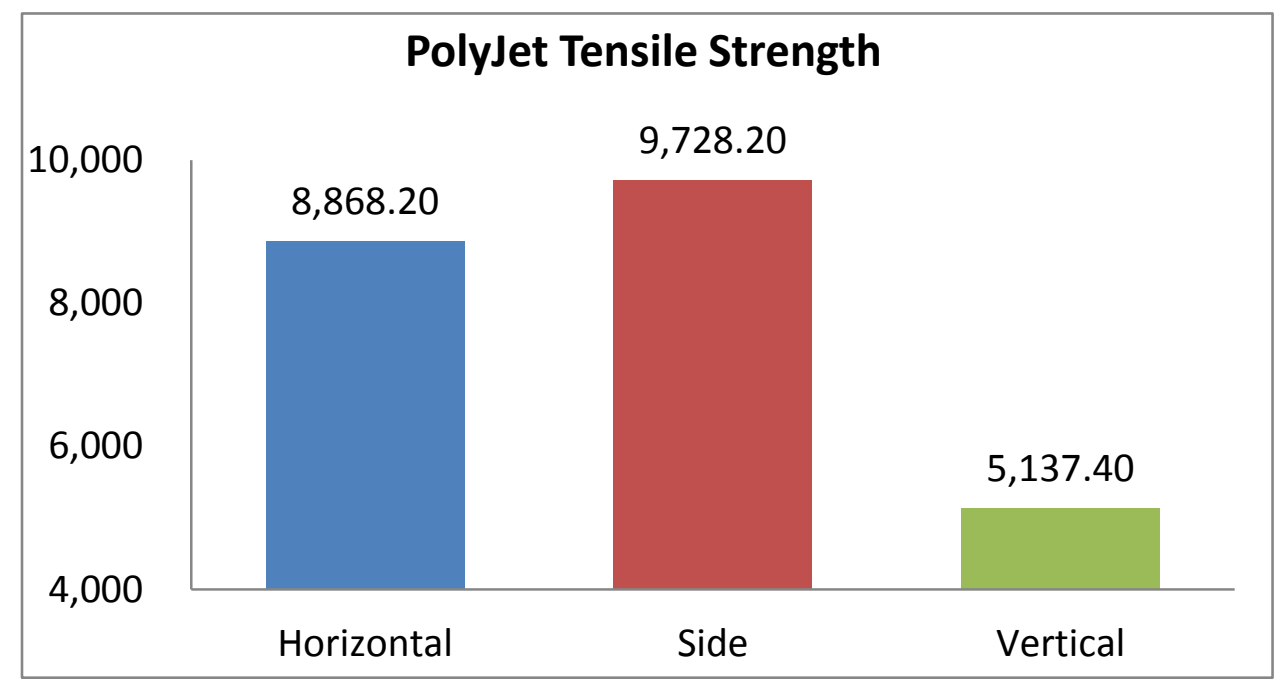

Figure 26. PolyJet Tensile Strength

\section{Statistical Analysis}

One-Way ANOVA was chosen to analyze the experiment results from the PolyJet technology. The ANOVA table in the image below shows a good indication that tensile testing with different build orientations for PolyJet specimens is significant at 0.000 . Therefore, we can conclude that build orientations affect tensile properties of specimens created in PolyJet technology (Objet Eden 350V) significantly. In Normal Probability Plot, most points are displayed near the straight line, and we can say that these experiment results can mostly satisfy the model adequacy and the points follow the normal distribution. In ANOVA table and the boxplot, it can be seen that Side build orientation has the greatest tensile strength comparing with Horizontal and Vertical orientations. 
One-way ANOVA: PolyJet Tensile Strength versus Orientation

$\begin{array}{lrrrrr}\text { Source } & \text { DF } & \text { SS } & \text { MS } & \text { F } & \text { P } \\ \text { Orientation } & 2 & 59556522 & 29778261 & 390.08 & 0.000 \\ \text { Error } & 12 & 916069 & 76339 & & \\ \text { Total } & 14 & 60472591 & & \\ \text { S }=276.3 & \text { R-Sq }=98.49 \% & \text { R-Sq }(\text { adj })=98.23 \%\end{array}$

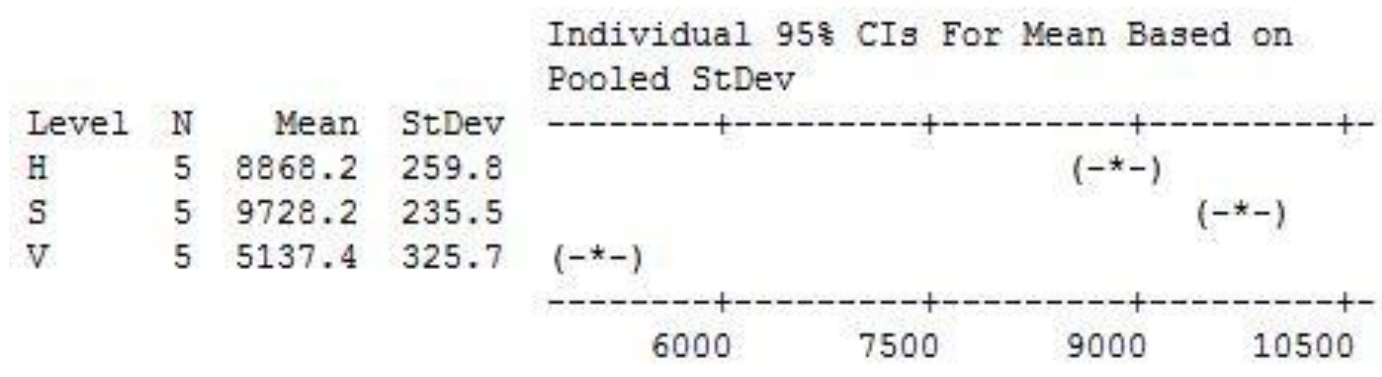

Pooled StDev $=276.3$

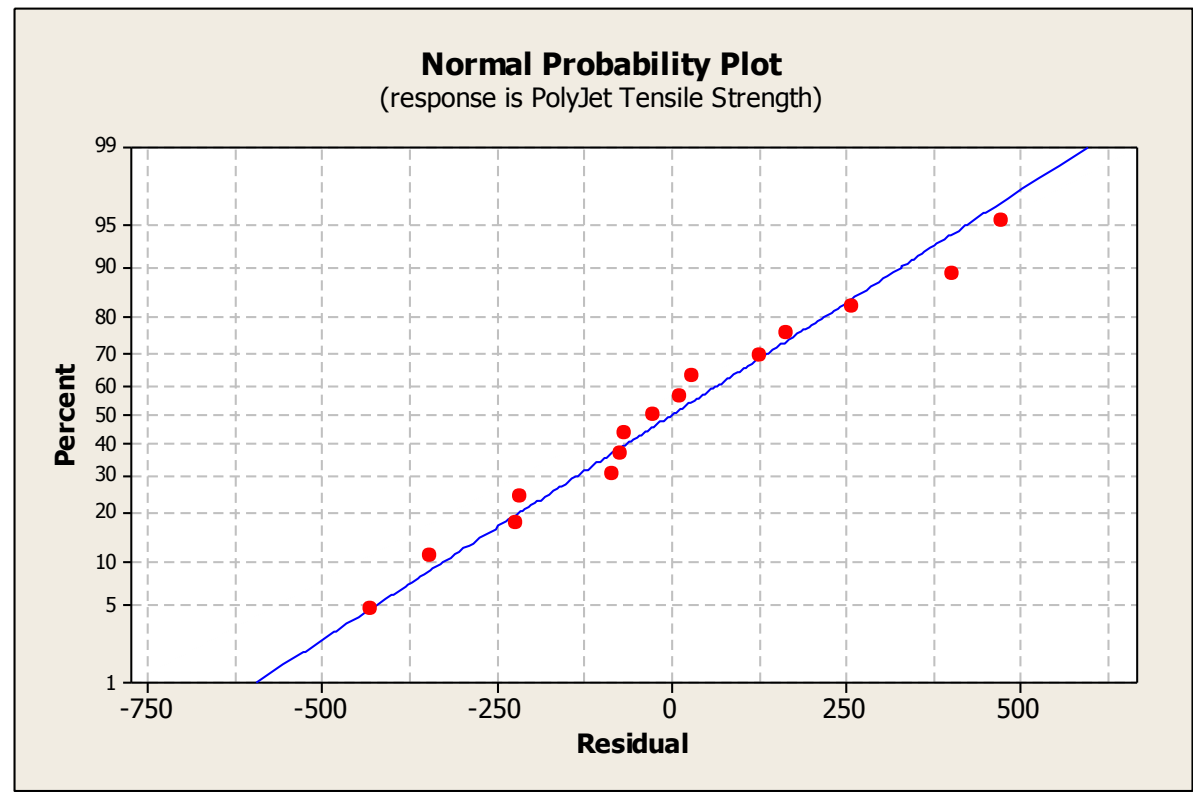




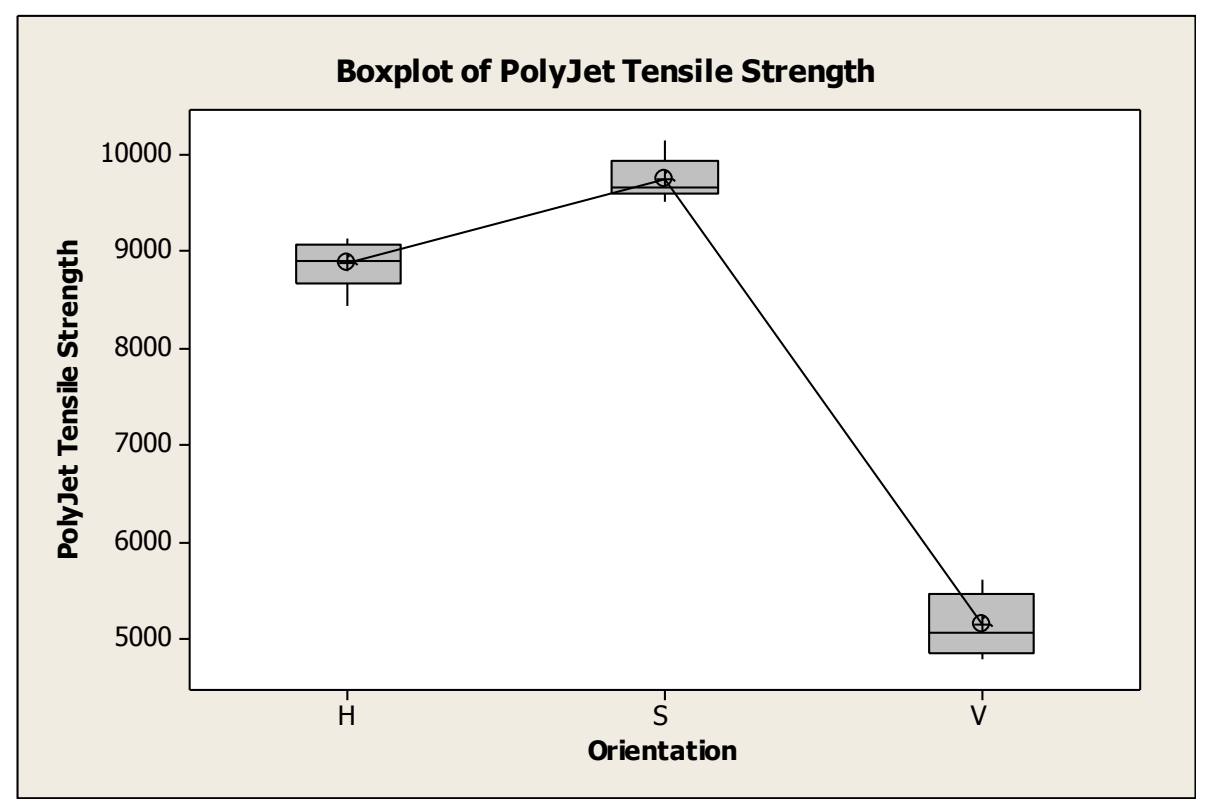

\subsubsection{FDM Tensile Properties}

The tensile testing results of specimens which were created with three build orientations in the FDM technology (Dimension Elite 3D Printer) are presented in this section. Table 13 showed the results of tensile testing and the data provided by the machine vendor. It can be found that the experiment results of tensile strength in the Side build orientation are close to the data provided by the manufacturer. Figure 27 summarized the results of tensile strength with three build orientation in FDM technology. The specimens which were created in Side build orientation have the highest value of tensile strength and elongation at break when compared with Horizontal and Vertical orientation, while the greatest elongation is shown in specimens which were created with Horizontal build orientation. The specimens 
created in Vertical build orientation resulted in the lowest tensile strength because the tensile loads were resisted only by the bonding between fibers, and not the fibers themselves. Considering this experimental result, users of FDM technology should consider build orientations to obtain the greater performance in tensile properties.

Table 13. FDM Tensile Properties

\begin{tabular}{|c|l|r|r|r|r|}
\hline \multicolumn{2}{|c|}{ RP System } & \multicolumn{4}{c|}{ FDM } \\
\hline \multicolumn{2}{|c|}{ Build Orientation } & Horizontal & \multicolumn{1}{c|}{ Side } & Vertical & Company \\
\hline \multirow{2}{*}{ Tensile Strength (psi) } & AVG & 4283.8 & $\mathbf{5 5 7 2 . 2}$ & 3563.2 & 5300 \\
\cline { 2 - 5 } & SD & 79.957 & 61.674 & 224.046 & \\
\hline \multirow{2}{*}{ Elongation (\%) } & AVG & $\mathbf{2 . 2 1 8 7}$ & 2.1818 & 1.4076 & 3 \\
\cline { 2 - 6 } & SD & 0.0337 & 0.0300 & 0.1068 & \\
\hline \multirow{2}{*}{ Elongation at Break (\%) } & AVG & 3.3834 & $\mathbf{3 . 7 1 0 4}$ & 1.4230 & NA \\
\cline { 2 - 6 } & SD & 0.2072 & 0.5259 & 0.1068 & \\
\hline
\end{tabular}

\section{FDM Tensile Strength}

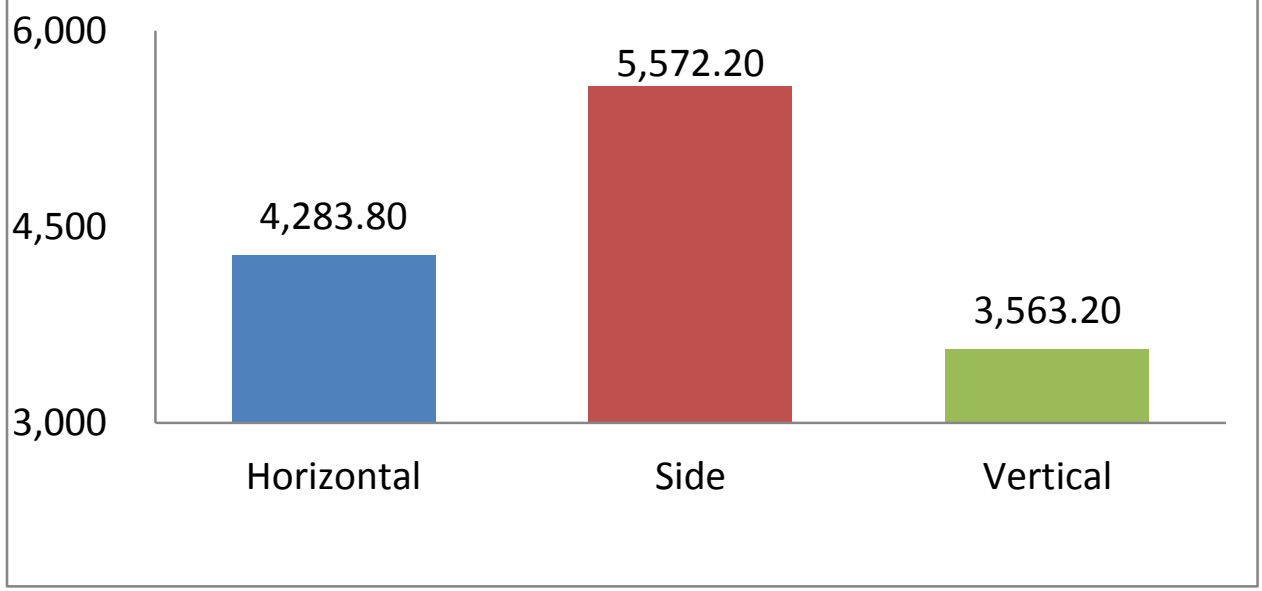

Figure 27. FDM Tensile Strength 


\section{Statistical Analysis}

One-way ANOVA was chosen to analysis the tensile testing results in FDM. The ANOVA table in the image below shows a good indication that tensile testing with different build orientations for FDM specimens is significant at 0.000 . Therefore, we can say the build orientations significantly affect the tensile properties in FDM. In Normal Plot of Residual, we can see most of the points displayed near the straight line and few points are a somewhat far from the line. We can claim that these experiment results mostly satisfy the model adequacy and the points follow the normal distribution. The boxplot shows the Side build orientation has the greatest performance of tensile properties compared with Horizontal and Vertical orientation.

\section{One-way ANOVA: FDM Tensile Strength versus Orientation}

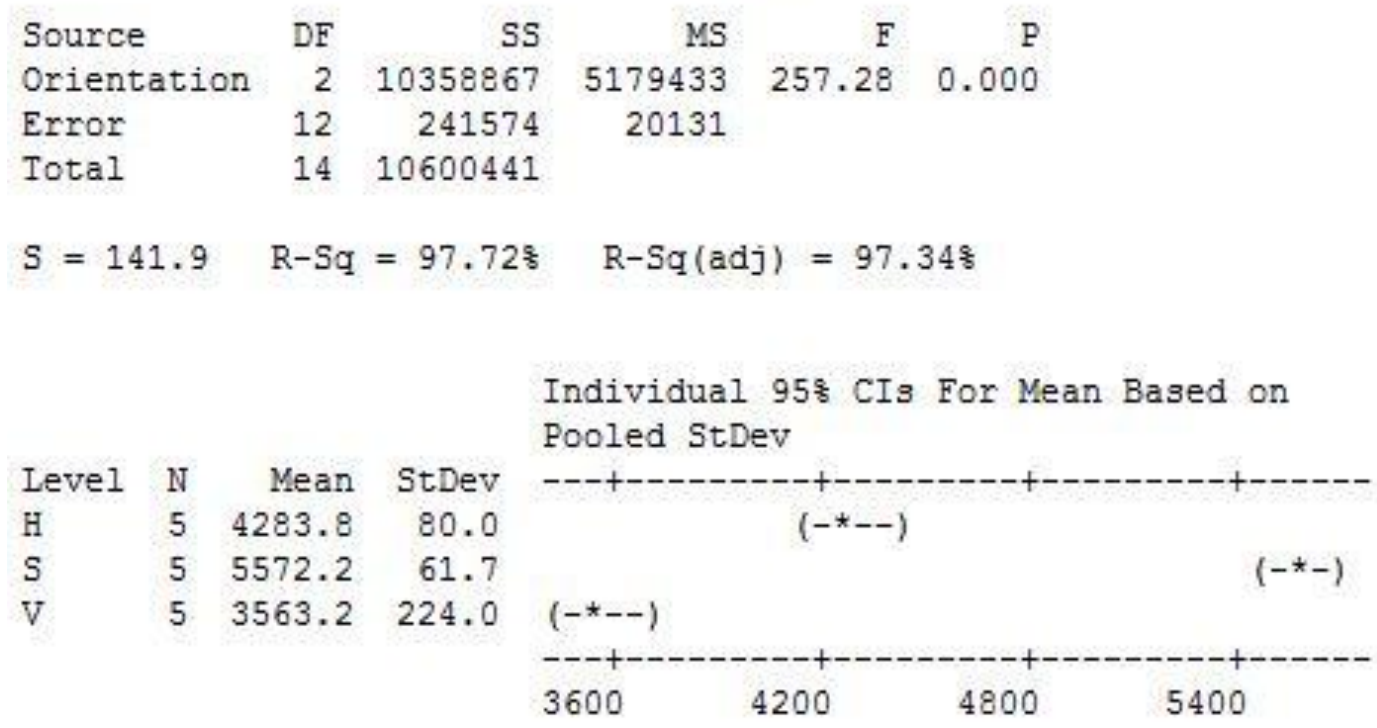

Pooled StDev $=141.9$ 

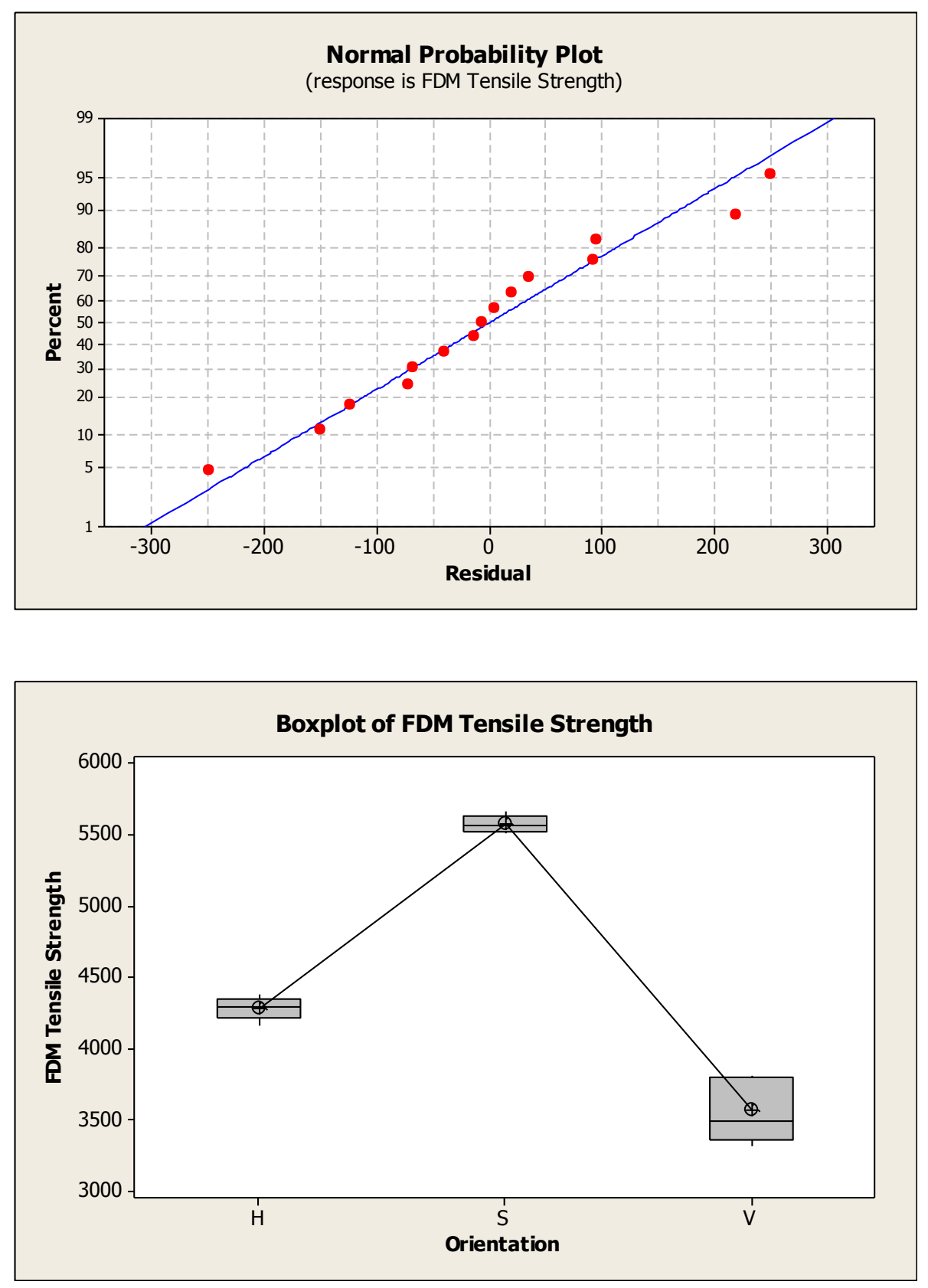

\subsubsection{DP Tensile Properties}

In this section, the tensile testing results of specimens which were created in 3DP (Z Corporation Spectrum Z510) technology are presented. Eight replicates were made with three build orientations. Once the specimens are completed and the 
support powder is removed, the specimens needed to be dipped in Z-Bond 90 binder and so that its strength could be improved. In Table 14, it shows the tensile testing results of specimens made from 3DP. It can be found that the experiment results of tensile strength are close to the data provided by the manufacturer. The best properties are shown in the Side build orientation. The mean value of maximal tensile strength is 2442.25 psi in Side build orientation, compared to 2249.875 psi in Vertical build orientation and 2182.375 psi in Horizontal build orientation. Figure 28 shows the tensile strength with three build orientations. The greatest elongation and elongation at break appeared in Horizontal build orientation. However, the test results of Side build orientation are really close to Horizontal $( \pm 0.0012 \%$ and \pm $0.0013 \%$ ). In addition, the weakest tensile strength is in Horizontal build orientation. Therefore, we can conclude that Side build orientation has the greatest performance of tensile properties in 3D Printing technology.

Table 14. 3DP Tensile Properties

\begin{tabular}{|c|c|c|c|c|c|}
\hline RP System & & \multicolumn{4}{|c|}{$3 \mathrm{DP}$} \\
\hline \multicolumn{2}{|l|}{ Build Orientation } & Horizontal & Side & Vertical & Company \\
\hline \multirow{2}{*}{ Tensile Strength (psi) } & AVG & 2182.375 & 2442.250 & 2249.875 & \multirow[t]{2}{*}{2059.535} \\
\hline & SD & 207.341 & 230.231 & 178.191 & \\
\hline \multirow{2}{*}{ Elongation (\%) } & AVG & 0.4984 & 0.4971 & 0.3831 & \multirow[t]{2}{*}{ NA } \\
\hline & $\mathrm{SD}$ & 0.0651 & 0.0559 & 0.0392 & \\
\hline \multirow{2}{*}{ Elongation at Break (\%) } & AVG & 0.5139 & 0.5127 & 0.3985 & \multirow[t]{2}{*}{0.23} \\
\hline & $\mathrm{SD}$ & 0.0651 & 0.0558 & 0.0394 & \\
\hline
\end{tabular}




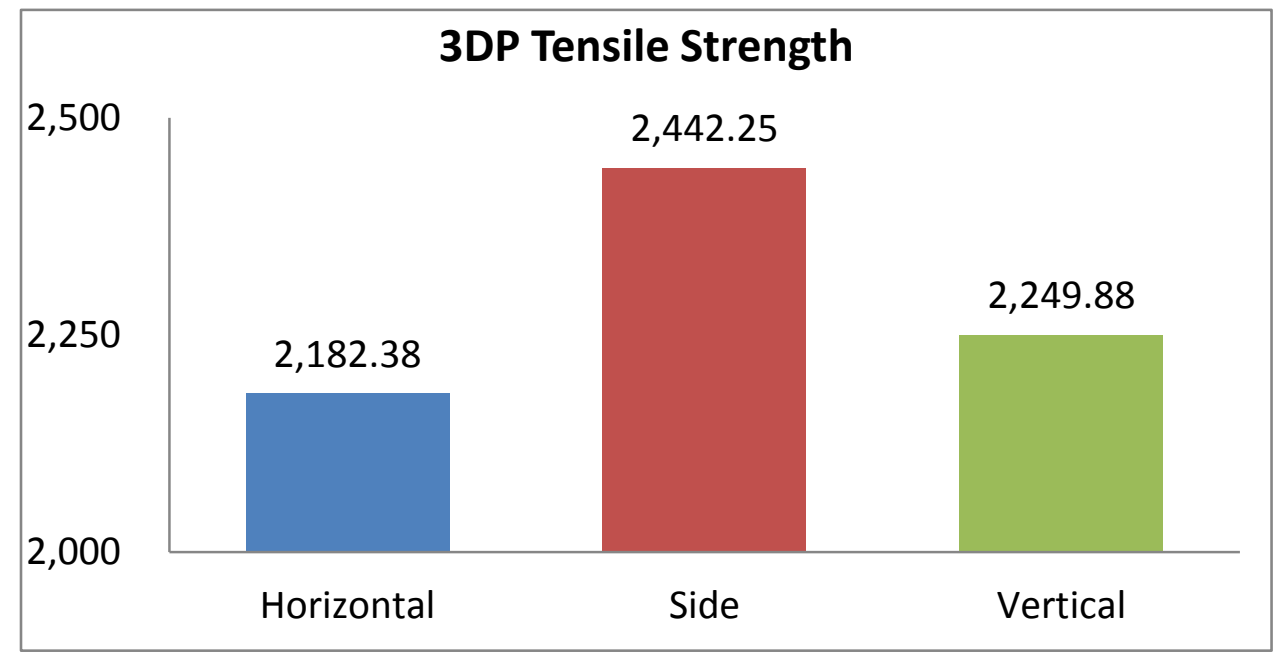

Figure 28. 3DP Tensile Strength

\section{Statistical Analysis}

One-way ANOVA was chosen to verify the tensile testing experiment of specimens which were fabricated in the 3D Printing technology. The ANOVA result shows the experiment to be mediocre with $\mathrm{P}$-value $=0.052$. Considering the post-processing used in the $3 \mathrm{D}$ Printing technology, the specimens need to be manually dipped in the Z-Bond 90 binder. Human variation may affect the experimental results of tensile properties. In the Normal Plot of Residual, we can see most of the points displayed near the straight line and few points are a little far from the line. In the Boxplot, only one testing result (2936 psi) in the Side build orientation is far from the mean (2442.25 psi). However, we can conclude that the specimens created in the 3D Printing technology are not affected by different build orientations as much as other three systems. 
One-way ANOVA: 3DP Tensile Strength versus Orientation

$\begin{array}{lrrrrr}\text { Source } & \text { DF } & \text { SS } & \text { MS } & \text { F } & \text { P } \\ \text { Orientation } & 2 & 290932 & 145466 & 3.42 & 0.052 \\ \text { Error } & 21 & 894242 & 42583 & & \\ \text { Total } & 23 & 1185174 & & \\ \text { S }=206.4 & \text { R-Sq }=24.55 \% & \text { R-Sq (adj) }=17.36 \%\end{array}$

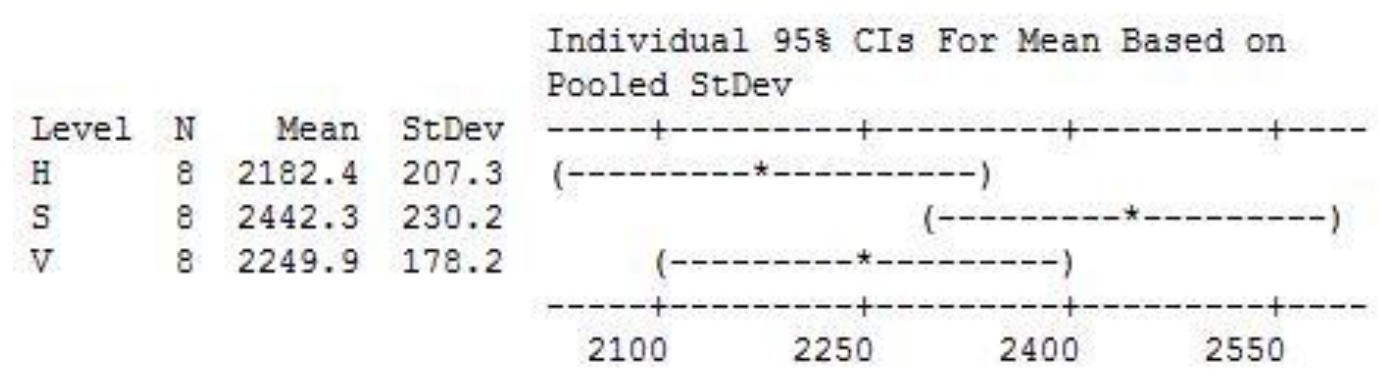

Pooled StDev $=206.4$

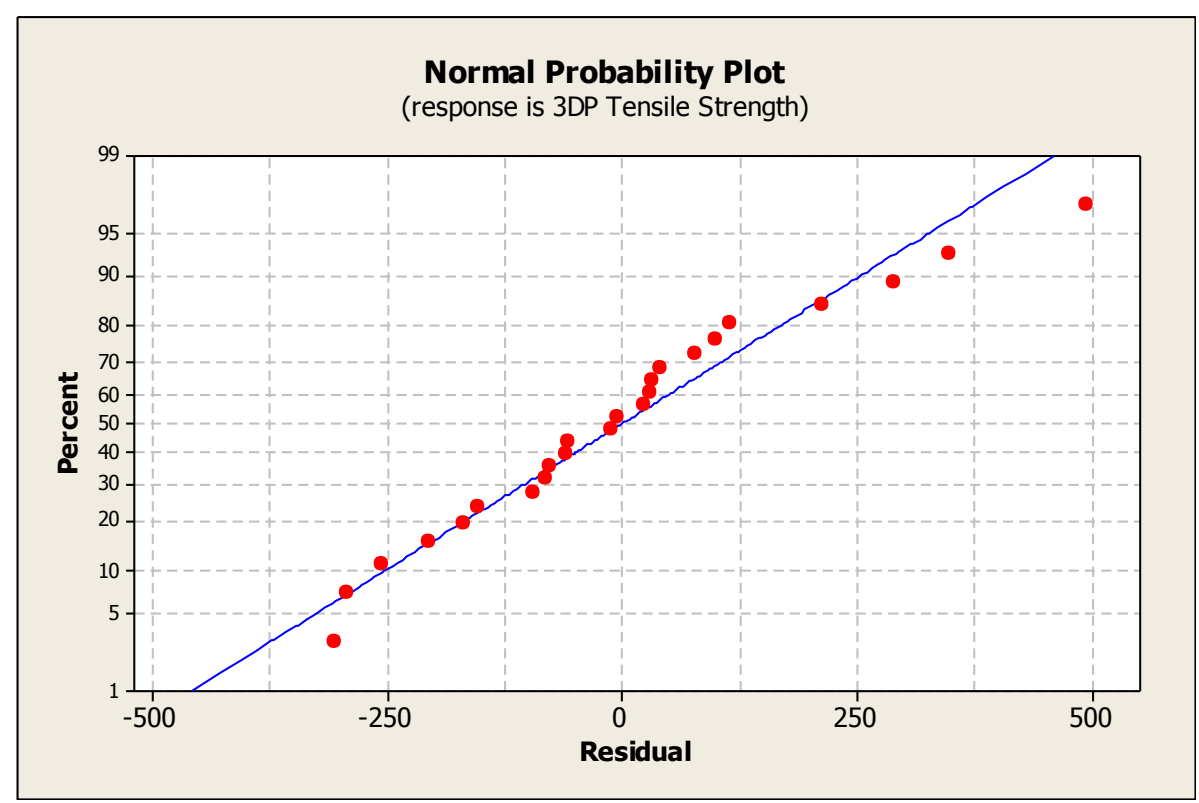




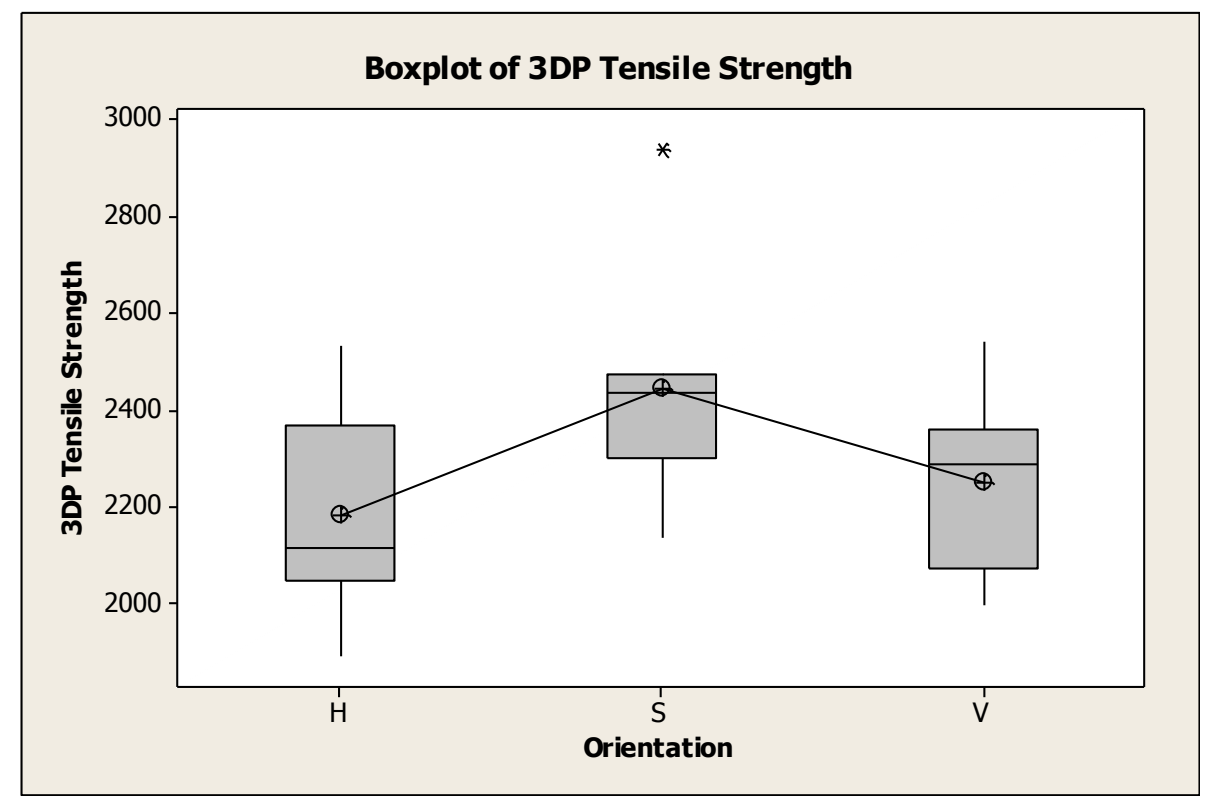

\subsubsection{Summary - Tensile Properties}

For comparisons of tensile testing as a function of direction and method of creation, the bar chart showed in Figure 29 was constructed. Figure 29 displays the average value of the Tensile Strength respectively of the specimens produced under the different rapid prototyping systems and each build orientation. 


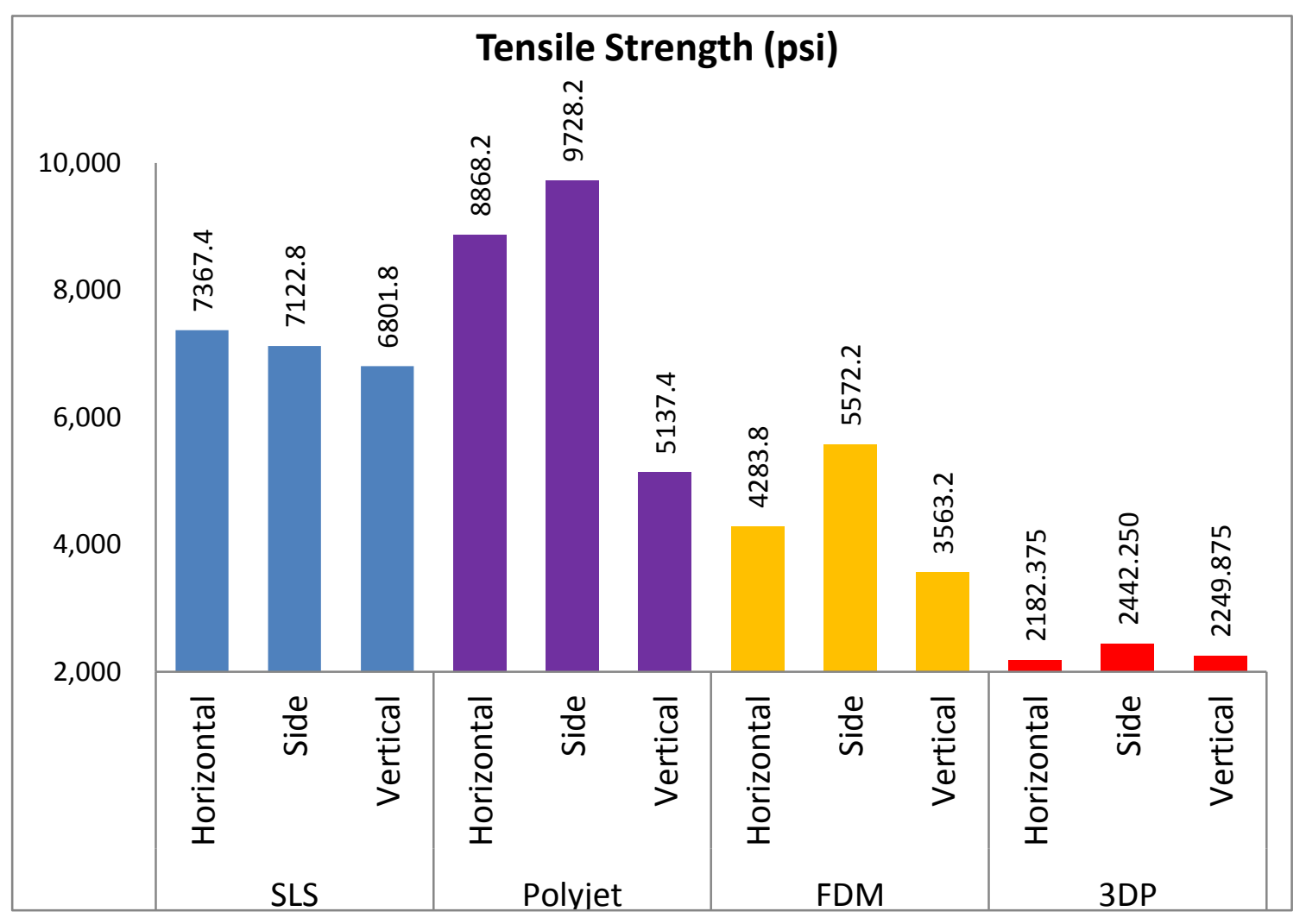

Figure 29. Tensile Strength

It can be seen that the difference in build orientations within the different RP systems does affect the tensile strength of the specimens. Considering effect of using different RP systems, it was found that PolyJet gave the greatest value of tensile strength, followed by SLS, FDM, and 3DP, respectively. Considering build orientation, the samples created in Side orientation in PolyJet, FDM, and 3DP showed the greatest tensile strength compared with Horizontal and Vertical samples. In the SLS system, the specimens created in Horizontal orientation have the highest tensile strength. Comparing the specimens built in three orientations in the SLS and 3DP systems only slightly varied in tensile strength. However, the One-Way 
ANOVA ( $\mathrm{p}$-value $=0.000)$ for the SLS system shows different build orientations significantly affects the tensile properties. Comparing Side and Vertical orientations in the PolyJet and FDM systems, a significant difference in tensile strength occurred.

In ASTM D638, the following definition is given:

Percent Elongation - Percent elongation is the change in gage length relative to the original specimen gage length, expressed as a percent.

Percent Elongation at Break - Calculate the percent elongation at break by reading the extension (change in gage length) at the point of specimen rupture. Divide that extension by the original gage length and multiply by 100 .

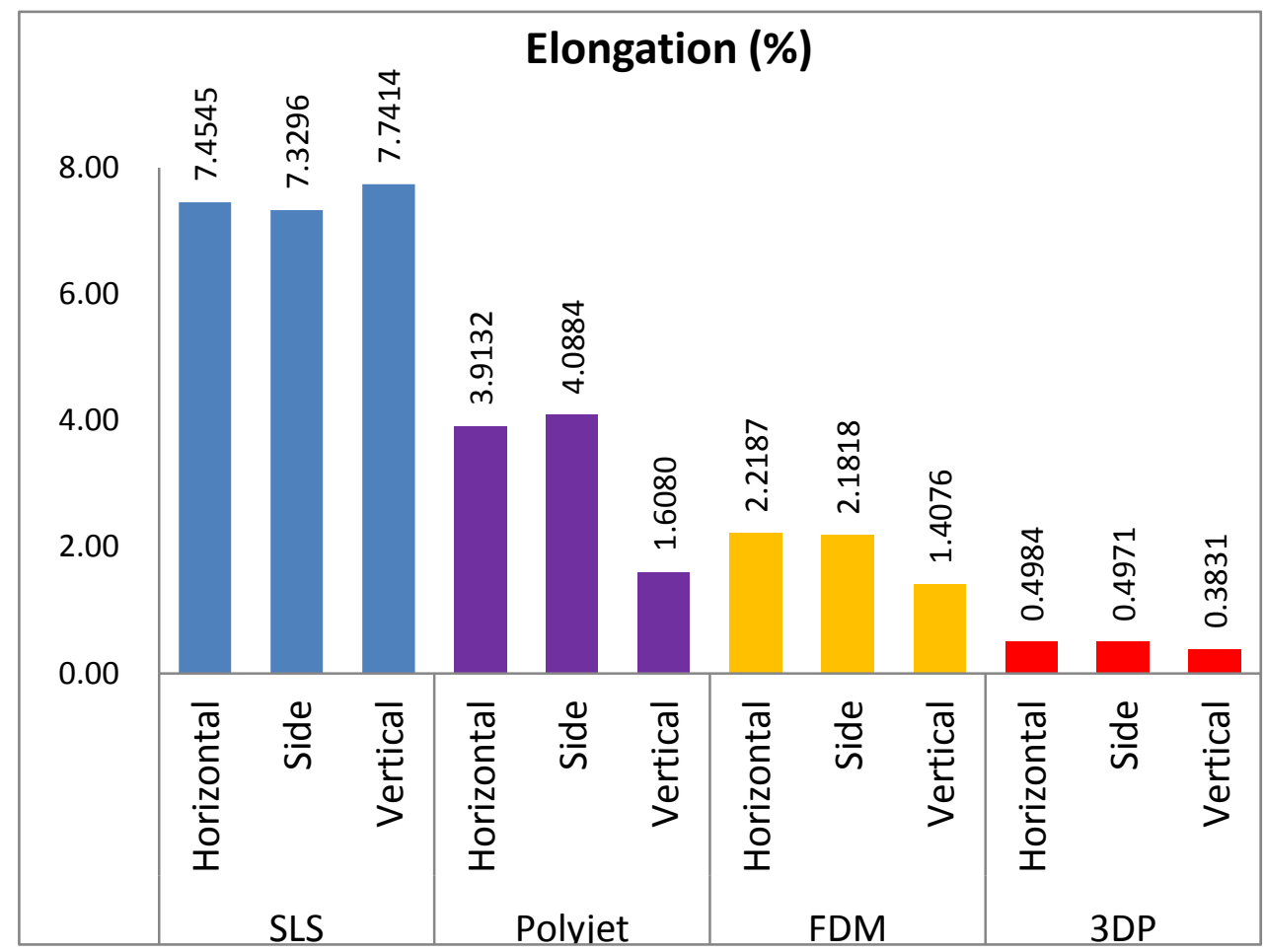

Figure 30. Elongation 


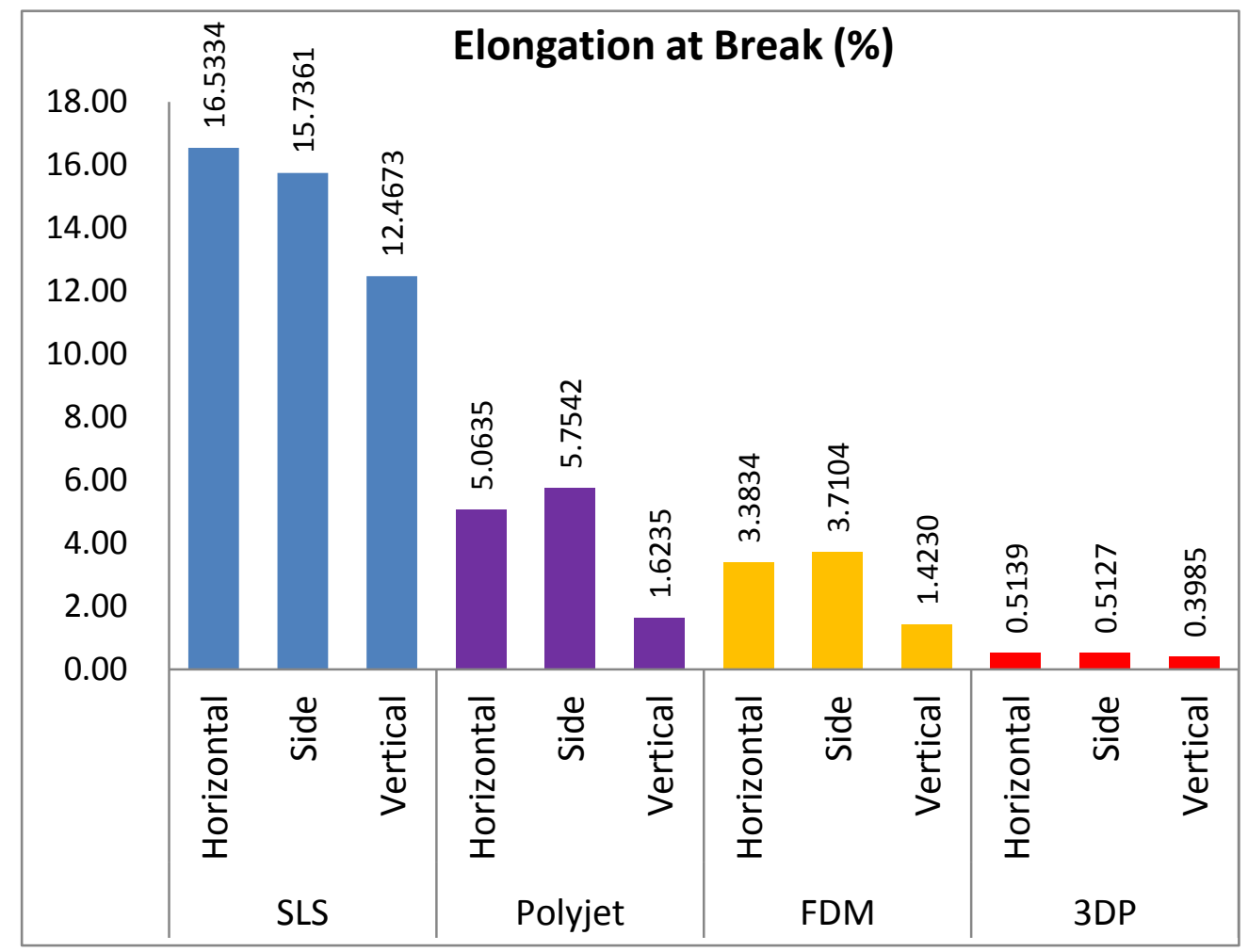

Figure 31. Elongation at Break

Figure 30 and Figure 31 show the Elongation and Elongation at Break, respectively, of the samples produced under the different RP systems and build orientations. It can be seen from the figures that there is a significant difference in Elongation and Elongation at Break between samples produced in SLS and the other three systems. The raw material (PA 2200 Balance 1.0) used in SLS system is based on polyamide 12 which may account for the higher elasticity. However, Elongation and Elongation at Break are different samples created in different orientations in the same RP system. Considering build orientations, the samples created in Horizontal and Side have a greater Elongation and Elongation at Break in PolyJet and FDM compared with the Vertical orientation. The specimens of Vertical build orientation 
resulted in the lowest Elongation and Elongation at Break because the tensile loads were resisted only by the bonding between layers, and not the layers themselves. Table 15 compares the testing results with the data provided by the companies. It can be found that the experiment results of Tensile Strength are generally close to the data provided by the manufacturer. Considering the Elongation and Elongation at Break, the experiment results of the SLS, PolyJet, and FDM are not as high as the data provided by the manufacturers. Therefore, further investigation is necessary.

Table 15. Tensile Properties

\begin{tabular}{|c|c|c|c|c|}
\hline \multirow{2}{*}{\multicolumn{2}{|c|}{ RP System }} & \multicolumn{3}{|c|}{ Tensile Properties } \\
\hline & & \multirow{2}{*}{$\begin{array}{r}\text { Tensile Strength (psi) } \\
\mathbf{7 3 6 7 . 4}\end{array}$} & \multirow{2}{*}{$\begin{array}{r}\text { Elongation (\%) } \\
7.4545\end{array}$} & \multirow{2}{*}{$\begin{array}{r}\text { Elongation at Break }(\%) \\
16.5334 \\
\end{array}$} \\
\hline \multirow{4}{*}{ SLS } & Horizontal & & & \\
\hline & Side & 7122.8 & 7.3296 & 15.7361 \\
\hline & Vertical & 6801.8 & 7.7414 & 12.4673 \\
\hline & Company & 6962 & $N A$ & 24 \\
\hline \multirow{4}{*}{ PolyJet } & Horizontal & 8868.2 & 3.9132 & 5.0635 \\
\hline & Side & 9728.2 & 4.0884 & 5.7542 \\
\hline & Vertical & 5137.4 & 1.608 & 1.6235 \\
\hline & Company & $7250-9450$ & $N A$ & $10-25$ \\
\hline \multirow{4}{*}{ FDM } & Horizontal & 4283.8 & 2.2187 & 3.3834 \\
\hline & Side & 5572.2 & 2.1818 & 3.7104 \\
\hline & Vertical & 3563.2 & 1.4076 & 1.4230 \\
\hline & Company & 5300 & 3 & $N A$ \\
\hline \multirow{4}{*}{ 3DP } & Horizontal & 2182.375 & 0.4984 & 0.5139 \\
\hline & Side & 2442.25 & 0.4971 & 0.5127 \\
\hline & Vertical & 2249.875 & 0.3831 & 0.3985 \\
\hline & Company & 2059.535 & $N A$ & 0.23 \\
\hline
\end{tabular}




\subsection{Water absorption}

Various plastic materials absorb varying amounts of water, and the presence of absorbed water may affect plastics in different ways. The increase in weight, dimensional variations, and the change in electrical and mechanical properties may need to be considered when plastic materials are used for different purposes. In this section, the experiment results for the relative weight change rate of water absorption will be presented.

The percentage increase in weight of the specimens fabricated in specified rapid prototyping systems when immersed in water for 24 hours can be seen in Table 16. The highest relative rate of water absorption appeared in the test specimens created by FDM technology with $11.2732 \%$, while the lowest relative rate of water absorption can be found in the samples created by PolyJet technology with $1.1696 \%$.

Figure 32 shows the internal structure of FDM specimen at 10 times magnification. As we can see, the ABS filaments used in FDM technology do not completely fuse and combine between layers. The distributed structure significantly affects the relative rate of water absorption.

The other factor, which was also found to affect the water absorption, was the type of materials used in specified rapid prototyping systems. Powder-based 
materials tend to absorb water greater than liquid-based material which is used in PolyJet technology. In 3DP technology, an ink-jet printing head deposits a liquid adhesive that binds the powdered material. The post-processing, to infiltrate printed parts in hardener, is needed to improve strength in 3DP technology. In SLS technology, the carbon dioxide $\left(\mathrm{CO}_{2}\right)$ laser heats powdered materials layer by layer so that the surface tensions of the grains are overcome and they fuse together. The new deposited layer is actually fused and combined with the previous layer. The materials used in 3DP and SLS are both powder based; gypsum powder for 3DP, nylon powder for SLS. However, the different ways the layers are bonded and the different materials used in 3DP and SLS affect the weight change when immersed in water. The relative rate of water absorption of samples at the end of test ( 24 hours) is in the order of: FDM > 3DP > SLS > PolyJet as shown in Table 16. 
Table 16. The relative rate of Water Absorption in the four RP systems

\begin{tabular}{|c|c|c|c|c|}
\hline \multirow{2}{*}{ RP System } & \multirow{2}{*}{ Sample \# } & \multicolumn{2}{|c|}{ Weight (g) } & \multirow{2}{*}{$\begin{array}{c}\text { The relative rate of } \\
\text { Water Absorption }(\%)\end{array}$} \\
\hline & & Before & After & \\
\hline \multirow[t]{3}{*}{ SLS } & 1 & 6.83 & 6.94 & 1.6105 \\
\hline & 2 & 6.77 & 6.86 & 1.3294 \\
\hline & AVG & 6.80 & 6.90 & 1.4700 \\
\hline \multirow[t]{3}{*}{ PolyJet } & 1 & 7.70 & 7.79 & 1.1688 \\
\hline & 2 & 7.69 & 7.78 & 1.1704 \\
\hline & AVG & 7.70 & 7.79 & 1.1696 \\
\hline \multirow[t]{3}{*}{ FDM } & 1 & 5.86 & 6.47 & 10.4096 \\
\hline & 2 & 5.85 & 6.56 & 12.1368 \\
\hline & AVG & 5.86 & 6.52 & 11.2732 \\
\hline \multirow[t]{3}{*}{$3 \mathrm{DP}$} & 1 & 10.65 & 11.20 & 5.1643 \\
\hline & 2 & 10.65 & 11.46 & 7.6056 \\
\hline & AVG & 10.65 & 11.33 & 6.3850 \\
\hline
\end{tabular}

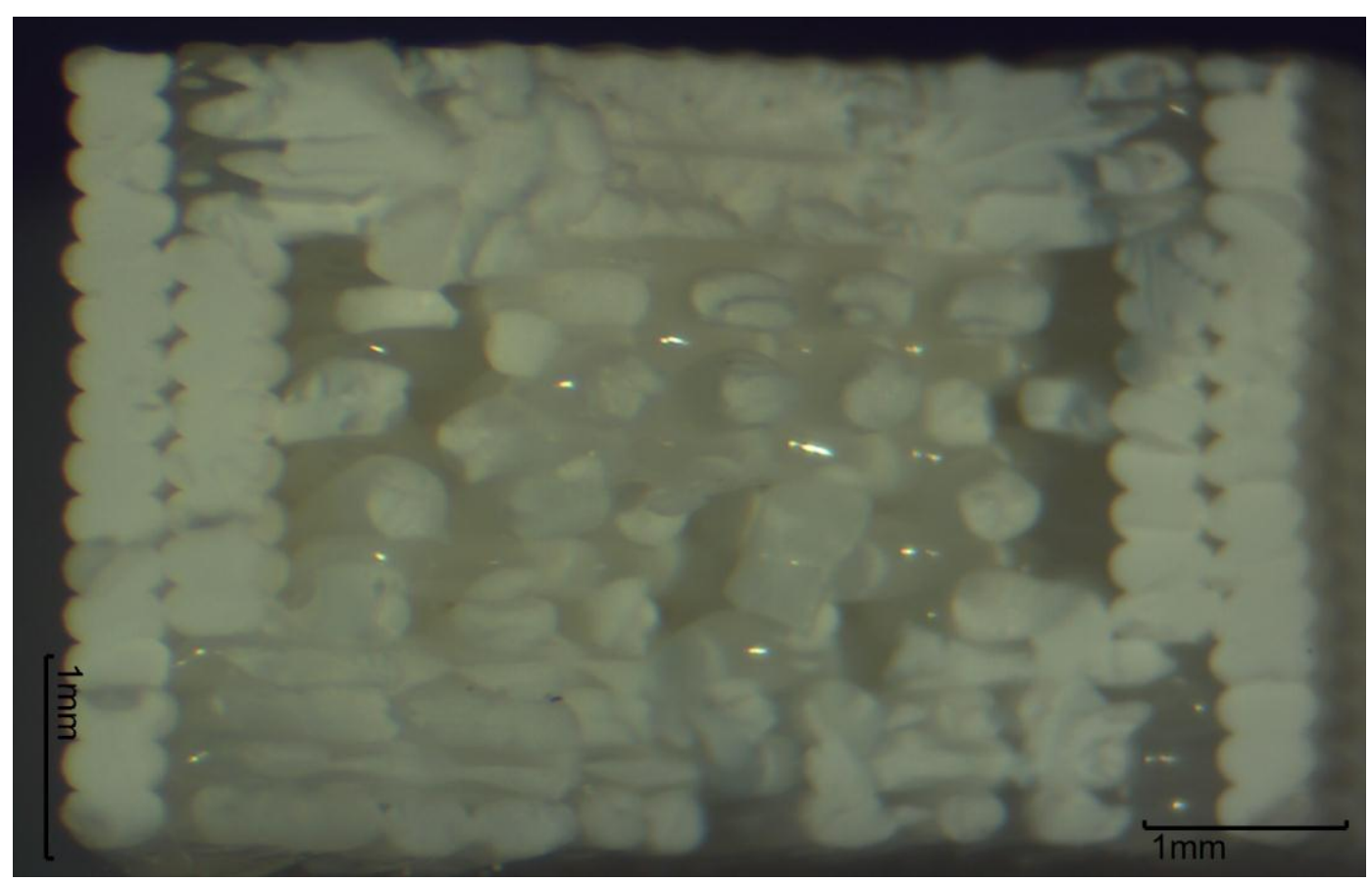

Figure 32. FDM specimen at 10 times magnification 


\section{Statistical Analysis}

One-Way ANOVA was chosen to verify the experimental results of water absorption. In the ANOVA table below from Minitab, the p-value 0.002 of factor (RP System) is less than 0.05 . We can say the different rapid prototyping systems significantly affect the relative rate of water absorption. In the Normal Probability Plot, most points are displayed near the straight line, we can say that these experiment results can mostly satisfy the model adequacy and the points follow the normal distribution. In ANOVA table and the boxplot, it can be seen that specimens created in FDM technology have the highest relative rate of water absorption. The lowest relative rate of water absorption can be found from the specimens created in PolyJet technology.

\section{One-way ANOVA: Water Absorption rate versus RP System}

$\begin{array}{lrrrrr}\text { Source } & \text { DF } & \text { SS } & \text { MS } & \text { F } & \text { P } \\ \text { RP System } & 3 & 136.76 & 45.59 & 40.42 & 0.002 \\ \text { Error } & 4 & 4.51 & 1.13 & & \\ \text { Total } & 7 & 141.28 & & & \\ \text { S }=1.062 & \text { R-Sq }=96.81 \% & \text { R-Sq (adj) }=94.41 \%\end{array}$

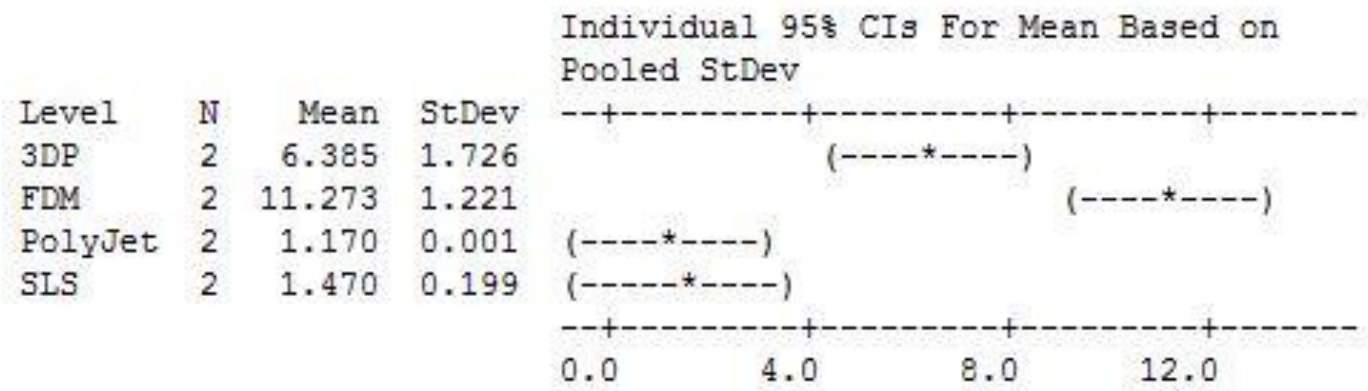

Pooled StDev $=1.062$ 

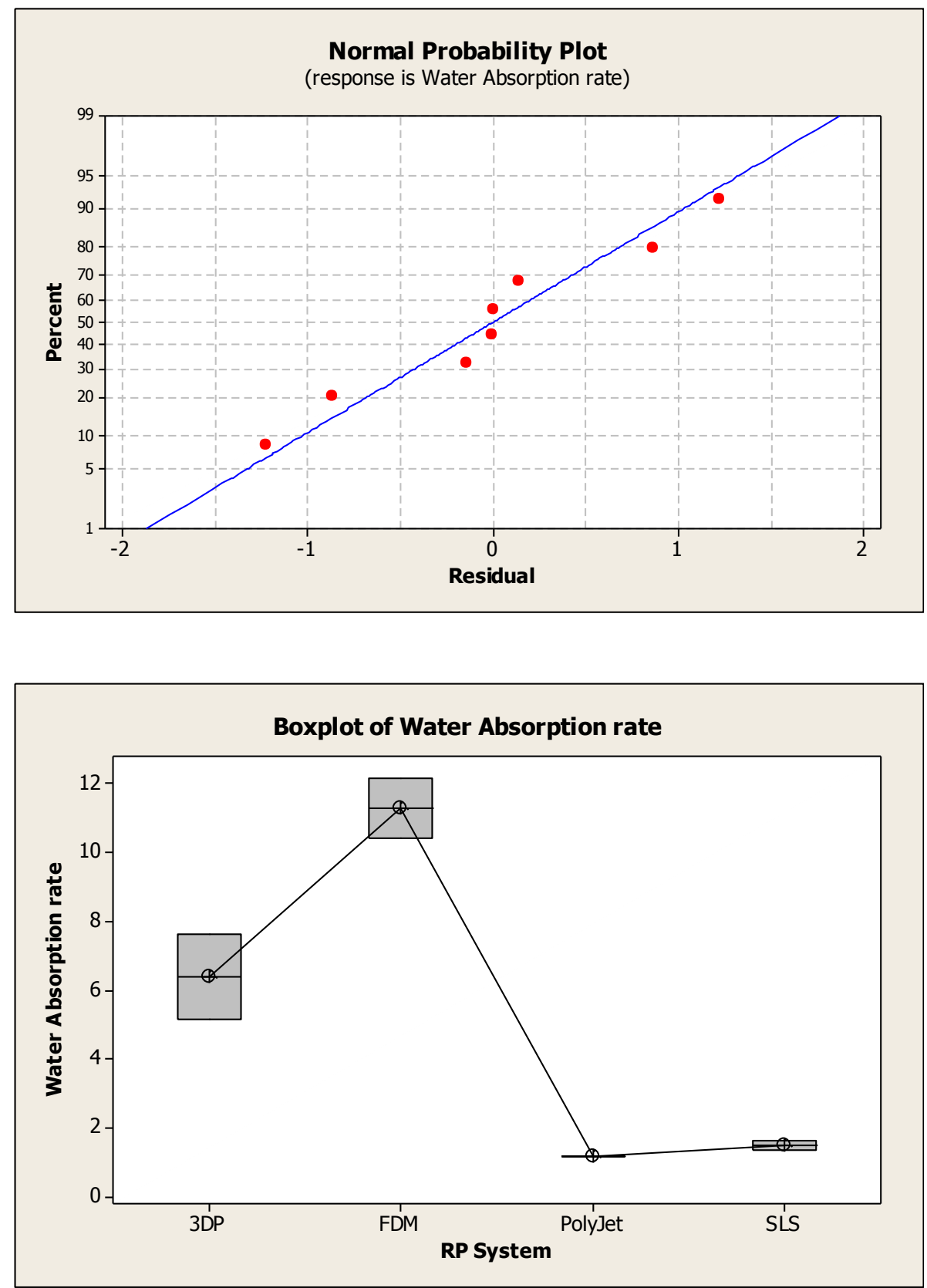

\subsection{Shore Hardness}

There are several durometer scales used for materials with different properties.

The two most common scales are the ASTM D2240 type A and type D scales. The 
type A scale is for softer plastics, while the type D scale is for harder ones. Hardness of hard elastomers and most other polymer materials (Thermoplastics, Thermosets) is measured by the Shore D scale. The scale results in a value between 0 and 100 , with higher values indicating a harder material.

Shore hardness is a measure of the resistance of a material to penetration of a spring loaded needle-like indenter. Two specimens were created in the Horizontal build orientation in each RP system: SLS, PolyJet, FDM, and 3DP. The reason to choose Horizontal build orientation was the shortest machine duration compared with Side and Vertical. For the Shore Hardness investigation, the independent variable was the specified rapid prototyping system and its relative material used, and the dependent variable was the Shore Hardness. The independent variable, build orientations, was not included in this investigation. There are three measured points on two long planes; total six measured points in one specimen. Table 17 shows the average measured values and standard deviations. The order of hardness is PolyJet > 3DP $>$ FDM $>$ SLS. The highest scale of Shore hardness appeared in the test specimens created by PolyJet technology with 84.75 , while the lowest scale of Shore hardness can be seen in the samples created by SLS technology with 77.1667. 
Table 17. Shore Hardness

\begin{tabular}{|l|l|l|}
\hline RP System & ASTM D2240 Type D scale & Standard Deviation \\
\hline SLS & 77.1667 & 1.7495 \\
\hline PolyJet & 84.7500 & 0.7538 \\
\hline FDM & 78.4167 & 2.1088 \\
\hline 3DP & 82.3333 & 1.3027 \\
\hline
\end{tabular}

\section{Statistical Analysis}

One-way ANOVA was chosen to analysis the experiment results. In the ANOVA table below, the p-value is less than 0.05 , therefore we can say the different RP systems affect the durometer scale significantly. In the boxplot, it can be seen that specimens created in PolyJet technology have the highest scale of Shore hardness. The lowest scale of Shore hardness can be found from the specimens created in SLS technology. In Normal plot of residuals, the majority of the points are displayed near the straight line and it follows the normal distribution. We can say that these experiment results can mostly satisfy the model adequacy. 
One-way ANOVA: Durometer Scale versus RP System

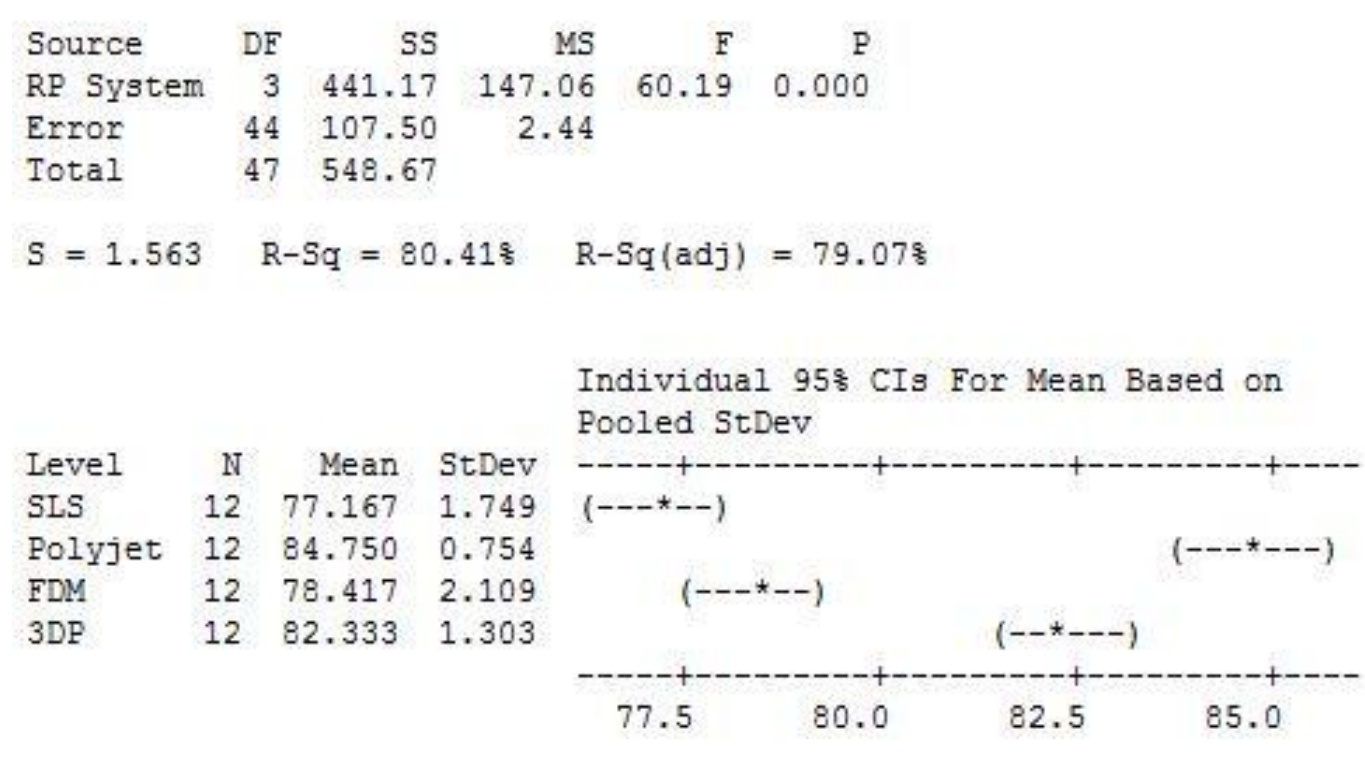

Pooled StDev $=1.563$

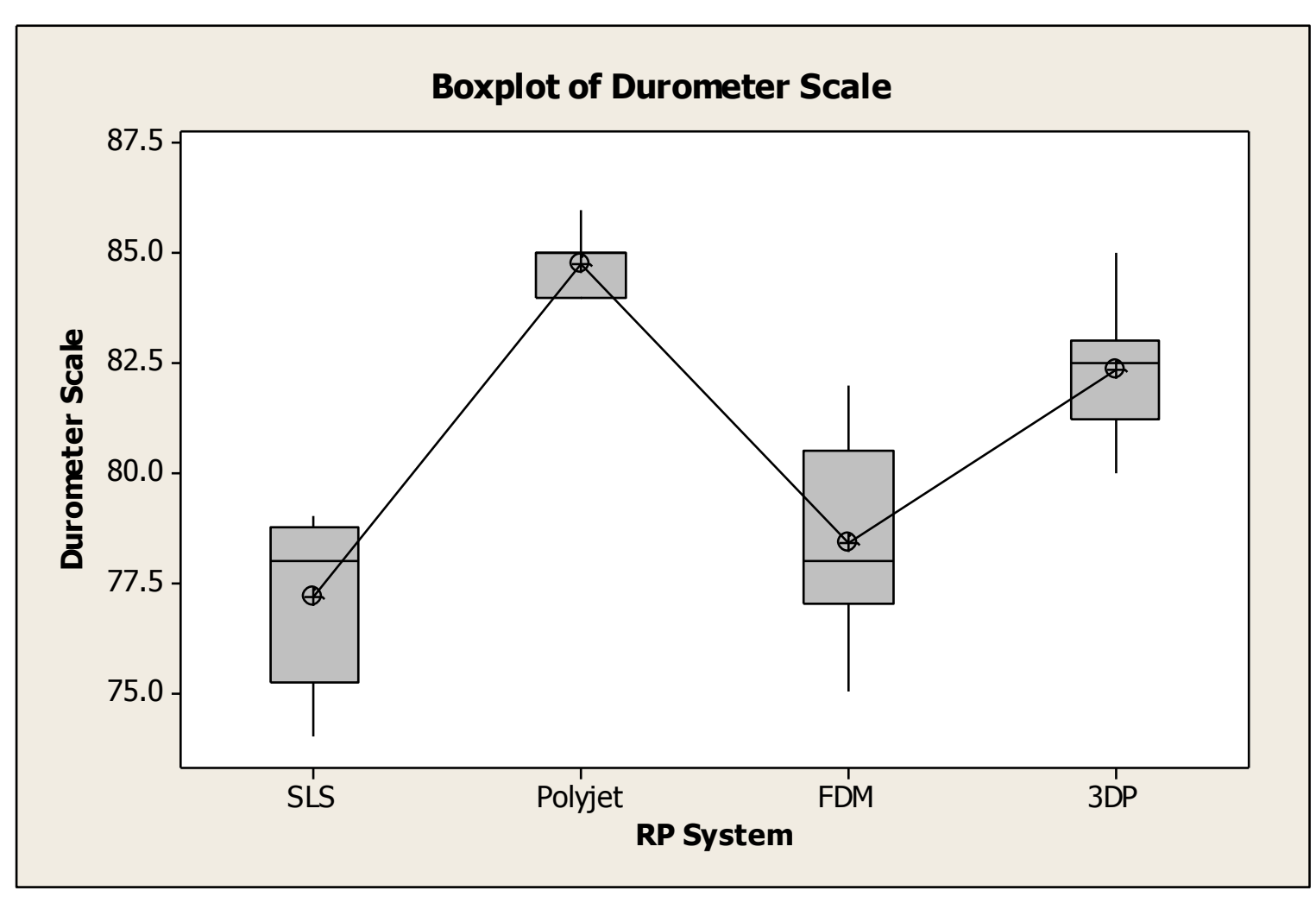




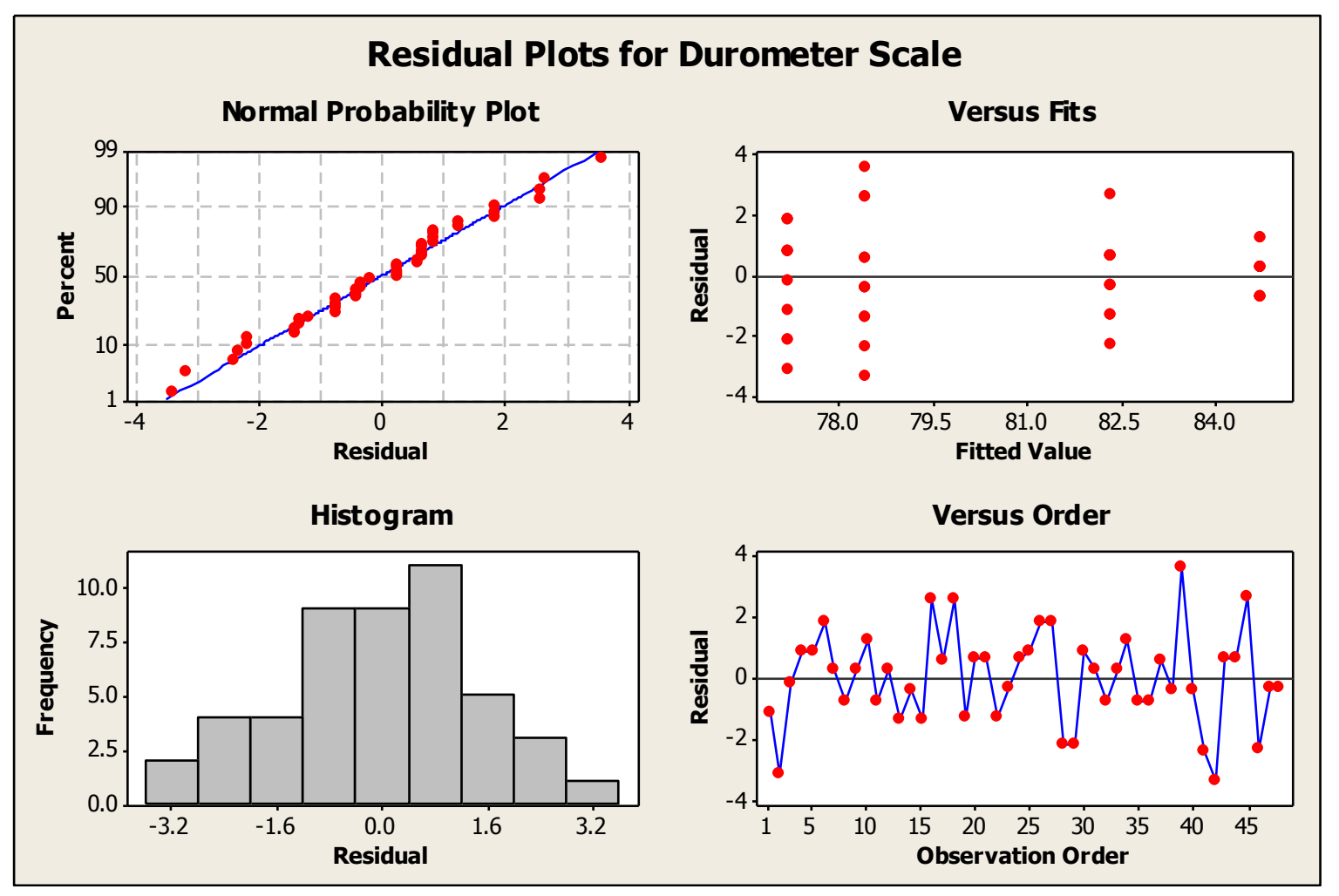




\subsection{Microscopy and Analysis}

In this section, the microscopic views of specimens built in three orientations for each rapid prototyping systems are presented. Table 18 shows magnified views of fractured surfaces of the tensile testing specimens.

Considering the magnified pictures in SLS system, it is hard to see the additive structure between layers because of the $\mathrm{CO} 2$ laser beam raises the temperature to fuse the powder-based material and bind the new deposited layer with the previous layer to form a solid model.

Considering the magnified pictures in PolyJet system, the liquid-based photopolymer material is completely solidified by UV light. However, the tensile strength showed significant differences between the three build orientations in PolyJet in Section 4.2.2 Table 12.

Considering the magnified pictures in FDM systems, there are apparent differences when compared with specimens in SLS, PolyJet, and 3DP. The extruded filaments bonded together instead of liquefied to form a solid model, and air gaps are present between filaments in the FDM specimens. This can help explain why the FDM specimens have the highest rate of water absorption as well as the high standard deviation in Shore hardness testing. Moreover, the specimens of Vertical 
build orientation resulted in the lowest tensile strength because the tensile loads were resisted only by the bonding between fibers, and not the fibers themselves.

Considering the magnified pictures in 3DP system, it can be found that the middle of the fracture surface did not bond with the binder during the post-processing. In 3DP technology, the post-processing hardening process where the part is immersed in a binder is a critical procedure to improve strength and surface finish. Further research is necessary to investigate the optimal strategies for post-processing in 3DP system. 
Table 18. Stereo microscope pictures of the fracture surfaces of tensile testing specimens

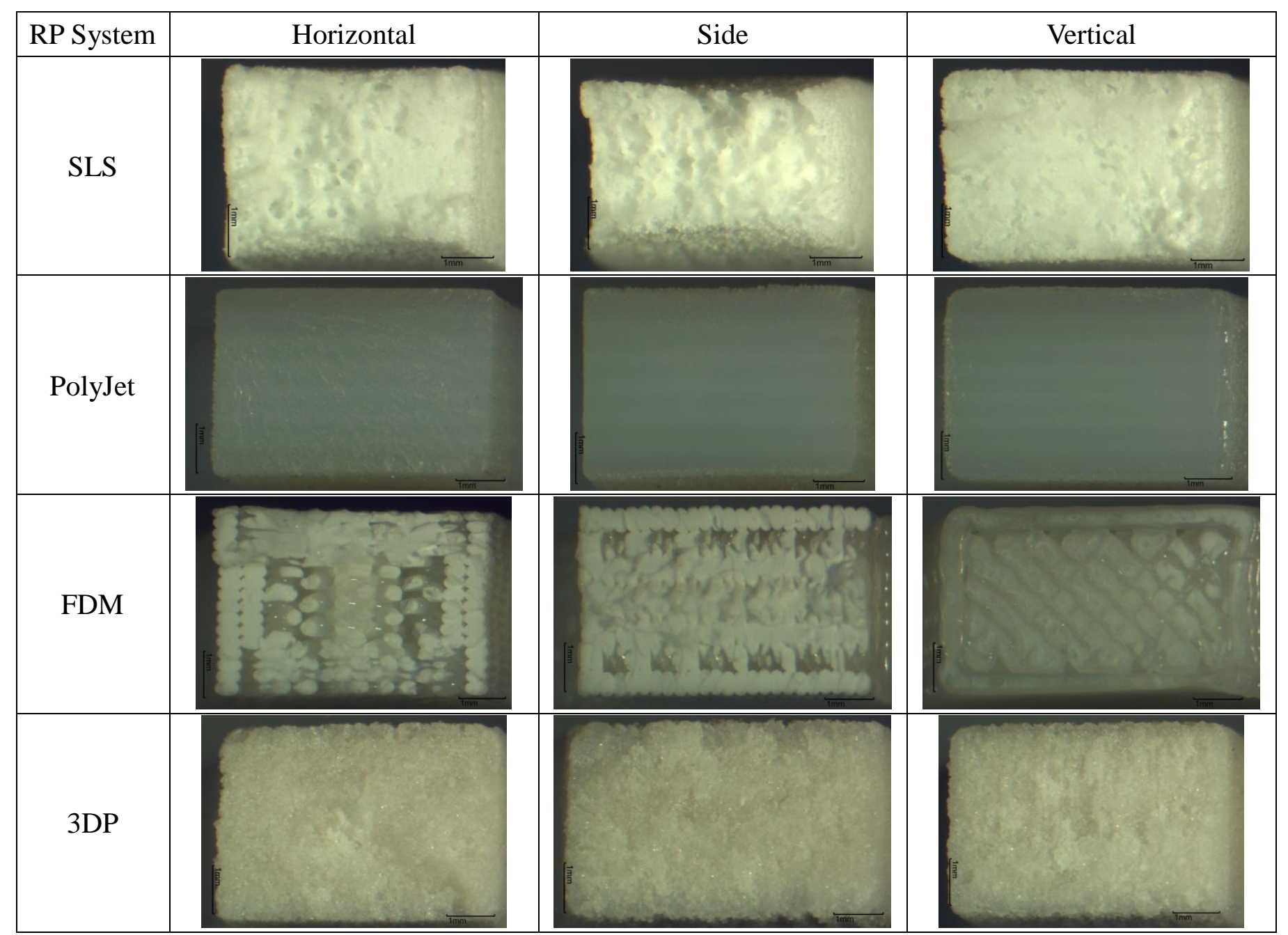




\section{Chapter 5: CONCLUSION AND FUTURE WORK}

\subsection{Conclusion}

Through analysis of this comparative study, rapid prototyping users interested in optimizing production will have an idea of the effect on dimensional accuracy and tensile properties of different build orientations and RP technologies, as well as the effect of different RP technologies on water absorption and the Shore hardness. In addition, this research can be a stepping-stone for further investigation of rapid prototyping technologies.

The results obtained in this paper include dimensional accuracy and tensile properties for different build orientations, and the relative rate of water absorption and the Shore hardness between different rapid prototyping systems: SLS, PolyJet, FDM, and 3DP. Table 19 summarizes the experiment results. Most of the experiment results were tested to be statistically significant in the SLS, PolyJet, and FDM, with the exception of 3DP in dimensional accuracy $(\mathrm{p}$-value $=0.091)$ and tensile properties (p-value $=0.052)$. In the 3DP technology, the post-processing, manual dipping parts in the binder may cause the variation in experiments. However, we can conclude that different build orientations had a significant effect on dimensional accuracy and 
tensile properties in the SLS, PolyJet, and FDM.

Considering dimensional accuracy in different build orientations, Horizontal was more accurate compared with Side and Vertical in the PolyJet, FDM, and 3DP, with the exception of the SLS system. In the SLS, Vertical build orientation was more accurate compared with Horizontal and Side. In the research presented by Steve Upcraft and Richard Fletcher [6], the experiment results related to dimensional accuracy showed the SLS - Nylon (97.8\%) was the most accurate compared with SLA - Epoxy (97.7\%), SLS - Polystyrene (97.7\%), LOM - Paper (97.2\%), and FDM - ABS (95.3\%). The test specimens of the FDM - ABS technology were the most inaccurate in this experiment. According to the experiment results in Section 4.1, the SLS system also performs with the better dimensional accuracy than the FDM system. Furthermore, a comparison of dimensional accuracy regarding different build orientations in the SLS, PolyJet, FDM, and 3DP technologies is provided in this research. In the paper presented by Ana P. et al. [26], the results of measuring the dimensions of test specimens showed that the PolyJet - Objet Eden 330 was more precise in production than the 3DP ZPrinter 310 Plus. However, there was no comparative information related to different build orientations in these two researches.

Considering tensile properties in different build orientations, Side build 
components were the strongest compared with parts created in Horizontal and Vertical build orientations in the PolyJet, FDM, and 3DP, except the SLS technology. In the SLS technology, Horizontal build orientation was the strongest compared with others. In the research presented by Steve Upcraft and Richard Fletcher [6], it listed information of mechanical properties regarding specified materials and relative rapid prototyping technologies: SLS, FDM, SLA, and LOM. However, the data was supplied by the material suppliers or rapid prototyping equipment manufacturers themselves, and there was no comparative information regarding different build orientations. In the research presented by Ana P. et al. [26], the experimental results regarding tensile properties and flexural properties showed that PolyJet - Objet Eden 330 had a greater performance than 3DP - ZPrinter 310. However, there was also no comparative information regarding different build orientations

Considering the relative rate of water absorption and the Shore hardness, all specimens created in the PolyJet had the greatest performance (the lowest water absorption and the highest Shore hardness).

Through analysis of the comparative data in Table 19, the information can be used as a preliminary guide to help users determine optimal strategies for rapid prototyping systems and build orientation selection. It was not possible to provide a definitive statement of the cost of particular rapid prototyping machines as list prices 
and machine specifications change regularly. However, an indication of machine purchase prices was given in the last column of Table 19. It provided approximate purchase prices of each rapid prototyping machine at the University of Missouri, Columbia. Generally, the purchase price of rapid prototyping machines has significantly declined over the past 10 years, mainly due to increased competition. Through an analysis Table 19, interested users can select the appropriate rapid prototyping system and the suitable build orientation, whether it was based on dimensional accuracy, mechanical properties, or initial investment.

Table 19. Experiment results summary (Boldface indicate the best performance)

\begin{tabular}{|c|c|c|c|c|c|c|c|}
\hline \multirow[b]{2}{*}{$\begin{array}{c}\text { RP } \\
\text { System }\end{array}$} & \multirow[b]{2}{*}{$\begin{array}{c}\text { Build } \\
\text { Orientation }\end{array}$} & \multirow[b]{2}{*}{$\begin{array}{c}\text { Dimensional } \\
\text { Accuracy } \\
(\%)\end{array}$} & \multicolumn{2}{|c|}{ Tensile Properties } & \multirow[b]{2}{*}{$\begin{array}{c}\text { Water } \\
\text { Absorption } \\
(\%)\end{array}$} & \multirow[b]{2}{*}{$\begin{array}{c}\text { Shore } \\
\text { Hardness } \\
\text { (Type D) }\end{array}$} & \multirow[b]{2}{*}{$\begin{array}{c}\text { Purchase } \\
\text { Price } \\
\text { (USD) }\end{array}$} \\
\hline & & & $\begin{array}{l}\text { Tensile } \\
\text { Strength } \\
\text { (psi) }\end{array}$ & $\begin{array}{c}\text { Elongation } \\
\text { at Break } \\
(\%)\end{array}$ & & & \\
\hline \multirow{3}{*}{ SLS } & Horizontal & 2.2136 & 7367.4 & 16.5334 & \multirow[t]{3}{*}{1.4700} & \multirow[t]{3}{*}{77.1667} & \multirow[t]{3}{*}{200,000} \\
\hline & Side & 1.4834 & 7122.8 & 15.7361 & & & \\
\hline & Vertical & 0.5093 & 6801.8 & 12.4673 & & & \\
\hline \multirow{3}{*}{ PolyJet } & Horizontal & 0.3227 & 8868.2 & 5.0635 & \multirow[t]{3}{*}{1.1696} & \multirow[t]{3}{*}{84.7500} & \multirow[t]{3}{*}{150,000} \\
\hline & Side & 1.2217 & 9728.2 & 5.7542 & & & \\
\hline & Vertical & 1.8137 & 5137.4 & 1.6235 & & & \\
\hline \multirow{3}{*}{ FDM } & Horizontal & 1.1025 & 4283.8 & 3.3834 & \multirow[t]{3}{*}{11.2732} & \multirow[t]{3}{*}{78.4167} & \multirow[t]{3}{*}{30,000} \\
\hline & Side & 2.2129 & 5572.2 & 3.7104 & & & \\
\hline & Vertical & 2.1845 & 3563.2 & 1.4230 & & & \\
\hline \multirow{3}{*}{$3 \mathrm{DP}$} & Horizontal & 2.5302 & 2182.4 & 0.5139 & \multirow[t]{3}{*}{6.3850} & \multirow[t]{3}{*}{82.3333} & \multirow[t]{3}{*}{40,000} \\
\hline & Side & 3.9861 & 2442.3 & 0.5127 & & & \\
\hline & Vertical & 2.8356 & 2249.9 & 0.3985 & & & \\
\hline
\end{tabular}




\subsection{Future work}

Further research should be attempted by building the same test specimens using other rapid prototyping technologies with different build layouts and orientations. For future work, technologies to be tested need to include the Stereolithography (SLA), the Laminated Object Modeling (LOM) technologies, and other rapid prototyping technologies. Different machine settings in different rapid prototyping systems are also an interesting topic. Furthermore, a comparative study should not be limited to only one type of material in each rapid prototyping technology, but it should be expanded to include other commercial materials and technologies used in industry. Once the database is created for material properties comparison, users could chose the appropriate material for the task under consideration.

The change of mechanical properties when UV light exposed on rapid prototyping products would be an interesting investigation. For the water absorption, there will still be more work to be done: the dimensional variations and the change in electrical and mechanical properties. These need be considered when plastic materials are used for different purposes. Since rapid prototyping will be used in the aerospace industry, testing under multi-temperature (at high and low temperatures) could be an 
important aspect of the material. Another component of the comparison study should include initial investment for start-up rapid prototyping technology, cost to manufacture the products, equipment maintenance costs, and projected useful life. 


\section{REFERENCES}

1. Chua, C.K., K.F. Leong, and C.S. Lim, Rapid prototyping : principles and applications. 3rd ed2010, Singapore ; Hackensack, NJ: World Scientific.

2. Peter D. Hilton, P.F.J., Rapid tooling: technologies and industrial applications2000, New York: Marcel Dekker.

3. Noorani, R., Rapid prototyping : principles and applications 2006 , Hoboken, N.J.: Wiley. xxi, 377 p.

4. Kruth, J.P., Material incress manufacturing by rapid prototyping techniques. CIRP Annals-Manufacturing Technology, 1991. 40(2): p. 603-614.

5. $\quad$ Klocke, F., T. Celiker, and Y.A. Song, Rapid metal tooling. Rapid Prototyping Journal, 1995. 1(3): p. 32-42.

6. Steve, U. and F. Richard, The rapid prototyping technologies. Assembly Automation, 2003. 23(4): p. 318-330.

7. Pham, D.T. and R.S. Gault, A comparison of rapid prototyping technologies. International Journal of Machine Tools and Manufacture, 1998. 38(10): p. 1257-1287.

8. PROTO3000. 3D Printing Advantages. Available from: http://www.proto3000.com/rapid-prototyping.aspx?topidcol=11.

9. Ibrahim, D., et al., Dimensional error of selective laser sintering, three-dimensional printing and PolyJet models in the reproduction of mandibular anatomy. Journal of cranio-maxillo-facial surgery : official publication of the European Association for Cranio-Maxillo-Facial Surgery, 2009. 37(3): p. 167-173.

10. Hopkinson, N., R. Hague, and P. Dickens, Rapid manufacturing: an industrial revolution for the digital age2006: Wiley, ISBN: 0-470-01613-2.

11. Pham, D., \& Dimov, S., Rapid manufacturing: the technologies and applications of rapid prototyping and rapid tooling2001, New York: Springer.

12. Fortus, S. FORTUS FDM Thermoplastics Material Comparison. 2013; Available from:

http://www.fortus.com/Materials/FDM-Material-Comparison.aspx.

13. CustomPartNet. Fused Deposition Modeling (FDM). 2008; Available from: http://www.custompartnet.com/wu/fused-deposition-modeling.

14. Cardona, J.A., An integrated approach for characterization of properties and 
mesostructure for FDM Ultem 9085, 2010, University of

Missouri--Columbia.

15. Bidanda, B., V. Narayanan, and R. Billo, Reverse engineering and rapid prototyping. Handbook of Design, Manufacturing and Automation, 2007: p. 977-990.

16. 3D Systems, I. 3D Systems Completes The Acquisition Of Z Corp and Vidar. 2012 [cited 2012; Available from:

http://www.zcorp.com/en/Press-Room/3D-Systems-Completes-Acquisition-o f-Z-Corporation/news.aspx.

17. CustomPartNet. 3D Printing. 2008; Available from: http://www.custompartnet.com/wu/3d-printing.

18. Jacobs, P.F., Rapid prototyping \& manufacturing: fundamentals of stereolithography1992: Sme.

19. Khaing, M.W., J.Y.H. Fuh, and L. Lu, Direct metal laser sintering for rapid tooling: processing and characterisation of EOS parts. Journal of Materials Processing Tech, 2001. 113(1): p. 269-272.

20. Pessard, E., et al., Complex cast parts with rapid tooling: rapid manufacturing point of view. The International Journal of Advanced Manufacturing Technology, 2008. 39(9): p. 898-904.

21. Durham, M., T. Grimm, and J. Rollins, SLS and SLA: different technologies for different applications. Promotional Literature, Accelerated Technologies Inc., Austin, TX, 1996.

22. Antonio, A., Assessment of surface quality on textured FDM prototypes. Rapid Prototyping Journal, 2006. 12(1): p. 35-41.

23. Weiss, E., et al., Accuracy of parts manufactured by rapid prototyping technology. Annals of DAAAM \& Proceedings, 2010(Journal Article): p. 461.

24. Kulkarni, P. and D. Dutta, Deposition strategies and resulting part stiffnesses in fused deposition modeling. Journal of manufacturing science and engineering, 1999. 121(1): p. 93-103.

25. Sung-Hoon, A., et al., Anisotropic material properties of fused deposition modeling ABS. Rapid Prototyping Journal, 2002. 8(4): p. 248-257.

26. Pilipović, A., P. Raos, and M. Šercer, Experimental analysis of properties of materials for rapid prototyping. The International Journal of Advanced Manufacturing Technology, 2009. 40(1): p. 105-115.

27. 3D Systems, I. 3D Systems ProJet ${ }^{\mathrm{TM}} 6000$ Professional 3D Printer. Available from: http://printin3d.com/projet-6000.

28. EOS. EOS Formiga P100. Available from: 
http://www.eos.info/en/products/systems-equipment/plastic-laser-sintering-s ystems/formiga-p-100.html.

29. Dimension. Dimension Elite 3D Printer. Available from:

http://www.dimensionprinting.com/3d-printers/3d-printing-elite.aspx.

30. Corporation, Z. Z Corporation Spectrum Z510. Available from: http://www.zcorp.com/en/Products/3D-Printers/Spectrum-Z510/spage.aspx.

31. PROTO3000. Objet Eden350V 3D Printers. Available from:

http://www.objet.com/3D-Printer/Objet_Eden350_Eden350V/. 